Portland State University

PDXScholar

$1-1-2010$

\title{
Parental Differential Treatment (PDT) of Siblings: Examining the Impact and Malleability of Differential Warmth and Hostility on Children's Adjustment
}

Brianne H. Kothari

Portland State University

Follow this and additional works at: https://pdxscholar.library.pdx.edu/open_access_etds Let us know how access to this document benefits you.

\section{Recommended Citation}

Kothari, Brianne H., "Parental Differential Treatment (PDT) of Siblings: Examining the Impact and Malleability of Differential Warmth and Hostility on Children's Adjustment" (2010). Dissertations and Theses. Paper 49.

https://doi.org/10.15760/etd.49

This Dissertation is brought to you for free and open access. It has been accepted for inclusion in Dissertations and Theses by an authorized administrator of PDXScholar. Please contact us if we can make this document more accessible: pdxscholar@pdx.edu. 
Parental Differential Treatment (PDT) of Siblings: Examining the Impact and Malleability of Differential Warmth and Hostility on Children's Adjustment

by

Brianne H. Kothari

A dissertation submitted in partial fulfillment of the requirements for the degree of

Doctor of Philosophy

in

Social Work and Social Research

Dissertation Committee:

Tom Keller, Chair

Lew Bank

Laurie Powers

Jana Meinhold

Jason Newsom

Portland State University

(C)2011 


\begin{abstract}
Parental differential treatment (PDT), the within-family differences in parenting experienced by siblings (Rivers \& Stoneman, 2008), has been linked to detrimental adjustment outcomes for children (e.g., Conger \& Conger, 1994). The primary goal of this research was to more closely examine how differential treatment in two domains of parent-child relations-displays of warmth and hostility- are associated with child outcomes. A secondary data analysis was conducted on a Randomized Controlled Trial (RCT) of a parent training intervention. Participants in this sample were high risk children and families, and they were randomly assigned to one of three groups: an intensive parent training program, the parent training program plus a sibling intervention, or the community control group.

Data were collected by multiple methods and from multiple reporting agents. Using baseline data from children (both older and younger siblings), mothers, observers and teachers, this study examined PDT agreement across two or more informants and whether PDT agreement was linked to child outcomes and also explored the extent to which these PDT domains were associated with both older and younger sibling's antisocial behavior. Using data collected at baseline and conclusion of the intervention from multiple informants, the study investigated whether the parenting intervention moderated the effect of PDT and the extent to which PDT was malleable. Agreement across two or more reporting agents of high PDT, especially for PDT-Hostility, was associated with worse outcomes for those children compared
\end{abstract}


to children in the more egalitarian group. This research replicated previous studies in demonstrating that PDT is associated with negative child outcomes in some circumstances even when controlling for other child factors. The results from exploratory analyses in this study do not provide support for the idea that PDT is altered after participation in a parenting intervention; however, the findings do provide some evidence that the intervention moderates PDT. Specifically, negative PDT directed at the older sibling was more likely to be associated with negative outcomes in the absence of the intervention. Potential explanations for these findings are presented, and implications for future research are discussed. 


\section{DEDICATION}

This dissertation is dedicated to the following people:

- $\quad$ My mom and dad who first ignited my love of learning and always encouraged me in my educational pursuits

- My brothers and sisters who have cheered me on throughout this journey

- My husband who supports me and always encourages me to be the best I can be 


\section{ACKNOWLEDGEMENTS}

It is a pleasure to thank those that made this dissertation possible. I owe much gratitude toward my committee members for their continued guidance, encouragement and support. I am especially grateful for the mentorship provided by Tom Keller and Lew Bank. Tom served as the chair of my committee and Lew served a co-chair role on my committee and they both provided great mentorship through the entire process. I have learned a great deal from their expertise. I want to thank Lew Bank and the Oregon Social Learning Center (OSLC) for access to this rich data source. Research participants help make this work possible, and I am grateful to all children and families who take the time to share their expertise. I also would like to thank my friends and family and all those that who supported me throughout this process. 


\section{TABLE OF CONTENTS}

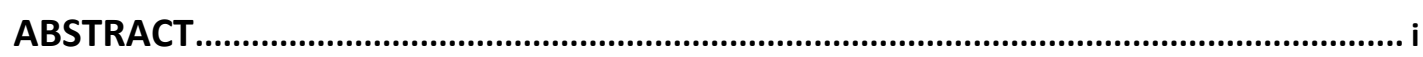

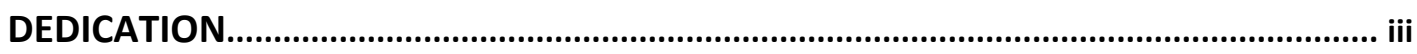

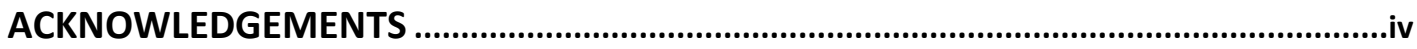

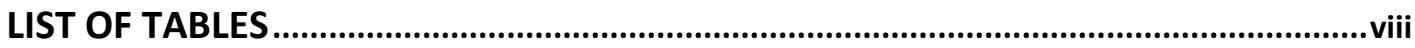

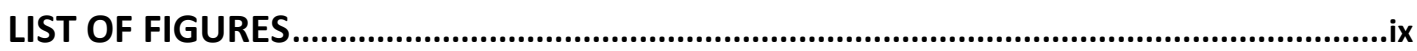

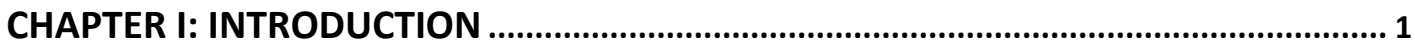

Significance, Prevalence and Implications of Parental Differential Treatment ...... 2

Purpose of and Motivation for the Proposed Research.............................................. 5

Importance to Social Work ............................................................................................ 7

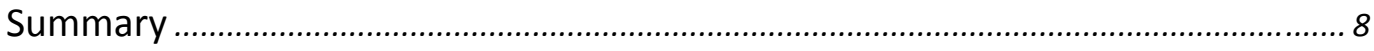

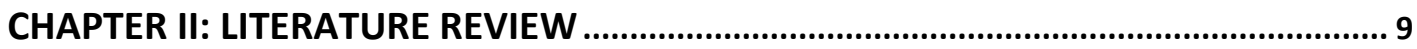

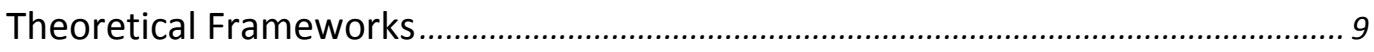

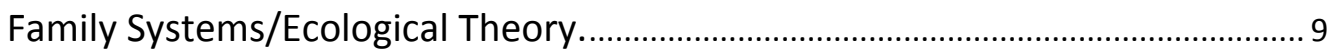

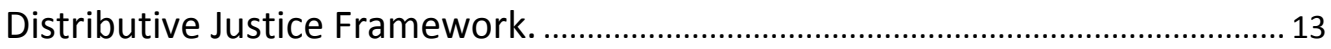

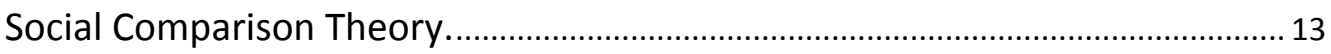

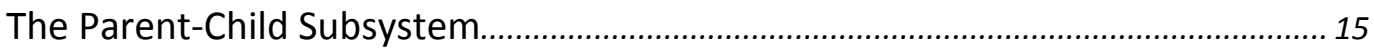

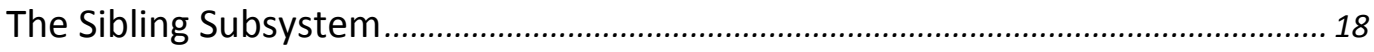

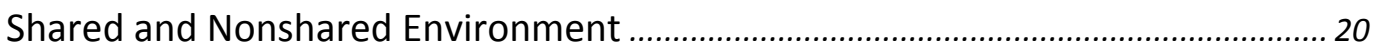

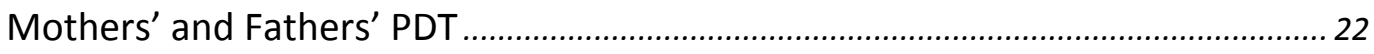

Cross-Sectional and Longitudinal Studies - Implications of PDT on Children's

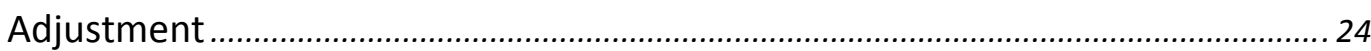

Cross-Sectional and Longitudinal Studies - Implications of PDT on Siblings'

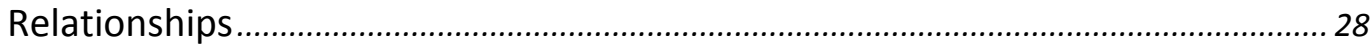

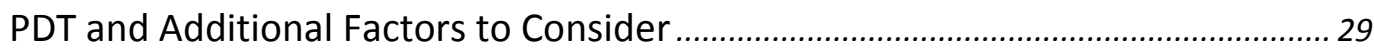

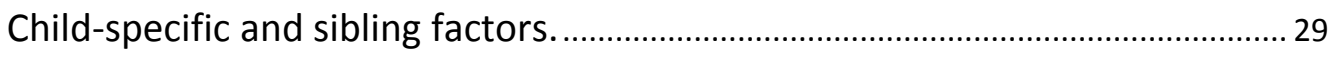

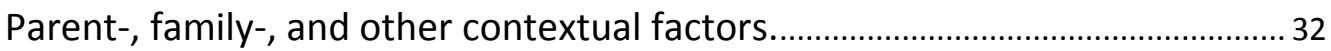

Methodologies, Measures and Analytic Approaches in the PDT Literature ........... 33 


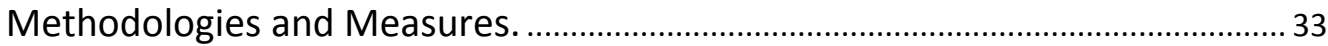

Analytic Approaches and Statistical Analyses. ........................................................... 37

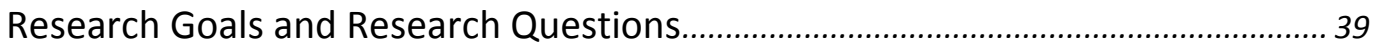

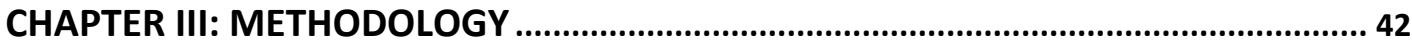

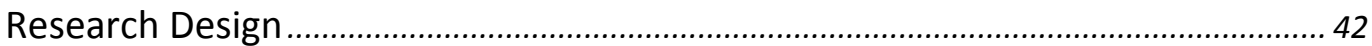

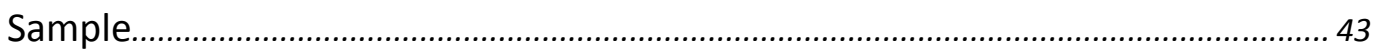

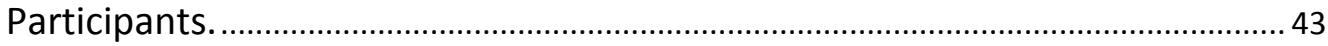

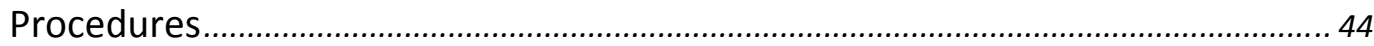

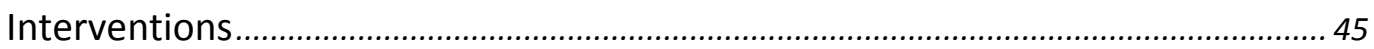

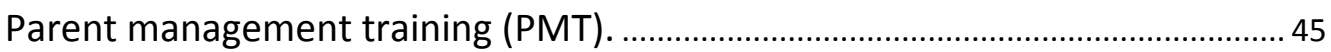

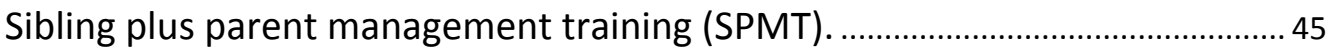

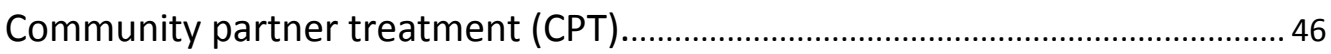

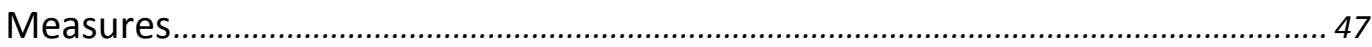

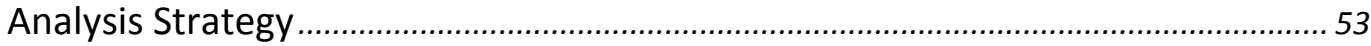

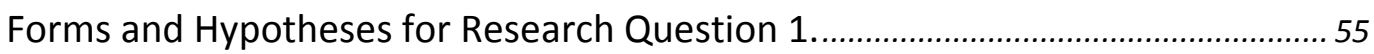

Forms and Hypotheses for Research Question 2.................................................. 56

Forms and Hypotheses for Research Question 3 ...................................................57

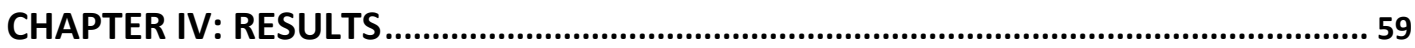

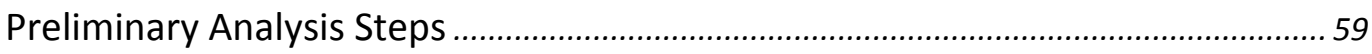

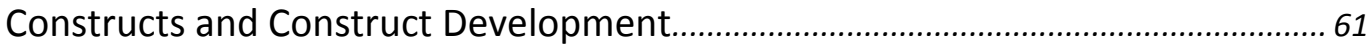

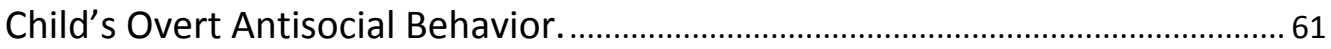

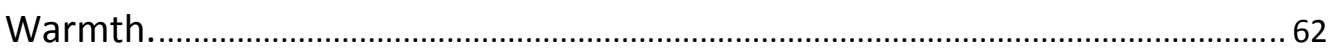

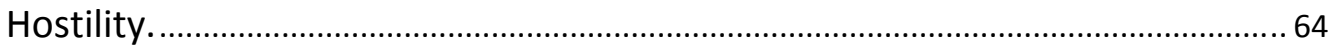

Difference Scores - Parental Differential Treatment ...................................................66

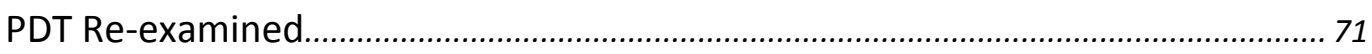

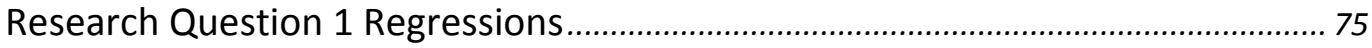

Research Question 2 Regressions - Exploring Moderation ..................................... 83

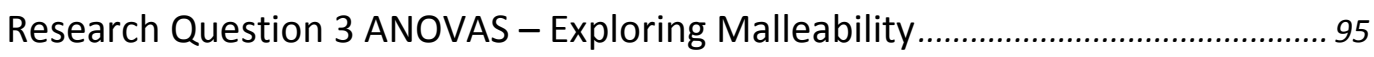

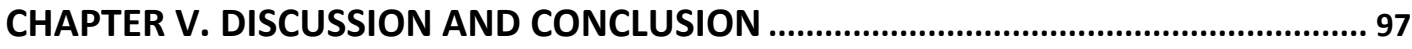

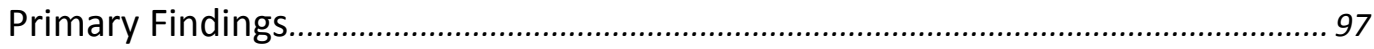




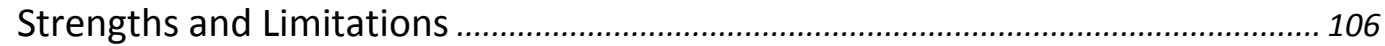

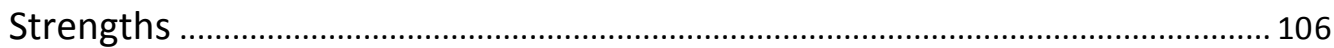

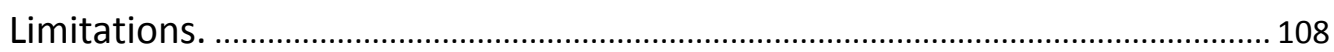

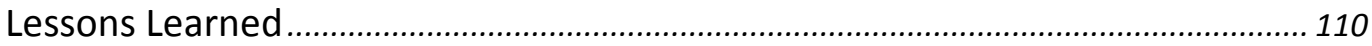

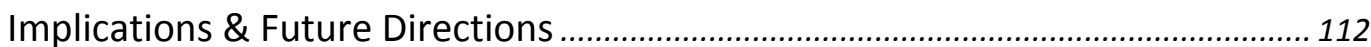

Implications for Practice, Policy and Future Research.......................................... 112

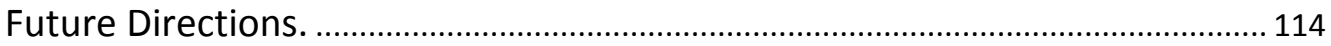

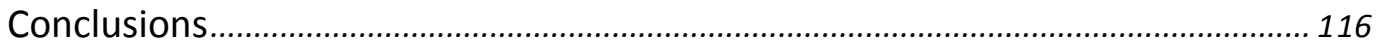

REFERENCES 


\section{LIST OF TABLES}

Table 1. Warmth Items by Reporting Agent........................................................64

Table 2 Hostility Items by Reporting Agent........................................................66

Table 3 Descriptive Statistics of Raw Difference Scores between older sibling and younger sibling for each reporter's perspective of PDT-Warmth and PDTHostility............................................................................................67

Table 4 Parental Differential Treatment (PDT) Interpretation Table. .....................68

Table 5 Correlations between direct parenting and PDT .....................................70

Table 6 Examining Mean Differences Between Egalitarian Group and High

PDT Group on Child Adjustment Outcomes based on Cross-Agent Agreement

of PDT by at least Two Informants................................................................... 74

Table 7 RQ\#1 Older Siblings' Antisocial Behavior with PDT-Hostility as a

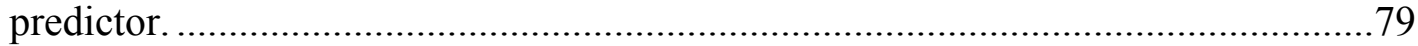

Table 8 RQ\#1 Older Siblings' Antisocial Behavior with PDT-Warmth as a

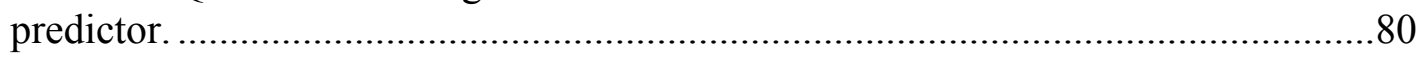

Table 9 RQ\#1 Younger Siblings' Antisocial Behavior with PDT-Hostility as a

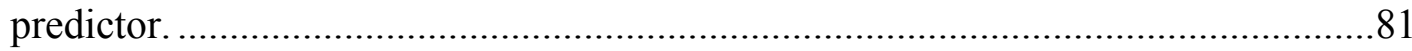

Table 10 RQ\#1 Younger Siblings' Overt Antisocial Behavior with PDT-

Warmth as a predictor.

Table 11 RQ\#2 Change in Older Siblings' Antisocial Behavior with PDT-

Hostility + RxStat

Table 12 RQ\#2 Change in Older Siblings' Antisocial Behavior with PDT-

Warmth + RxStat

Table 13 RQ\#2 Change in Younger Siblings' Antisocial Behavior with PDT-

Hostility + RxStat

Table 14 RQ\#2 Change in Younger Siblings' Antisocial Behavior with PDT-

Warmth + RxStat

Table 15 Older Siblings' Significant Interactions using Binary Moderator for

Treatment Group.

Table 16 Parent reported PDT-Hostility predicting Change in Younger Sibling Antisocial Behavior .94

Table 17 Examining Malleability of Parental Differential Treatment: Means of

Each Group. 


\section{LIST OF FIGURES}

Figure 1. Older Sibling Interaction: Youth reported PDT-Hostility * Group $\mathrm{n}=58$

Figure 2. Older Sibling Interaction:Youth reported PDT-Warmth*Group $n=69$.....93 Figure 3: Younger Sibling Interaction: Parent Reported PDT-Hostility*Group $\mathrm{n}=40$ 


\section{CHAPTER I: INTRODUCTION}

Family relationships are among the most significant influences on children's healthy growth and psychological well-being. Researchers and family scholars, however, have tended to focus primarily on parents, one child, and their parent-child interactions (the parent-child subsystem) rather than involving siblings (and the sibling subsystem) as an additional layer in studying the intricate processes, mechanisms, and influences within the family. This relatively common approach in past studies made an assumption that all other children within the home were exposed to similar family and environmental factors and therefore were affected in the same way. These between-family studies have made a significant contribution to the literature by examining the impact parents have on child behavioral outcomes, but they do not account for the complexity that exists when additional children are present in families. The findings from these between-family studies have not been helpful when examining the outcomes of the other children (siblings) in the home. Therefore, within-family investigations are conducted to better understand differences that may exist between individuals within a given family, and one of the most compelling topics in this area has continued to be parental differential treatment of siblings.

More than $80 \%$ of families in the United States have more than one child. A desire to better understand family systems dynamics in their entirety has encouraged researchers to include siblings and examine sibling relations (e.g., Conger \& Elder, 1994). Individuals within a sibship are influenced by their parents, other family members, and their surrounding environment. It is important to point out that each child or sibling 
also impacts family members and the environment. While parenting is experienced by both siblings, research has demonstrated that siblings may experience and/or perceive parenting, or certain domains of parenting, very differently. Plomin and Daniels' (1987) seminal article highlighted the fact that children raised in the same family turn out quite differently. After accounting for genetic relatedness, siblings raised in the same home do not seem to be much more similar than individuals picked at random (Plomin \& Daniels, 1987). Research has revealed that children in the same family do have different experiences and their behavior can be significantly different from one another (Dunn \& Plomin, 1991; Plomin \& Daniels, 1987). Recent studies on sibling differences have focused on ways to examine the influential components of the intra- and extrafamilial nonshared environment and the ways in which those factors impact siblings differently. Parental Differential Treatment (PDT) is an area of research that has been shown to help explain some of the differences.

\section{Significance, Prevalence and Implications of Parental Differential Treatment}

Parental differential treatment (PDT) is the within-family differences in parenting experienced by siblings (Rivers \& Stoneman, 2008). Even when parents do not treat their children completely equally, PDT may be appropriate or even desirable in some ways. Children living within the same home may have dissimilar ages, opposite genders, diverse attributes and particular developmental needs which often require specific types of attention. For these reasons, parents may treat their children differently and this may be seen as being sensitive to particular child needs. Nevertheless, differential treatment has also been shown to have detrimental effects on children, particularly on the 
disfavored child (Conger \& Conger, 1994; Dunn, Stocker \& Plomin, 1990; McHale, Crouter, McGuire \& Updegraff, 1995; McHale, Updegraff, Jackson-Newson, Tucker, \& Crouter, 2000). Parents' partiality towards one child may become problematic. In extreme cases, favorites may develop when parents punish and ignore one child and praise and pamper another. Evidence suggests that PDT is associated with negative child outcomes including social and emotional adjustment and behavior problems above and beyond what occurs within the parent-child relationship (Boyle, Jenkins, Georgiades, Duku \& Racine, 2004; Feinberg \& Hetherington, 2001). Children who experience more negative and less positive treatment, in comparison to their siblings, display poorer adjustment as well poorer relationships (Conger \& Conger, 1994, Deater-Deckard et al., 2001, McGuire, Dunn, \& Plomin,1995).

Using naturalistic observation Dunn and colleagues revealed significant differences in the attention, affection, responsiveness, control, and play behaviors mothers displayed with their two children (Dunn and Munn, 1986b; Dunn, Plomin, and Daniels, 1986; Stocker, Dunn, \& Plomin, 1989). Much of the research on PDT has focused on mothers' differential treatment towards their children (Brody, Stoneman, \& McCoy,1992; Crouter, McHale, \& Jenkins-Tucker, 1999; Stocker, 1995; Volling \& Belsky, 1992). More recent studies (e.g., Atzaba-Poria \& Pike, 2008; McHale et al., 1995), however, have also examined fathers' differential parenting and the influence it has on children. These studies using diverse methodologies have elucidated that differential treatment happens and also that both parents and children are aware of its existence and respond to it. Even though researchers in the past have debated whether 
differential treatment has a significant influence beyond quality of treatment by parents, evidence does suggest that children are vulnerable to differential treatment, and PDT does make an independent contribution to outcomes (Boyle, Jenkins, Georgiades, Duku \& Racine, 2004; Feinberg \& Hetherington, 2001; Tamrouti-Makkink, Dubas, Gerris, \& van Aken, 2004). Additionally, PDT has captured and held the interest of researchers largely because of the negative implications that seem to arise in its presence.

Determining the prevalence of PDT is not completely straightforward because the numbers reported in studies often reflect differences in sample characteristics as well as measurement approaches. For example, some studies are based on small sample sizes whereby researchers conduct intensive observations of young children and parents and others conduct large scale secondary analyses on items from national surveys. Family constellations and economic situations as well as other factors influence the prevalence. Brody, Copeland, Sutton, Richardson, \& Guyer (1998) found that $65 \%$ of their sample reported the occurrence of PDT. Similarly, Dunn, Stocker and Plomin (1990) also found differential treatment in $65 \%$ of families based on their calculations of observational data. In another sample, however, differential treatment was only reported by one third of families (Kowal \& Kramer, 1997).

There have been many convincing findings about PDT across various research studies, yet the current literature lacks methodological rigor. One key weakness is that the direction of effects is still unknown. A majority of the research has been correlational. Since it is well known that associations do not establish causation, it has been difficult for researchers to get clarity about the ways in which PDT operates. Additionally, it has been 
challenging for family scholars in this area to understand the determinants and mechanisms of PDT. Some results have been convincing, yet there are inconsistencies across studies due to the many characteristics at play within the family. Numerous factors including child factors (e.g., siblings' genders, ages, age difference, sibling dyad composition, and birth order), parent factors (e.g., marital dissatisfaction, parenting stress, and parents' educational levels), family factors (e.g., family size), and environmental factors (e.g., economic stressors and household chaos) may influence the impact of PDT. Parenting is a dynamic construct, and families do not operate within vacuums. Many decisions need to be made by investigators in these studies to determine the best ways to make advances in the field. Furthermore, because it is not always possible to account for each and every contributing factor, researchers have chosen to focus on or control for certain factors or a combination of them, and the results have revealed that sometimes these factors are related to the outcomes of interest, and sometimes they are not. Moreover, no true experiment has been conducted in this area to better understand this phenomenon.

\section{Purpose of and Motivation for the Proposed Research}

As the adage goes, if you want to understand something, try to change it. The purpose of this study is to examine the impact of PDT on children's (both older and younger siblings) antisocial behavior. More specifically, this study will examine two domains, PDT-Warmth and PDT-Hostility, measured by multiple perspectives including siblings, parents, and observers. This study also seeks to examine the extent to which PDT is malleable and whether PDT is associated with outcomes (controlling for specific 
factors). These questions will be examined on a high-risk sample of families participating in a randomized controlled trial (RCT) parenting intervention. The goal of this study is to fill in some of the holes in the current literature base. Much of the literature is largely correlational, and no known study has examined PDT using an experimental design. Information gathered from this study will replicate some of what has been done in previous studies, extend the current literature, and add to the utility of this work.

Motivation for this study came from the fact that PDT is an area of research that has captured and held the attention of investigators for decades. To a certain degree, however, family scholars neglect the importance of siblings and the ways in which siblings can increase our understanding of how families operate. The majority of people in the population have siblings, can easily relate to this topic, and many have anecdotal evidence of its impact and existence. In pondering the ways to advance this area of research and perhaps apply a new angle to this area of study, it was decided that examining PDT in the context of a true experimental design would help make progress in this area. Although it would be unethical and likely impossible to assign parents to groups in which they would treat their children equitably - or - inequitably, it is possible to examine PDT in the midst of a RCT parenting intervention. It is logical to think that when parents increase their knowledge, attain parenting skills, and practice those parenting skills, the treatment of children in their home will become more equitable. This study seeks to better understand PDT by examining it within the context of a RCT. 


\section{Importance to Social Work}

Wakefield (1988) claims that each profession has an organizing value, identifies social work as a justice-oriented profession and argues that "social work aims to promote distributive justice" (p. 188). Inequitable treatment, therefore, does not fit the value of this field. PDT is a relatively common phenomenon that occurs between parents and children in families. It reflects inequitable treatment and can have detrimental effects on individuals and families. Researchers should then work to understand the inner workings of PDT and develop the knowledge necessary to improve the ways parents treat their children. Social workers as well as other family practitioners should be aware of the existence of PDT, the deleterious effects it can have on children, as well as ways in which they can help to reduce PDT within families.

Social workers and other helping professionals work with and assist individuals and families regularly. Therefore, it is important that they better understand the ways in which PDT operates, how PDT relates to ineffective parenting, and the extent to which PDT can be changed. Knowing this information will allow researchers and practitioners to work with these families in a more appropriate fashion and develop the skills necessary to truly address the heart of the problem. More knowledge will also allow social workers as well as individuals in other fields to design and/or modify parenting and family interventions to target and address this particular problem.

These results could also have organizational and policy implications. Poor parenting is a risk factor to children's development (Forehand, Miller, Dutra, \& Chance, 1997). Parent skills training has shown to give parents the tools they need to avoid 
unsuccessful family management behaviors (Farrington \& Hawkins, 1991; Hawkins, Catalano \& Miller, 1992). Parent skills training has also demonstrated improvements in family interactions and reductions in maladaptive behaviors and delinquency (Dumas, 1989; Miller \& Prinz, 1990). If the level of parental differential treatment can be also reduced or eliminated through participation in a parenting program, organizations could clearly incorporate strategies that focus on reducing parenting differentials into their practices. Policies could be developed to educate people about how parenting can be (and often is) experienced very differently among different children in the same household as well as how these differences in experience can result in detrimental outcomes for children. Education could focus on both the occurrence of the phenomena and potentially the ways children's behavior improves when it is addressed.

\section{Summary}

This dissertation will review the theoretical frameworks associated with children and families generally and Parental Differential Treatment specifically, examine the research on PDT in more detail including cross-sectional and longitudinal findings and implications, provide an overview of methodological approaches used in previous studies, identify the strengths and limitations of previous research about PDT, and highlight some of the gaps in the literature base. This dissertation will present the research questions and report the results of the current analysis utilizing data that has already been collected from a RCT of a parenting intervention. This investigation using data from an experimental design adds to the existing literature base. This dissertation concludes with a discussion of the findings and recommendations for future research. 


\section{CHAPTER II: LITERATURE REVIEW}

The literature guiding this study is based on theoretical frameworks related to children and families as well as explanatory theories specifically related to the impact of PDT. The review will cover the various frameworks, illustrate what is known in regards to PDT, review the mixed results that have been found in prior investigations, as well as explain the ways in which this study aimed to address a particular gap in the literature. In addition, this section will also describe how a parenting intervention may have an influence on PDT.

\section{Theoretical Frameworks}

One theoretical framework in particular has been used to examine families generally as well as siblings more specifically. This is the ecological or family systems framework (Minuchin, 1981; Minuchin, 1988; Nichols \& Schwartz, 2001). This perspective provides a necessary viewpoint for studying siblings and families, the processes at play within these relationships, as well as the ways in which a parenting intervention comes into play. The social comparison theory (Festinger, 1954) and the distributive justice framework (Roth, 1990), provide a more specific justification for the ways in which differential parenting can affect children's adjustment.

Family Systems/Ecological Theory. Family Systems theory has developed over the years and is anchored in a more general systems theory. This theory adheres to the basic idea that to study a system, researchers must study "wholes" instead of "parts" (Bevelas \& Segal, 1992). In the last few decades, this theory has been applied to families.

Family members are mutually influential as they share physical and emotional closeness. 
The ecological perspective (Bronfenbrenner, 1979) takes a broader contextual view and also incorporates the ways in which the family system is influenced beyond the household. Systems also have subsystems which is why the family systems framework fits very well for sibling research. In this theory the subsystems (i.e., the parent-parent, parent-child, and sibling relationships) all function together as part of an embedded system. Using this framework, researchers can examine subsystems (i.e., husband-wife, parent-child, and sibling subsystem) separately as well as the system as a whole, and while each subsystem may serve a specific purpose, no one subsystem produces the"truth" because there is not just one reality within this framework (White \& Klein, 2008).

Family Systems Theory has some standard assumptions and concepts (Bochner \& Eisenberg, 1987). Within this framework, all parts of the system (which include each and every parent and child in the family) are interconnected and the whole is greater than the sum of its components. The behaviors of the family system affect its environment, and in turn the environment affects the family system (which can serve as feedback for individuals within the family as well as the family as a whole). Problems (e.g., inappropriate differential treatment) or pathology, therefore, are seen as a system dysfunction and are not located within any one individual.

Using this viewpoint, behavior is guided by circular causality (the notion that multiple factors and forces are at work simultaneously) as opposed to linear causality (A causes B). Therefore, this theory allows for examining "relationships" and "contexts" in families as opposed to "forces" or causes" (Bochner \& Eisenberg, 1987, p. 4). Within 
each family, family rules are developed by repetitive interactions and patterns, and an 'acceptable' way of functioning is created (e.g., ways of treating one another). In addition, positive and negative feedback loops guide the behavior of family members. Negative feedback occurs when individuals are punished for breaking rules in an attempt to correct the individual and re-establish the acceptable behavior, whereas positive feedback rewards a deviation the established norm. For example, problematic differential parenting may be the accepted form of interaction within a family. It may be tacitly accepted that the parents favor one child over another when the children's grades arrive in the mail even though their grades are fairly equivalent. If one child pointed out the inequity to his parents, he would be disturbing the balance of the previously created norm. This is an example of a feedback loop. Another assumption is that pathological communication contributes to and/or causes relationship problems within the family. There are many common, confusing, and unhealthy communication patterns that can develop and continue within families and these greatly contribute to the dysfunctions that exist within families.

Family systems theory has shown to be most useful when examining and interpreting the complex interactions that exist within families. Individual actions and behavior are often the result of multiple factors and interactions of elements, rather than caused by just one component. A plethora of components are often working together to produce a given outcome (rather than the linear approach where A causes B). Since this theory allows researchers to examine subsystems as well as the family system in its entirety, researchers can focus on the mechanisms, processes, and communication that 
exist for a specified dyad and then how that pair influences the rest of the family and vice versa. Moreover, since family systems theory sees the dysfunction or problem in the whole system, inequitable parenting cannot be explained only by a child's challenging behavior or a parent's attempt to parent the child in a specific way to meet his or her needs. Instead, multiple factors are at work and likely need to be examined and addressed.

For these reasons, this theory becomes particularly relevant for examining how an intervention can influence the family system because a change in the family system (e.g., participating in an evidence based intervention program) can result in both improved parent-child relationship or even sibling-sibling relationship. Participation in a parenting intervention alone or in combination with a sibling intervention (e.g., PMT alone or SPMT) would likely disrupt or change the unique roles of members in the family. For example, if parents and children practice their newly acquired skills, they may change their communication patterns and consequently their unique roles within the family. Moreover, problematic behaviors such as unjustified differential treatment would likely reduce if not disappear over time.

Even though many researchers have recognized this theory as valid and essential when studying siblings and family processes, few studies (e.g., Minuchin, 1974) have studied both the attributes and behavior of all siblings within the family. Recent efforts, however, have begun to incorporate additional family members and take a systems oriented approach to better understand mechanisms (e.g., coercive processes) within families (e.g., Bank \& Patterson, 1989). 
Distributive Justice Framework. This framework focuses on social justice highlighting the significance of equitable treatment (see Roth, 1990). Distributive justice theory has become popular in philosophy and across the social sciences, and rests on the idea that social justice results when individuals have fair and equal opportunity which serves to benefit the least well-off in society (or within a family for that matter), and John Rawls is a prominent theorist in this framework. This theory is focused on the distribution or allocation of goods. Since parenting resources are finite, parental treatment becomes a significant resource for children particularly in situations where demands are high and the quantity of resources is low. This theory emphasizes that each person has the right to basic liberties and deserves a fair share of those. Applied to parenting, this means that each child within a family is worthy of fair and equal opportunity, and therefore should be treated evenhandedly. This theory sheds light on the importance of treating each and every person within the family justly and with respect. This theory not only supports this study, but also the goals of the field of social work.

Social Comparison Theory. Social comparison theory (Festinger, 1954) refers to the idea that individuals tend to examine others to evaluate their own opinions and abilities. This is a human drive or "natural tendency" and these comparisons can have negative effects. Unfavorable social comparisons have often been shown to result in negative self-evaluations, and explicit comparisons have even been witnessed in preschoolers (REF). For the past few decades, this theory has been popular in the social psychological literature especially around peer groups (Ruble \& Frey, 1987; Santrock, Smith \& Bourbeau, 1976), but it has not been as widely applied to the family. This is 
particularly interesting considering the fact that targets of social comparison are usually people who are in close physical proximity and who have similar personal attributes such as age or gender (Wills, 1991). Investigations have shown that these social comparison processes become relevant when children and adolescents are evaluating their roles and identities (e.g., Levine, Smolak, \& Hayden, 1994). Middle childhood, therefore, is a period where these comparisons are at their peak.

Research has revealed that these comparisons often start within the family context (Dunn \& McGuire, 1994; Santrock, Readdick, \& Pollard, 1980). Cross-sectional research has shown that children observe and monitor their relationship with their parents and their sibling's relationship with their parents starting at an early age (Dunn \& Munn, 1985). It is likely that the sibling who consciously or unconsciously perceives the treatment received as unequal will exhibit detrimental adjustment outcomes. Again, with a finite amount of resources in the home, siblings may compete for affection and attention from parents and compare themselves regularly to their siblings. These comparisons may have a significant influence on a child's sense of self. Plomin and Daniels (1987) indicated that small differences in children's perceptions may lead to large differences in their development. Others have also suggested that children's perceptions may be more important than the actual behavior especially since children are very sensitive to perceived injustices.

Family scholars have illustrated the complexity in family research and revealed the numerous ways in which parents and siblings impact children's adjustment and relationships and vice versa. These theories are all relevant and important when studying 
children and families, particularly when examining the impact of PDT. Child developmental theories (including developmental theories such as Piaget's theory of cognitive development and Erikson's theory of social development) should also be considered because they underscore the significance of a child's developmental level and how their skills and abilities may influence particular family dynamics. However, the theories reviewed above best shape the foundation needed for this particular study. The Distributive framework highlights the injustice that exists when parental treatment is inequitable and how that can be problematic for children's adjustment. Social comparison theory describes the reasons and ways in which PDT may impact children's thoughts and behavior. Yet, this study draws primarily from family systems theory because it focuses on siblings, the ways in which family members influence each other, and how participation in an intervention may reduce problematic behavior (e.g., unjustified PDT). Family systems theory allows for studying different subsystems, the factors at play within those subsystems as well as the dynamics of the system as a whole. Therefore, family systems theory serves as the primary backdrop for this study.

The subsequent sections will review some of the components of family from a systems perspective by reviewing the parent-child subsystem and the sibling-sibling system in an attempt to dissect some of the complexity that exists within families.

\section{The Parent-Child Subsystem}

Parents serve as models and socialization agents (Parsons, Adler, \& Kaczala, 1982), and parenting practices impact children's health and development (Bornstein, 1995; Maccoby, 1992). A vast array of research has demonstrated the significant 
influence parents can have on children's lives; however, there is no "unifying theory" of parenting (see O'Conner, 2002). Parents tend to create and help develop their children's expectations about certain situations and events (Parsons, Adler \& Kaczala, 1982). Research has shown that parents are the primary molders of their children's cognitions and that child outcomes are also mediated by parents' cognitions and associated emotions (Bugental \& Johnston, 2000). Since parents tend to dictate the direction of interactions, parent-child relationships are generally thought of as vertical and unilateral (Russell, Pettit, \& Mize, 1998). There are fundamental differences, however, between how parents raise and relate to their infants versus their adolescents, and successful parents are sensitive to the developmental and changing needs of their children.

Parents have a particular collection of skills and employ those skills in ways that often result in certain styles (e.g., authoritative or authoritarian) (Baumrind, 1971). Moreover, there are a myriad of ways in which the role of parents can be explicated; yet, two common approaches emphasize the characteristics present in positive and negative parenting. Positive parenting qualities include warmth, responsiveness, support and engagement (Collins, Maccoby, Steinberg, Hetherington, \& Bornstein, 2000) and are associated with positive child outcomes including competence, cognitive functioning, and behavior regulation. On the other hand, negative parenting characteristics include disapproval, hostility, harshness and inconsistency (Collins et al., 2000), and tend to be associated with child outcomes such as emotional and behavioral challenges as well as antisocial behavior and aggression (Patterson, 1982). 
Much of the existing work on parents has focused primarily on general parenting or the absolute levels of direct parenting. Absolute levels of parenting or direct parenting across particular domains have been linked to specific outcomes for children and these findings have been well documented in the literature. For example, investigations with parents and adolescents have demonstrated that lower levels of warmth are related to both internalizing and externalizing behavior problems such as emotional distress, social withdraw and somatic symptoms (e.g., Lamborn, Mounts, Steinberg, \& Dornbusch, 1991). Additionally, parental coercive control has shown to be linked to children's internalizing behavior problems and parents' harsh and inconsistent discipline has shown to be associated with children's externalizing behavioral problems (e.g., Scaramella, Conger, \& Simmons, 1999). However, as stated previously, many studies have also examined differential treatment and some studies have looked at both of these components simultaneously (Feinberg \& Hetherington, 2001).

Parenting has an influence on individual children, but it also impacts siblings and sibling relationships. For example, maternal behaviors including positivity/negativity, control (e.g., Brody et al., 1987), and responsiveness (e.g., Dunn \& Stocker, 1989) have shown to be linked to siblings' actions toward one another. Studies have also revealed that mothers' attentive monitoring is associated with children's close and affectionate relationships with siblings (McHale, Updegraff, Tucker, \& Crouter, 2000) whereas parents' uninvolved parenting is correlated with sibling conflict both concurrently and 1 year later (Brody, Stoneman, \& McCoy, 1994). While particular parent actions or behaviors have been associated with certain child outcomes, it is also important to 
emphasize that the parent-child relationship is bi-directional. Many associations in the literature have not completely figured out which factors serve as the cause and which serve as the effect; however, it is clear and important to highlight that bidirectionality (i.e., parents influence children and children influence parents).

\section{The Sibling Subsystem}

Sibling relationships also develop within the context of family and family subsystems particularly the parent-child relationship (Criss \& Shaw, 2005). Some of the longest lasting and most solid relationships are those formed with siblings. Siblings are “powerful vehicles of socialization” (Bank, Burraston, \& Synder, 2004), and sibling relationships can influence social and emotional development (Daniels, Dunn, Furstenberg, \& Plomin 1985; McHale \& Gamble, 1989) as well as serve as important contexts for individual development (East \& Khoo, 2005; Patterson, 1986). Siblings serve as friends, advocates, allies, playmates, as well as models and socialization agents of positive and negative behavior (Brody, 1994). Despite the fact that sibling relationships grow, develop, and change over time, studies have shown that during some life stages, children report spending more free time with their siblings than with friends, parents, or even by themselves (see McHale and Crouter, 1996-reports on 11year olds).

Additionally, sibling relationships are generally ascribed rather than voluntary. They do not choose each other and may not even like each other. Siblings may be born into a family with others of similar biological origin or may become part of a family through the blending of families or adoption. Even when families undergo change (e.g., divorce) siblings and the relationships they create often continue to exist. Even elements 
that separate siblings such as physical distance and time spent devoid of sibling interaction do not necessarily disrupt the sibling relationship. While the sibling-sibling connection may be related to other subsystems within the family such as parent-child or parent-parent subsystem, some investigators suggest that the sibling relationship is influential above and beyond that of the parent-child relationship (Boyle, Jenkins, Georgiades, Duku \& Racine, 2004). This means that siblings are uniquely influential and are more influential than parents or peers when considering certain factors and circumstances (e.g., substance use). Even when controlling for the quality of parent-child relationships, there is "evidence for associations between quality of sibling relationships and children's externalizing and various aspects of antisocial behavior" and "also evidence (though less consistent across studies) for independent contributions of sibling relationship quality to depressive behavior and internalizing” (Dunn, 2005, p. 654).

Siblings not only provide unique socialization experiences, but they may also emulate their parents' cognitions and behaviors. Furthermore, siblings teach and reinforce behavior. Even though siblings can serve these similar roles or functions, the nature of siblings' relationships are different than parent-child relationships, and siblings may be more proximal determinants of child outcomes especially during certain life stages (Synder \& Stoolmiller, 2002). Siblings tend to share responsibility during their interactions which means sibling relationships tend to be more horizontal or balanced (Buhrmester \& Furman, 1990). In other words, there tends to be less of an established hierarchy in sibling relationships as opposed to parent-child relationships. Additionally, the amount of influence siblings have on each other can be influenced by certain factors 
such as the closeness of their relationship or the amount of power a sibling holds. For example, studies have demonstrated that when siblings have a warm and close relationship, their behavioral patterns are more similar (Ary, Tildesley, Hops, \& Andrews, 1993; Rowe \& Gulley, 1992). Influence as a socialization agent is also determined by the amount of power one holds or is perceived to hold within the relationship. Older siblings tend to hold (or are perceived to hold) more power (Furman \& Buhrmester, 1985). This perceived power or influence of siblings can be greater than other individuals in the child's life. Some studies have shown that siblings can have more influence on substance use and deviant behavior than parents and can have equal or greater influence than peers (e.g., Pomery et al., 2005). Practiced strategies and behaviors with siblings may also spill over into other relationships such as those with peers.

Sibling researchers have demonstrated numerous differences that exist between siblings in a family, and have sought to figure out what accounts for those differences. Some investigators have concluded that the nonshared environment is what in large part accounts for sibling differences (see Dunn \& Stocker, 1989; Hoffman, 1991), and the literature on shared and nonshared environment has increased dramatically in recent years.

\section{Shared and Nonshared Environment}

In order to tease apart the differences in siblings' outcomes and experiences and to clarify the dynamics occurring within the family, it is important to understand the environmental influences siblings share, the unique environments each individual experiences, and the potential impact of each. The behavioral-genetics literature, where 
twin and adoption studies are very common, have helped tease apart some of the various influences on children's adjustment. These studies have examined the influence of genetic similarity among siblings, but have demonstrated that genetics alone do not explain the differences in siblings' cognition, personality and psychopathology. In particular, monozygotic twin studies have shown that twins' antisocial behavior (Caspi et al., 2004; Pike Reiss, Hetherington, \& Plomin, 1996), their emotional distress (Crosnoe \& Elder, 2002), and their social-emotional adjustment (Deater-Deckard et al., 2001) are correlated with differences in parents attitudes, treatment and behaviors toward their twins.

Shared environment includes elements such as the shared physical space that siblings may reside in together or the similar treatment they receive by parents, and genetics may play a role especially for certain forms of siblings (i.e., full siblings). More recent studies have also demonstrated that the shared environment can have differential effects (Jenkins, Rasbash, \& O'Connor, 2003). This is in part because each sibling's interpretation or perception of the same event may be drastically different from one another. In addition to shared influences, researchers need to examine the environmental influences that are specific for each child and not general to the whole family (Plomin et al., 1994).

The nonshared environment exists both outside of the home and within the home and these factors contribute to the dissimilarity among members (Conger \& Conger, 1994). Nonshared environment outside the home is relatively straightforward and includes factors such as different friends, classes, teachers, and general exposure to life 
events. Nonshared environment experienced by siblings within the home may be less clear cut, and includes factors such as events experienced by one sibling and not the other, sibling interactions, and differential treatment. Nonshared environment theoretical approach focuses on the environmental features that differ for children within a family and which lead to different outcomes for siblings (Feinberg \& Hetherington, 2001). Researchers have concluded that the nonshared environment is what in large part accounts for sibling differences (see Dunn \& Stocker, 1989; Hoffman, 1991). In fact, it is commonly thought that shared environment and shared genes help create similarities between siblings in the same household; whereas, nonshared environmental factors and experiences help to explain the dissimilarities that may exist between siblings.

\section{Mothers' and Fathers' PDT}

Until this point, PDT has been used to refer to both mothers' and fathers' treatment of siblings; however, some studies have examined mothers' and fathers' treatment separately. Early research in PDT focused on mothers' differential treatment (MDT), and primarily focused on the affectionate and controlling behaviors they exhibited to two children (Bryant \& Crockenberg, 1980; Brody, Stoneman, \& Burke, 1987; Daniels, Dunn, Furstenberg, \& Plomin, 1985). Over time, studies expanded this focus and examined fathers' involvement (e.g., Harris \& Morgan, 1991) and fathers' differential treatment (FDT) (e.g., Volling \& Belsky, 1992) in an attempt to identify the ways in which fathers' inequitable treatment impacts children's adjustment and siblings' relationships. Studies have examined the specific patterns of MDT and FDT as well as the congruence between mothers' and fathers' treatment. 
Studies have examined patterns that exist between mothers' and fathers' differential treatment (Brody, Stoneman, \& McCoy, 1992; Volling \& Belsky). Volling and Belsky (1992) reported correlations between mothers' and fathers' differential treatment towards their children $(\mathrm{r}=.20$ through $\mathrm{r}=.40)$. Their findings examined how PDT relates to sibling conflict and prosocial interactions. They also took the relationship context into account with the assumption that the attachment history is also influential. For example in their longitudinal analysis, sibling conflict was more prevalent when the older sibling had an insecure mother-child attachment at year one (Volling \& Belsky, 1992). When mothers were more controlling towards the older sibling, more sibling conflict erupted. Moreover, when fathers' were more affectionate towards the younger sibling, there was less prosocial interaction between the sibling pair (Volling and Belsky, 1992).

However, some patterns that have been examined between mothers' and fathers' differential treatment have shown to be quite different. For example, Brody, Stonemann, \& McCoy (1992b) examined MDT and FDT in relation to the sibling relationship and found FDT to be particularly salient to sibling relationships in middle childhood. On the contrary, a recent study (Atzaba-Poria \& Pike, 2008) demonstrated that maternal malaise was associated with MDT as was expected, but paternal malaise was unrelated to FDT. Fathers' reports of FDT likely did not yield significant associations to children's reports because fathers reported relatively high consistency in their treatment of their children. These researchers speculated that fathers' role may be less scripted and they indicated that mothers' more traditional role may have been the reason why their resources were 
more salient in regards to differential treatment (Atzaba-Poria \& Pike, 2008).

Interestingly, mothers' and children's reports of MDT were similar, but father's and children's reports of FDT were not similar.

Additionally, researchers have examined the congruence between MDT and FDT and how that connects to children's well-being as well as family relations. McHale and colleagues (1995) examined congruent (both parents displayed preferential treatment to same child) and incongruent (one parent favors one child and the other reports equal treatment) patterns as well as complementary (one parent favors one child and the other parent favors the other child) patterns. The rationale for examining parenting in this way was that the negative implication of favoring one child may be offset by the other parent. Interestingly, about $55 \%$ of families reported congruent patterns for differential affection and $63 \%$ for differential discipline, $42 \%$ exhibited an incongruent pattern for differential affection and $22 \%$ for differential discipline, and only $5 \%$ of families had a complementary pattern for differential affection and $6 \%$ for differential discipline. They revealed that differential affection (a form of favoritism) almost always was toward the younger sibling. This study also demonstrated that equal treatment was associated with the most positive correlates for children.

\section{Cross-Sectional and Longitudinal Studies - Implications of PDT on Children's}

\section{Adjustment}

Studies have shown that parental differential treatment of siblings is linked to poorer individual adjustment (Conger \& Conger, 1994; Dunn et al., 1990; McHale et la., 1995, Dunn, Stocker, \& Plomin, 1990; Volling \& Belsky, 1992). Throughout cross- 
sectional and longitudinal studies in the general sibling literature, differential parenting has repeatedly been associated with negative sibling outcomes including less prosocial behavior (Brody et al., 1987), greater competition (Stocker et al., 1989), increased conflict (Brody et al. 1992; McHale et al. 1995; Stocker et al 1989; Volling and Belsky, 1992), social adjustment and other social and emotional problems (Anderson, Hetherington, Reiss, \& Howe, 1994), delinquency (Conger \& Conger, 1994), behavioral problems (Dunn et al., 1990; McGuire et al., 1995), self-esteem (McHale et al., 2000), bulimia (Wagner \& Cohen, 1994), and suicide ideation (Wonderlich, Ukestad, \& Perzacki, 1994). Studies by Feinberg and Hetherington (2001) and Tamrouti-Makkink et al.(2004) have revealed that PDT is uniquely linked with child outcomes above absolute levels of parenting. Investigations have also indicated that the favored or "preferred" sibling tends to profit whereas the sibling receiving less favorable treatment may exhibit additional adjustment problems (Dunn, Stocker, \& Plomin, 1990; McHale \& Pawletko, 1992; McHale et al., 1995). However, recent studies seem to suggest that both siblings exhibit adjustment problems in the presence of PDT.

A number of child adjustment outcomes have been examined including depression and other internalizing behaviors, conflict and other externalizing behaviors, self-esteem, and relationship positivity (see McHale et al., 2000). PDT has been shown to be associated to sibling differences in internalizing symptoms (Daniels, Dunn, Furstenberg, \& Plomin, 1985; Tamrouti-Makkink et al., 2004). Less maternal affection and more control toward older siblings have shown to be linked to children's internalizing problems, whereas more control has shown to be linked to children's 
externalizing problems (Dunn, Stocker, \& Plomin, 1990). While these findings have largely been based on maternal reports of child symptoms, recent studies are examining reports from other informants, including children.

Several studies have been cross-sectional, yet there are longitudinal investigations that have also shown the impact of PDT on children's adjustment over time. For instance, Conger and Conger (1994) examined PDT among 359 intact families (parents and adolescent siblings) and the results revealed that parents' differential hostility towards their adolescents was associated with sibling delinquency 2 years later after controlling for differences in delinquency at baseline (Conger \& Conger, 1994). In this study, relative difference scores were calculated from the adolescents' reports of delinquent behavior (which was an index score of each sibling's self reported delinquent behavior) and observer reports of parental hostility (which consisted of 2 tasks, 3 items each). Correlations were run and latent-variable structural equation models were implemented to test the proposed questions. Conger and Conger demonstrated that parental differential hostility helps to explain adolescent sibling differences in delinquency, but the reverse (i.e., sibling adjustment predicting PDT) did not show to be true.

McGuire, Dunn, and Plomin (1995) studied the effects of direct parenting (i.e., warmth, negative control) and PDT among siblings in middle childhood. There were 82 families that completed both waves. In this study, mothers completed an interview about differential treatment (i.e., affection and ease and frequency of discipline) at time 1 and time 2 and interviewers rated mothers responses (1=younger child much more often to $5=$ older child much more often). Adjustment was reported by mothers (CBCL) and 
Teachers (TRF). Correlations and cross-lagged path analyses were conducted. Similar to Conger and Conger, PDT (differential discipline-disciplining older sibling more) at wave 1 ( 7 years) predicted children's externalizing reported by the teacher 3 years later at wave 2 ( 11 years). This study also illustrated the stability of PDT in middle childhood.

Richmond, Stocker and Rienks (2005) assessed 133 families including both preadolescent and adolescent siblings at three timepoints, and hierarchical linear modeling (HLM) was used to examine change over time. Parents reported on children's externalizing behavior and children reported on parental differential treatment and depressive symptoms. Findings indicated that as children were less favored over time, their externalizing problems increased. They also found that changes in PDT were associated with internalizing problems (i.e., depressive symptoms) in younger siblings.

Shanahan, McHale, Crouter and Osgood (2008) tested the links between PDT and children's depressive symptoms on 201 Dutch families. PDT was calculated through use of difference scores from youth reports of dyadic parent-child relationships (older sib score was subtracted from younger sib score and vice versa, so a negative score indicated "self less" a zero score indicated "equal treatment" and a positive score indicated "self more"). This study also used an HLM approach, and correlations and growth models revealed that a decrease in parent-child warmth in comparison to the sibling results in increases in depressive symptoms for girls and older siblings. Findings demonstrated that first borns and girls seem to have stronger reactions to unfavorable treatment. 


\section{Cross-Sectional and Longitudinal Studies - Implications of PDT on Siblings' Relationships}

In addition to examining how PDT relates to individual child outcomes, studies have also shown support for the idea that parental differential treatment of siblings is linked to poorer or more negative sibling relationships (Brody et al., 1987; Brody, Stoneman, \& McCoy, 1992; Bryant \& Crockenberg, 1980; Conger \& Conger, 1994; Dunn, Stocker, \& Plomin, 1990; Stocker, Dunn, \& Plomin, 1989; Volling \& Belsky, 1992). Hetherington (1988) found that when "one sibling was treated with less warmth and affection and more coercion, punitiveness, irritability, and restrictiveness than the other, that sibling was more likely to behave in a aggressive, rivalrous, avoidant, and unaffectionate manner toward his or her sibling" (p.45). PDT influences the sibling relationship in a variety of ways. Although the independent contribution of PDT on sibling relationship quality may be modest ( $r$ s range from .30 to .31 ), predictions of sibling relationship quality have shown to be enhanced by considering additional factors such as children's reasoning as to why PDT occurred (Kowal \& Kramer, 1997). Many of these studies that have examined correlates of PDT and the sibling relationship and have shown that differential affection and control are correlated with more negativity in the sibling relationship (Brody et al., 1992; Bryant \& Crockenberg, 1980; Stocker, Dunn \& Plomin, 1989). When examining PDT and child outcomes or PDT and the sibling relationship, disparity in treatment tends to be more important than the absolute levels of parental behavior in particular instances (Feinberg \& Hetherington, 2001). Recent studies have even examined how the PDT has an impact on sibling relationships among middle- 
aged adults (see Boll, Ferring, \& Filipp, 2003). These findings illustrate that the inequality or perceived inequality may be what leads to potential problems for children. In an ecological context, however, numerous other factors need to be considered.

\section{PDT and Additional Factors to Consider}

As stated earlier, the family does not operate within a vacuum, so numerous factors are continuously influencing the sibling subsystem, the parent-child subsystems, and the family system as a whole. Many researchers have highlighted the importance of better understanding the mechanisms and processes that lead to parents' differential treatment. Some studies have examined moderators whereas others have examined determinants, risk factors, or precursors of PDT. Taking a developmental angle, researchers have started to determine how and when certain factors have an effect although results across studies are not always consistent. The following subsections, child factors and parent- family- and other contextual factors, will list these additional influences that may play a role as well as some of the findings from current research.

Child-specific and sibling factors. There are many child factors that may play a role when it comes to PDT. These factors can be specific to either sibling or factors relating to both siblings. For example, child factors include: age, gender, gender socialization, sibling structure and constellation (number of siblings, age spacing, birth order, ratio of young to old, and ratio of male to female), temperament, skills or ability, and challenges or disability, and these are just some of the child factors that may impact the sibling and family dynamics. Much of the research on PDT has focused on these child and/or sibling characteristics with the assumption that PDT is affected primarily by these 
factors (Brody et al., 1992). Some of these factors have been examined in the literature with mixed results. Others have shown more consistent patterns across PDT studies. For example, when children have difficult temperaments, differential parenting has been found to be more evident (Brody et al. 1992; Feinberg et al. 2000; Jenkins et al. 2003). Likely if a particular child is exhibiting challenging behavior, a parent will treat that child in a different fashion than a child who is not exhibiting those same challenges. A child's negative affect, therefore, has the potential to evoke higher levels of negative parental behavior and less positive parental behaviors (Anderson, Lytton, \& Romney, 1986; Jenkins et al., 2003). These findings demonstrate the bidirectional nature of PDT. Shanahan, McHale, Crouter, and Osgood (2008) identified sibling's gender, the gender constellation, age and birth order as factors that may moderate the relationship between PDT and child outcomes. Additionally, PDT has shown to be more strongly correlated with differences in siblings' emotionality as opposed to each child's absolute level of negative emotionality (Brody et al., 1992).

Gender. Child gender has also been studied in relation to PDT. Parents (both mothers and fathers) reported that they had more conflictual relationships with their children from same-sex dyads than with children from opposite-sex dyads (Stocker, 1995). This finding has been explained by suggesting that parents may have expectations for same-sex children to act and develop more similarly to one another. Therefore, when one child within a same-sex dyad is less well behaved, parents may develop a more conflictual relationship with that particular child. Other researchers have suggested that parents may more easily admit to differential treatment with their children when the two 
children are noticeably different (e.g., boy and a girl) (Crouter, McHale, and JenkinsTucker, 1999). This is likely because treating children who are obviously dissimilar differently is considered or perceived to be more "normal". Children's gender may also influence the amount of time parents spend with their children. As stated earlier, Harris and Morgan (1991) found that fathers are more likely to spend time with children if there is a boy in the sibship. The current data collected on sibling constellations does not depict a straightforward pattern in regards to this child factor. In fact, many studies have shown no differences (e.g., Brody, Copeland, Sutton, Richardson, \& Guyer, 1998; McGuire, Dunn, \& Plomin, 1995). However, Tamrouti-Makkink and colleagues (2004) firmly state that studies on PDT should only be conducted if both child gender and birth order are taken into consideration.

Age and age gap. Child age or sibling age gap has, however, shown to be more consistently related to PDT (Dunn \& Plomin, 1990). Harris and Morgan (1991) demonstrated that the age difference between siblings is linked to greater variability in paternal involvement with children with fathers participating more with younger children. Of the child-specific predictors, Jenkins and colleagues (2003) also found child age to be the strongest predictor of parental differential positivity and negativity. Again, future efforts need to focus on determining when differential treatment is inappropriate and whether children's characteristics (e.g. challenging behavior) are a result of these child qualities (e.g. children's temperament) or whether they are a result of the differential treatment received from their parents (i.e., need to determine directional effects). 
Investigators also need to keep the child development in mind when examining each of these and the relation they may have to parental treatment.

Parent-, family-, and other contextual factors. Researchers, especially in more recent studies, have examined factors beyond the child that may help explain the variance in PDT. It has been shown that if families and the family environment are rated as generally harmonious, conflicted relationships are less likely to result even in the presence of impartial parenting (Brody \& Stoneman, 1994). Recent efforts have begun to examine numerous contextual factors simultaneously in order to capture the impact of various forces. Aztaba-Poria and Pike (2008) demonstrated that parental and contextual factors may be particularly potent contributors to PDT as these factors accounted for $15 \%-17 \%$ of the variance in PDT depending on the reporter $(15 \%$-child reports and $17 \%$ mother reports). They revealed that "single mothers were at higher risk for treating their children differently only in the presence of high maternal anger" (Aztaba-Poria \& Pike, 2008, p. 229). This supports the notion of cumulative risk. On the flip side, even though being part of the two-parent family does not serve as a protective factor on its own, "mothers from two-parent families showed the lowest levels of differential hostility only when coupled with low household chaos" (Aztaba-Poria \& Pike, 2008, p. 229). These findings indicate a "double-risk" for single mothers facing difficult contextual factors and a "double-buffer" for two-parent families in low contextual risk situations. As can be seen, these potentially influential factors are not exactly simple and linear.

Financial and relationship stress including stressors like marital conflict or dissatisfaction (Crouter, McHale, \& Jenkins-Tucker, 1999; McHale et al., 1995; Jenkins, 
Rasbash, and O'Conner, 2003), and low SES and economic pressure have shown to be related to PDT (Henderson et al., 1996; Jenkins et al., 2003; Mekos, 1996). Harris and Morgan (1988) also found an association between marital satisfaction and paternal involvement. Less marital conflict and higher marital satisfaction were linked to more paternal involvement with children. These findings reveal how parents' gender as well as the relationship with their partner may impact the differential treatment with their children. Chaotic household environments indexed by a lack of established routines, large family size, and mental health challenges (e.g., depression) have also been studied in relation to PDT (Tarullo, DeMulder, Ronsaville, Brown, \& Radke-Yarrow, 1995). Not only are these contextual factors associated with PDT, researchers (e.g., Jenkins et al., 2003) have also suggested that family stressors including marital conflict or dissatisfaction, low SES, and/or children in the home with disabilities may exacerbate PDT. Jenkins and colleagues (2003) suggested that the shared family context (e.g., SES, family size, chaotic environment) plays a role in differential parenting because it seems that these shared attributes influence nonshared effects.

\section{Methodologies, Measures and Analytic Approaches in the PDT Literature}

Methodologies and Measures. As noted previously, much of the research has been observational. However, interviews and surveys have also been used to analyze data in this area. The particular perspective (i.e., reporting agent - child, parent or observer) being examined makes a difference in any given results. Also, the way in which differences between children are calculated can also make a difference in findings. This 
section will review information about specific perspectives as well as some of the common measures and methods that have been utilized in the literature.

The particular informant or perspective being analyzed is important to understand. Some evidence suggests that children's perceptions of PDT may be more important than objective levels of PDT (Kowal \& Kramer, 1997). It is thought that older siblings with more responsibilities and more advanced cognitive skills may be more understanding or accepting of parents' behaviors. Older children, particularly first borns with an inherent role, may understand when differential treatment is legitimate. Therefore, it is reasonable to conclude the differential treatment perceived as legitimate will likely have different emotional consequences than treatment perceived as unfair (McHale \& Pawletko, 1992). Parents thought processes have also been taken into consideration when examining PDT. Interestingly, parents tend to believe they are being more impartial than their children do (see Boer \& Dunn, 1992). More recent studies (e.g., Kowal \& Kramer, 1997; McHale et al., 2000) have examined children's perceptions in regards to fairness and these thought processes seem to play a significant role in the extent to which children view differential parentingas problematic. Research has indicated that if children perceive the differential treatment as fair and understand or can find meaning in treatment differences, they do not always object to these differences in parenting (Kowal et al. 2002; McHale et al. 2000).

The Sibling Inventory of Differential Experience (SIDE; Daniels \& Plomin, 1985) has been used across many research studies. This measure is used to assess perceived maternal and paternal differential treatment and its magnitude. Children rate how well their parents treat them in comparison to their sibling on a 5-point scale. Two domains of 
PDT are assessed in this measure, namely control and affection. The Control scale contains 4 items and the Affection scale contains 5 items. These domains have therefore been examined in a number of studies (e.g., Kowal \& Kramer, 1997;Volling \& Belsky, 1992).

Another increasingly common method used in this literature is the Berkeley Puppet Interview (BPI; Ablow \& Measelle, 1993). This technique allows children to respond to questions from two puppets who make opposing statements about a member of their family (e.g., parent). Then children's responses are coded on a 7-point scale ( $1=$ most negative score and $7=$ most positive $)$. Amplified codes are coded at one of the two extremes ( 1 or 7$)$, agreeing with the statement is coded closer in on the scale ( 2 or a 6), and qualified statements are coded closer to the center of the scale (receiving a 3 or a 5).

Sometimes PDT composites or scores have been created to capture an individual perspective from various instruments or methods to capture specific domains of parenting. For example, Feinberg, Neiderhiser, Reiss, \& Hetherington (2000) conducted a factor analysis on the Nonshared Environment in Adolescent Development (NEAD) data to capture two distinctive parenting constructs namely warmth/support and conflict/negativity. These same constructs have shown to be distinct in previous work as well (see Steinberg, 1990).

Observations have also been extensively conducted in this area. Often interactions between dyads (parent and child) and triads (parent and siblings) are coded by trained individuals to measure particular domains of PDT. 
Specific domains and associated outcomes. Parents may treat their children differently in regards to any number of issues, and much of the existing research on PDT has looked at parental differences in regards to certain domains including but not limited to warmth, conflict, hostility, and responsivity. The specific domains studied often fit within the positive and negative parenting approaches that were discussed previously in this paper (see Collins, Maccoby, Steinberg, Hetherington, \& Bornstein, 2000) likely because stark differences in treatment of siblings in these areas begins to capture inappropriate or unjustified PDT. Previous studies have demonstrated that differential treatment within these parenting domains has been associated with particular outcomes. For example, differential parental warmth has shown to be associated with differences in sibling behavioral problems (Dunn et al., 1990; McHale \& Gamble, 1989; McHale \& Pawletko, 1992). Bryant and Crockenberg (1980) examined mothers' differential responsitivity and sensitivity and found these differential treatments to be associated with greater discomforting and disparagement among girl-girl sibling dyads. Fathers' differential responsiveness has shown to predict higher rates of younger siblings' negative behavior toward their older sibling (Brody et al., 1992). Dunn and Stocker (1989) examined differential discipline and reported that both older and younger siblings experienced PDT, but boys with sisters were more likely to experience differential discipline in comparison to other children. The "popular" domains of study often fit into positive and negative parenting, and are common likely because large differences have shown to be problematic (i.e, associated with negative child outcomes) 
Analytic Approaches and Statistical Analyses. As stated above, correlations have been extensively used throughout the PDT literature. Often this has been done by correlating the difference on siblings' adjustment with the difference between parenting received. One technique that is often used and implemented before these correlations can occur is the sibling difference score (Rovine, 1994). This dyadic score is based on treatment received by Sibling A minus treatment received by Sibling B. If one child is exposed to higher negativity, for instance, their score will reflect that discrepancy - in both direction and magnitude. This approach examines adjustment as a function of differential treatment (Boyle et al., 2004, p. 1458).

In some studies (e.g., Feinberg \& Hetherington, 2001), the sample is separated into older siblings and younger siblings. Scores of direct parenting are used as predictor variables in the first step in a hierarchical regression, and then the PDT score is added in the next step. Utilizing this analytic technique and drawing on a sample of 516 families, Feinberg and Hetherington illustrated how and when particular PDT domains accounted for unique variance in siblings' adjustment (as measured by a multi-agent construct score) controlling for absolute levels of parenting using different reporting agents. Feinberg and Hetherington (2001) tried to reduce the effects of method variance by using one agent's report of direct parenting and another's report of PDT in their regression analyses. Other studies (e.g., McGuire et al., 1995) have also used different measures to examine direct parenting and differential parenting. For the most part, researchers are aware of the effects of method variance and try to use different reporters for the independent and dependent variables. 
Statistical analyses such as analysis of variance (e.g., ANOVA and MANOVA) have been used throughout the PDT literature to examine mean differences between groups. Multivariate analyses such as linear and hierarchical regression have been used to examine the extent to which PDT predicts particular child adjustment outcomes. Crosslagged path analyses have also been used to examine how PDT at one time 1 predicts child or sibling outcomes at Time 2. More recent studies (e.g., Jenkins, Rashbah, \& O’Connor, 2003) have also used multilevel modeling (MLM) to account for nestedness and tease apart child effects such as age, gender, and temperament and shared family context effects including SES, marital conflict, and other factors experienced by all children in the family. This technique allows researchers to examine these factors simultaneously. Using this approach, researchers can go beyond studying individuals and dyads and move towards examining entire family units. Since an array of family forms and constellations exist, MLM is a useful tool when examining diverse family constellations (including, for example, older sisters and moms, older brothers and moms, other sisters and dads, older brothers and dads, younger sisters and moms, younger brothers and moms, younger sisters and dads, younger brothers and dads). This technique is advantageous for many reasons, but often requires large samples which do not readily exist especially among studies that conduct intensive observations of children and parents.

To sum up, this literature review has illustrated a need for future studies and provided at least two ways to corroborate previous findings as well as extend the research in this area. First, new approaches could be implemented to tackle unaddressed questions. 
Warmth and hostility reflect positive and negative parenting. These warmth and hostility domains may more clearly focus on potentially unjustified or 'problematic' PDT as opposed to justified or developmentally appropriate PDT because it would be difficult to give good reasons for treating one child with lots of warmth and not their sibling, or treating a child with lots of hostility but not their sibling. Examining differences between siblings on these domains may help focus on the problematic or inequitable treatment that youth receive, and evaluating these two domains from multiple perspectives simultaneously may add to what is currently in the literature.

Second, true causal effects have not been claimed because the literature has not yet used Randomized Controlled Trials (RCTs). An experimental design could be used to determine whether the intervention interacts with PDT and whether PDT is malleable (i.e., whether it can be changed by an intervention). Examining PDT within an experimental design may make a solid contribution to the literature by revealing causal effects and directionality.

\section{Research Goals and Research Questions}

The literature has established that Parental Differential Treatment (PDT), the within-family differences in parenting experienced by siblings (Rivers \& Stoneman, 2008), has a variety of implications for children's adjustment. Differentials have been examined across domains reflecting both positive and negative parenting, and research has determined that parental differential treatment can be problematic for children. PDT is associated with behavior problems for both the child that is disfavored as well as for 
the other sibling. The majority of the current research has been correlational and no known study has examined PDT using an experimental design.

The primary goal of this research study was to examine two domains of PDT, PDT-Warmth and PDT-Hostility, in more detail across different reporting agents as well as examine PDT within the context of a parenting intervention. First, Warmth and Hostility constructs were created for each parent-child subsystem (e.g., mother's treatment towards older sibling and mother's treatment towards younger sibling) by reporting agent. Since there were multiple agents, this step was done separately for each informant type: older sibling, younger sibling, mother, and observer. This yielded 3 reports for each parent-child dyad for each domain (i.e., 3 reports of warmth for motherolder sibling, 3 reports of warmth for mother-younger sibling, 3 reports of hostility for mother-older sibling, and 3 reports of hostility for mother- younger sibling). Second, PDT was calculated as the discrepancy between each informant's report of parent's treatment towards older sibling and parent's treatment towards younger sibling (e.g, parent reported hostility toward younger sibling subtracted from parent reported hostility toward older sibling). Next, these direct parenting constructs (i.e., warmth and hostility for each informant) and differentials (i.e., PDT-Warmth and PDT-Hostility for each informant) were examined alongside child adjustment outcomes for both older sibling and younger siblings. Finally, these domains of direct parenting (i.e., warmth or hostility by informant) and PDT were examined in the context of an intervention to determine whether there were interaction effects between PDT and treatment group. There were three general research questions: 
1.) To what extent is PDT Warmth and PDT-Hostility associated with both older and younger siblings' overt antisocial behavior?(regression analyses)

2.) Is the effect of PDT-Warmth and PDT-Hostility on child antisocial behavior moderated by a parenting intervention?(regression/interaction analyses)

3.) Is it possible to change PDT-Warmth and PDT-Hostility? That is to say, is PDT malleable with an intervention? (ANOVA analyses)

The study examined how PDT-Hostility and PDT-Warmth are linked to older siblings' and younger siblings' antisocial behavior. Additionally, this study examined whether PDT can be changed, the extent to which PDT interacts with an intervention, and the impact child factors (i.e., age and gender) as well as direct parenting have on this process. This added knowledge will make a strong contribution to the existing literature because it will expand the utility of PDT. Better understanding PDT from various perspectives and the malleability of PDT will augment its usefulness for researchers, practitioners and interventionists. It should be noted that even though there were three primary research questions, they had many forms which were replicated in order to examine effects for each domain with both older and younger siblings. 


\section{CHAPTER III: METHODOLOGY Research Design}

This was a quantitative, secondary data analysis. The three primary research questions (plus all their forms/replications) were examined using an existing data set of high risk youth and families enrolled in a Randomized Controlled Trial (RCT) conducted by the Oregon Social Learning Center (OSLC) within the last decade.

The larger RCT project, known as the Sibling Interaction Behavior Study (SIBS) intervention, was a multi-method, multi-informant study. Participants were randomly assigned to one of three conditions: Parent Management Training (PMT), Sibling plus Parent Management Training (SPMT), or Community Partner Treatment (CPT). These groupings will be described in more detail below. Data were collected at baseline (before the intervention), intervention term (upon completion of the intervention 6 months after enrollment), and follow-up (six months after intervention completion). Data were collected in this larger project from multiple family members including fathers, mothers and siblings as well as teachers and observers. This dissertation study, however, focused only on data collected from mothers, siblings, teachers and observers at baseline and intervention term. It is important to point out that the intervention was not specifically designed to reduce PDT; however, as stated earlier, there is reason to believe that parents who learn positive parenting skills will treat their children more equitably. Parents who participate in parent training tend to develop a greater awareness of how they are treating their children and they practice skills including ways to encourage their children and set 
appropriate limits. This increased awareness along with increased skills is thought to lead to more equitable treatment of children.

\section{Sample}

Families served by the Oregon Health Plan (OHP) with preadolescent children (ages 4-11) were contacted by letter to describe the availability of an intervention for children with conduct problems. Eligibility in OHP was based on family income below the Federal poverty line. Families were screened into the intervention based on parent daily reports (PDR; Chamberlain \& Reid, 1987) of significant conduct problems of the target child (i.e., older sibling) as well as the presence of a younger sibling in the family. Although the older sibling was the child screened in the study with significant conduct problems, many of the younger siblings also had significant conduct problems.

Participants. The families were characterized by substantial disadvantage and economic challenge, frequent marital transitions and other serious stressors. Parents had a median monthly income of $\$ 1,020$ at baseline; $51 \%$ of parents reported a gross annual household income under $\$ 15,000,30 \%$ reported an income of $\$ 15-30,000$, and $18 \%$ reported earnings over $\$ 30,000$. In $42 \%$ of households no parent was employed, and $51 \%$ had no parent employed over 20 hours per week. Only $40 \%$ had one parent who was employed full time (over 35 hours per week). No parent had an education beyond a high school diploma in $40 \%$ of households, and $92 \%$ had no parent with a 4 -year college degree. Many parents reported histories of antisocial behavior. At baseline, 23\% had a parent with a history of chemical dependency treatment (inpatient or outpatient), and $29 \%$ had at least one parent with a history of incarceration. In $49 \%$ of families, at least 
one parent reported a history of illicit drug use, including marijuana, cocaine, speed, LSD, mushrooms, heroin, angel dust, or morphine. Two-parent households included nonmarried partners and relatives such as grandparents, aunts and uncles. Self-reported ethnicity of participating parents was $72 \%$ "White-American", 15\% across all other ethnicities including "multiracial-American", and 13\% unknown

Most of the target children (older siblings) evidenced significant, multi-setting conduct problems. For the two siblings, ethnicity was 67\% "White-American", 26\% across all other ethnicities, and 7\% unknown. $43 \%$ of target children lived in singleparent households. One hundred twenty seven sibling dyads enrolled in this project, completed baseline assessment, and were randomly assigned to Parent Management Training alone (PMT; Forgatch \& Rains, 1997, N=44), sibling plus PMT (SPMT; Bank, Snyder \& Prescott, 2002, N=48), or community partner treatment (CPT; N=35). The mean age of the older and younger siblings was $8.5(\mathrm{SD}=1.53)$ and $6.1(\mathrm{SD}=1.45)$ years, respectively. Fifty four of the older siblings were girls and 73 were boys, whereas 57 of the younger siblings were girls and 70 of the younger siblings were boys. There were approximately equal number of same gender $(n=63)$ and mixed gender $(n=64)$ sibling dyads.

\section{Procedures}

Parents were informed of group assignment to intervention after baseline assessment completion. All families enrolled in the study and assigned to one of the three groups were asked to complete assessments at each study phase. Assessments were 
completed during home visits, during lab visits, and over the phone. Again, this study will focus on data completed at baseline and intervention term (6 months after enrollment in the study).

\section{Interventions}

The following provides a glimpse of the three random assignment groups. A more complete description of the interventions and treatment fidelity, however, are available elsewhere (see Bank, Snyder \& Wilson, 2005).

Parent management training (PMT). Parent management training is an evidence-based OSLC parent training program, the basic components of which have been described in many places (e.g., Bank et al., 1987; Forgatch \& Patterson, 1989; Patterson \& Forgatch, 1987; Patterson, Dishion, \& Chamberlain, 1993). Parents were taught skills for pinpointing behaviors for change, contingent positive reinforcement, effective discipline practices, monitoring children's activities, communication and problemsolving, and promoting school success. Discipline is a key issue for most families. Parents often fail to give consequences for inappropriate behaviors or they think that it is appropriate to use harsh discipline to gain control over children who may be difficult to manage. Parents were taught to use small consequences, which require that they act on minor problem behaviors such as noncompliance to parental requests. They were also taught the importance of using encouragement with their children and other skills which were practiced both during sessions and at home between sessions.

Sibling plus parent management training (SPMT). For this grouping, the sibling intervention developed at OSLC and Wichita State University was embedded in 
parent management training (PMT) as a whole family approach. SPMT has been manualized, and this combination has shown to be particularly powerful for children and families.

The eight-session sibling intervention was designed to enhance sibling relationships, to foster socially skilled behavior in each individual sibling, and to reduce dyadic conflict and aggression. The sessions address a set of hierarchically arranged issues pertaining to social and self-regulatory skills that operate in sibling relationships and that are critical to adjustment (e.g., cooperation, communication, emotion selfregulation, problem solving, conflict abatement, and social relationship repair strategies). The activities are selected to be age appropriate, engaging, and emphasize discovery, learning and practice in the context of experiencing and doing rather than talking and listening. Each activity is accompanied by specific behavior change strategies used by interventionists to describe, model, shape and reinforce critical social relational skills in the context of natural sibling interaction and to generalize those skills to home and peer environments.

Bank, Snyder, and Prescott (2002) provide commentary for each sibling session organized around the specific skills being addressed and the central activities and strategies being used. The commentary provides a step-by step rationale for intervention activities, a detailed description of tactics and strategies used to shape sibling relationships, and activities useful to teach and practice skills.

Community partner treatment (CPT). All community partner therapists were experienced, well respected at their respective agencies, and agreed to work with study 
participants. In addition to their usual salaries, CPT staff received project funds per session to cover anticipated extra workload required with project families, including regular phone contacts, higher rates of rescheduling appointments, and occasional home visits. CPT families benefited from the same incentives as SPMT and PMT families (e.g., family activity passes, gas or bus reimbursement for intervention sessions). This group can also be thought of as community treatment as usual or the comparison group. Intervention treatment group was treated as an ordinal variable $(0=\mathrm{CPT}, 1=\mathrm{PMT}$, and $2=$ SPMT) for the purposes of this study because of how the intervention groups were designed. PMT alone was thought to provide parents with important skills; however, PMT plus the sibling component (i.e., SPMT) was thought to have an additive influence for children and families. Moreover, the combination of these interventions has shown to be particularly powerful.

\section{Measures}

An extensive array of measures were collected from multiple informants throughout the entirety of the larger SIBS intervention project. This section will review a smaller number of measures that will be used for this dissertation research. The following subsections will review the measures and items used by reporting agent. For information on other instruments used in the larger SIBS study, see Bank and colleagues (2005) Assessments were the same for both waves being analyzed in this dissertation studybaseline and intervention term. Baseline measures were completed at enrollment in the study, and intervention term measures were completed 6 months after enrollment in the study. 
Demographics. Parents completed a measure about various demographics. These items asked about parents themselves, their partners, and their children. Each child's age (standardized) and their gender $(0=$ female and $1=$ male $)$ were used in the analyses.

Parent measures. Parent reported items came from various parenting instruments including the Child Rearing Attitude Scale (CRPR; Block, 1965), the My Child's Relationship with Me Scale (PIANTA; Pianta, 1992), the Parent-Child Rearing Task (PCRT), the Sibling Parent Interview (SPINT), and the Child Behavior Checklist (CBCL). For each of these measures, parents reported separately on their two children in the study (older sibling (OS) and younger sibling (YS)). Each item in each of the parent measures was adapted so that parents could report on both siblings. They first responded about the older sibling enrolled in the study and then about the younger sibling enrolled in the study.

The CRPR is a 91 item measure assessing attitudes, goals and values about child rearing. The My Child's Relationship with Me Scale (Pianta, 1992) is a 15-item measure developed to assess parent-child relationship with children as young as three. In this measure parents or the primary caregivers report on closeness, dependency, and conflict in the parent child relationship. The PCRT asks parents to rate how much they enjoy particular activities with their child. The SPINT is a measure developed at OSLC to examine a variety of areas including how things are going for the child at school and at home among a wide variety of areas. Parents responded to items on all of these measures on a Likert scale. Items from these measures were used to create the parent-reported warmth and hostility constructs. 
Parent-child attachment and ineffective discipline were the other parent-reported constructs in this study were measured by scales included in the sibling parent interview (SPINT). Parent-child attachment was a 7-item scale which measured the closeness or warmth between parent and child. Examples of items include '[Child] likes to talk to me' and '[Child] gives really good hugs'. At baseline, internal reliability was adequate for these measures ( $\alpha=.66$ for older sibling; $\alpha=.57$ for younger sibling). Ineffective discipline practices was another scale derived from the parent interview. This 9 item scale (e.g., I get angry when I discipline [this child]) demonstrated good internal consistency at baseline ( $\alpha=.75$ for older siblings; $\alpha=.78$ for younger siblings). Scores for these two scales were created by taking the mean of the items within each scale.

Parent ratings of child overt antisocial behavior were obtained using an adaptation of the Child Behavior Checklist (Achenbach, 1991). Parents were asked to rate their child's behavior over the previous two month interval. The overt, aggression scale was comprised of 23 items (e.g., argues, cruel/bullies, disobeys, fights, teases, temper tantrums). For the older target siblings, Cronbach's alpha reliabilities for these scales ranged from 0.87 to 0.94 for overt antisocial behavior. For the younger siblings, alphas ranged from 0.82 to 0.92 for overt antisocial behavior.

Observer measures. Observer reports consisted of items from interviewer and observer ratings (see Capaldi \& Patterson, 1989). These measures used in the larger SIBS study were tailored to the specific content of a given assessment and were adapted to be age-appropriate. These forms were completed by the interviewer immediately following the given assessment or home visit. Interviewer ratings are commonly used at OSLC with 
internal validity alphas ranging from approximately .65 to .85 depending on the number and content of the items. The items used from observers for this dissertation research came from the Home Visit Impressions (HVIMP) form and were used to create the observer-reported warmth and hostility constructs.

Child measure. Child reports came from the Computer Assisted Child Interview (CACI; Bank et al., 2000). Each sibling completed the CACI. The CACI instrument contains 110 items which were developed to assess 4-11 year olds on 11 theoretical constructs: Parental Discipline, Parent Supervision, Parent Involvement, Parent-Child Attachment, Internalizing Behavior, Externalizing Behavior, Sibling Conflict, Peer Relations, School Satisfaction/Experience, Chore Engagement, and Neglect and Hygiene. A computer (laptop or desktop) was used for children to respond to statements on a keyboard. Pictures were present with each statement and response options (not at all, some, and a lot) were presented with a corresponding picture - a jar of jelly beans (empty jar, half-filled jar, or full jar of jelly beans). Each item was also accompanied by a voice overlay. It was possible for items to be repeated if childrequested. Moreover, each staff person was trained to pause the program and replay a given item if the child did not appear to be engaged or paying attention (e.g., if a child turned away from the computer screen). Child reported items reflecting parent-child warmth and parent-child hostility were pulled from this instrument.

Teacher measure. Each sibling's teacher reported on their student's behavior over the previous 2 months on a 3-point Likert scale $(0,1,2)$ using an adaptation of the Teacher Report Form (TRF; Achenbach, 1991). The primary outcomes of interest were 
older and younger sibling's overt antisocial behavior. Teachers were asked to rate the child's behavior over the previous two month period. In the larger SIBS project, different teachers often completed these scales at baseline, termination, and follow-along. Teachers completed the TRF in a modified phone interview format during evening or weekend hours, including scales for withdrawn- and anxious-depressed behavior, attention problems, delinquent behavior and aggressive behavior. The overt, aggression scale was comprised of 25 items (e.g., argues, cruel/bullies, disobeys, fights, teases, temper tantrums). The psychometric properties of this nationally standardized instrument are well established. Internal consistency for the full scale ranges from .72 to .95 .For the older sibling and the younger sibling, Cronbach's alpha for these scales ranged from 0.94 to 0.95 for overt antisocial behavior. For this dissertation research, only baseline and intervention term data were analyzed. Teacher reported overt antisocial behavior was the primary outcome of interest in this study.

\section{Description of Analyses Utilized}

The primary statistical analyses utilized for this research study were correlations, hierarchical regressions, and Analysis of Variances (ANOVAs). Pearson's correlations have been used to explore the relationship between two interval level/continuous variables and are based on the variance of two variables. This statistic also known as Pearson product moment correlation ("r") indicates both the strength and direction of the relationship and the values range from -1 to +1 . The sign determines the direction of the relationship and is either positive or negative. A positive correlation reveals that as one variable increases the other also increases. A negative correlation reveals that as one 
variable increases, the other decrease. The absolute value of the statistic provides the strength or magnitude of the relationship with the higher the number indicating the stronger the relationship. The Pearson $r$ does assume that the two variables are normally distributed. Rosenthal (1996) indicated that .10 is a small effect size, .3 is a moderate to medium effect size, .5 is a strong effect sized, and .7 or greater is a very strong effect size.

Partial correlation is similar to Pearson correlation; however, with this statistic, an additional variable can be controlled. This statistic allows for controlling the influence of a potential confounding variable. So, if three variables are intercorrelated, the partial correlation can isolate the unique influence of one variable on another.

Multiple linear regression is another technique used to explore the relationship between variables and was used in this study. It is a technique used to examine the predictive ability of a set of independent variables on one continuous variable. It can be used to determine the extent to which a set of variables is able to predict a specific outcome (e.g., children's antisocial behavior); which variable is the best predictor of a given outcome; and whether a specific predictor variable can continue to predict a given outcome when controlling for the effects of other variables.

Hierarchical regression is a type of multiple regression in which variables are entered in specific blocks or steps in a predetermined order based on theory. An individual variable or multiple variables are included in each step, but the researcher determines which variables are included in each step rather than the computer (as is done 
in step-wise regression). The results of each step reveal how well the variable or set of variables predict the outcome variable after controlling for variables in the previous steps. Multiple regression has also been used to examine moderation and mediation (see Baron \& Kenny, 1986). A moderator alters the strength of a relationship between two variables $(\mathrm{X}$ and $\mathrm{Y}$ ) and this is often tested through the use of interaction terms (Aiken \& West, 1991).

ANOVAS are statistics used to compare mean scores of two continuous variables on two or more groups. This technique tells whether a significance difference exists between groups. Post hoc tests can then be conducted to determine where the true significance difference lies between groups.

\section{Analysis Strategy}

This section will provide a brief overview of the specific steps of the analytic strategy utilized in this dissertation research to answer the three primary research questions and all their forms. First, data were examined and cleaned. Data were also checked for patterns of missing data. Second, Hostility and Warmth constructs were developed for each reporting agent. These constructs will also be referred to as direct parenting of warmth and direct parenting of hostility henceforth. Reliability and validity of these individual agent's perspectives were examined, and sum scores were created for each reporting agent for each domain. It was initially thought that there may be enough convergence between reporting agents to create a higher order construct for each domain. 
However, because informants revealed unique perspectives of these warmth and hostility direct parenting constructs, another way of viewing PDT across agents was examined.

Third, PDT- Hostility and PDT-Warmth scores were created by calculating the relative difference scores. There were two sum scores (i.e., parent-older sibling and parent-younger sib) for each reporting agent as well as for each domain (i.e., warmth and hostility). PDT scores were calculated by subtracting younger sibling's direct parenting sum score from the older sibling's direct parenting sum score for each domain. Concurrent validity of the PDT-Warmth and PDT-Hostility indicators were also examined. Fourth, a series of hierarchical multiple regression analyses were conducted to examine research question one and all its forms. These cross-sectional regressions were tested with two blocks: for block one, child age, child gender, and direct parenting toward the individual were included; for block two, the PDT score of a different reporting agent was added. These analyses were conducted separately for older and younger siblings. In each regression, the dependent variable was the child's baseline TRF score.

Fifth, a series of hierarchical multiple regression analyses were conducted to answer research question two and all its forms to take a longitudinal approach and test whether intervention interacts with PDT. These analyses were based on a priori predictions of significant interaction effects between intervention group assignment (SPMT, PMT, or CPT) and PDT level for behavior changes from baseline assessment to post-intervention 6-month assessments. Interactions terms were computed between each reporting agent's interval level PDT score and the intervention treatment group. These hierarchical regressions were also tested in two steps: for block 1, child gender, direct 
parenting for one reporting agent, PDT from a different reporting agent, and treatment group were included; for block 2, the interaction score between PDT and treatment group was added. For each regression, the dependent variable was the TRF change score (intervention term TRF score minus the baseline TRF score). These analyses were also conducted separately for older and younger siblings. This question and its forms addressed the extent to which PDT interacts with the intervention.

Sixth, a series of ANOVAs were conducted to determine whether there were mean differences in PDT change scores by treatment group. These analyses were conducted to examine the third question and all its forms, which addressed the potential malleability of these two PDT domains.

The following subsections provide some additional details about the three research questions and all their forms plus hypotheses and expected findings.

\section{Forms and Hypotheses for Research Question 1.}

1. To what extent are PDT Warmth and PDT-Hostility associated with older sibling's (OS) and younger sibling's (YS) antisocial behavior?

This question has four forms which can be further divided into subquestions:

\section{$\underline{\text { PDT-Hostility }}$}

- $\quad$ To what extent is PDT-Hostility associated with older sibling's overt antisocial behavior?

- To what extent is PDT-Hostility associated with younger sibling's overt antisocial behavior?

\section{$\underline{\text { PDT-Warmth }}$}

- $\quad$ To what extent is PDT-Warmth associated with older sibling's overt antisocial behavior? 
- To what extent is PDT-Warmth associated with younger sibling's overt antisocial behavior

\begin{tabular}{|c|c|}
\hline Parental \\
Differential \\
Treatment
\end{tabular}$\longrightarrow \begin{gathered}\text { Child's Antisocial } \\
\text { Behavior }\end{gathered}$

Hypotheses for research question 1. It is expected that initial bivariate correlations between direct parenting and antisocial behavior will demonstrate that higher levels of direct warmth are related to lower levels of antisocial behavior for older and younger siblings, and that higher levels of direct hostility will be related to higher levels of antisocial behavior for both older and younger siblings. At the bivariate level, it is also expected that larger PDT-Hostility scores will be positively associated with children's antisocial behavior. It is also hypothesized that the regression analyses will demonstrate a similar trend even when controlling for child factors (age, gender) and direct parenting levels (i.e, warmth or hostility). That is, greater differentials between siblings (i.e., larger PDT-Warmth and/or larger PDT-Hostility) will be related to higher levels of antisocial behavior. In other words, the bigger the gap in treatment between siblings, the worse the child's antisocial behavior outcomes.

\section{Forms and Hypotheses for Research Question 2.}

2.) To what extent does intervention treatment moderate PDT-Warmth and PDTHostility? (regression/interaction analyses)

This question has forms which can be further divided into subquestions: $\underline{\text { PDT-Hostility }}$ 
- $\quad$ To what extent does the intervention moderate PDT-Hostility for older siblings??

- $\quad$ To what extent does the intervention moderate PDT-Hostility for younger siblings?

\section{$\underline{\text { PDT-Warmth }}$}

- $\quad$ To what extent does the intervention moderate PDT-Warmth for older siblings?

- $\quad$ To what extent does the intervention moderate PDT-Warmth for younger siblings?

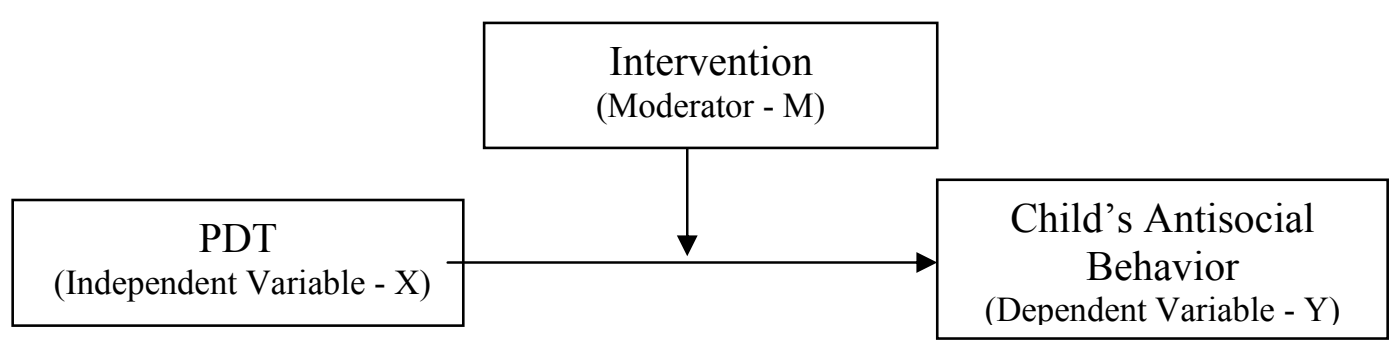

Research Question 2 Hypotheses. It is expected that there will be a significant interaction effect between the interval level PDT score and the continuous intervention treatment variable for both older siblings and younger sibling in at least some of the replications. Moreover, it is expected that the interaction effects will be more easily visible and of stronger magnitude for PDT-Hostility.

\section{Forms and Hypotheses for Research Question 3}

3.) Is it possible to change PDT-Warmth and PDT-Hostility? That is to say, is PDT malleable with an intervention? (ANCOVA analyses)

This question also has forms which can be further divided into subquestions:

\section{$\underline{\text { PDT-Hostility }}$}

- Is PDT-Hostility malleable with an intervention? 


\section{$\underline{\text { PDT-Warmth }}$}

- Is PDT-Warmth malleable with an intervention?

It is hypothesized that children in both intervention treatment groups (i.e., SPMT and PMT) should exhibit reduced antisocial behavior at intervention term, and the control group will be virtually unchanged. In other words, it is expected that levels of PDT for each domain will be similar for the treatment and control groups at baseline. However, PDT will be reduced in both intervention treatment groups upon completion of the intervention, but will remain largely unchanged — no statistically significant difference between baseline and term - in the control group. It is also expected that this will be most pronounced for older siblings. If less PDT is observed at intervention term as compared to baseline in the intervention group, this could mean that participation in the parenting intervention reduced PDT compared to control. See below.

\begin{tabular}{|l|c|c|c|}
\hline \multirow{2}{*}{} & \multicolumn{2}{|c|}{ Treatment } & Control \\
\cline { 2 - 4 } & PMT & SPMT & CPT \\
\hline PDT Baseline & (similar) & (similar) & (similar) \\
\hline PDT Term & Reduced & Reduced & Unchanged \\
\hline
\end{tabular}




\section{CHAPTER IV: RESULTS}

\section{Preliminary Analysis Steps}

As mentioned above, the first step was to clean and carefully examine the data. The Statistical Package for the Social Sciences (SPSS) version 17 was used. The SPSS data files from the larger SIBS intervention project were transferred from Oregon Social Learning Center (OSLC) to Portland State University (PSU). Data sets existed for each measure at each wave, and those were combined for the purposes of this study. These datasets were combined so that an individual dataset existed for each measure which included data from baseline and term. At that point, each dataset for each measure was screened for missing data. Patterns of missingness were examined carefully. Tabachnick and Fidell (2007) have indicated that missing data tends to be one of the most pervasive problems when analyzing data. Therefore, the pattern of missing values was assessed. There was quite a bit of attrition at intervention term (6 months after enrollment in the study) since these families were high risk families and highly mobile. Data were missing primarily at intervention term, and tests were conducted to ensure that families still participating in the study 6 months later were similar those families participating at baseline.

Cases were selected for families that completed the Teacher Report Form (TRF) for older siblings at both baseline and term, then ANOVA analyses were conducted on those same families at baseline to examine whether mean differences existed between the three treatment groups for individuals who had complete data. As anticipated, no 
significant mean differences were found at baseline assessment on TRF antisocial behavior between the three groups: $\operatorname{SPMT}(M=.33, S D=.35), \operatorname{PMT}(M=.36, S D=.33)$, and CPT $(M=.21, S D=.23)\left(\mathrm{F}_{(\mathrm{df}=2,90)}=1.469, p=.236\right)$. To determine if families who dropped after completing the baseline assessment were comparable to families that completed both baseline and intervention term assessment, t-tests were conducted on a few demographic variables to determined whether or not there were any significant differences between families that only completed baseline assessment and those families that completed both baseline and intervention term assessments. The t-tests revealed that there were no significant differences on income $[t(113)=.286, p=.78]$, parent ethnicity $[t(110)=.553, p=.58]$ older sibling age $[t(120)=-.420, p=.68]$ or younger sibling age $[t(72)=-.005, p=.996]$. These analyses suggested that families participating at baseline and intervention term were very similar. Therefore, it was decided to use the information that was available for participants, rather than impute data.

Both univariate and bivariate analyses were conducted on continuous variables as preliminary analyses to get a better sense of the data as well as to ensure that assumptions were not being violated. Data were checked for normality, linearity, and homoscedasticity (Pallant, 2005). Frequency distributions, histograms, and scatterplots were examined to explain these factors as well as identify the presence of any outliers (Cohen, Cohen, West, \& Aiken, 2003; Tabachnick \& Fidell, 2007). In this process, a couple of items of interest originally were dropped as they were highly skewed and/or highly kurtotic. Multicollinearity was also assessed by examining the correlation matrix (Pallant, 2005). After the initial examination of data was conducted, individual data sets 
for each measure were combined to create a master data file which included all measures of interest at baseline and intervention term (6 months later) for both older and younger siblings. Additional information on construct development, difference scores, and the specific tests were conducted to answer the three primary research questions of interest can be found below.

\section{Constructs and Construct Development}

Child's Overt Antisocial Behavior. The outcomes of interest in this study were older siblings' and younger siblings' overt antisocial behaviors which were measured by an adapted version of the Teacher Report Form (TRF). At baseline, 117 teachers reported on older siblings' overt antisocial behavior $(M=.37, S D=.41)$ and 72 teachers reported on younger siblings' overt antisocial behavior $(M=.32, S D=.40)$. At intervention term, 96 teachers reported on older siblings' antisocial behavior $(M=.38, S D=.39)$, and 74 teachers reported on younger siblings' antisocial behavior $(M=.30, S D=.39)$. On average, teachers reported antisocial behavior reveal higher scores for older siblings at both waves. This may be somewhat related to the fact that older siblings were the ones screened in the study for their behavior. However, the standard deviations also reveal that there is similar variation in younger siblings' antisocial behavior.

Some analyses also examined parents' reports of children's antisocial behavior on an adapted version of the CBCL. At baseline, 101 parents reported on older siblings' $(M=.83, S D=.36)$ and younger siblings' $(M=.67, S D=.34)$ overt antisocial behavior. At intervention term, 63 parents reported on older siblings' $(M=.58, S D=.41)$ and younger siblings' $(M=.51, S D=.34)$ antisocial behavior. A similar trend was found with older 
siblings' scores slightly higher than younger sibling scores at both baseline and intervention term. The other constructs examined were parent reported parent-child attachment and ineffective discipline (described earlier).

Warmth. Warmth constructs were created to assess warmth in the mother-older sibling dyad and warmth in the mother-younger sibling dyad. Three informant types [i.e., children (older and younger sibling), parents, and observers] reported on items that represented parent-child warmth. Face valid items were carefully selected from the various measures completed by each informant in the larger SIBS study. The original items selected were thought to capture the spirit of this domain as it has been studied in the literature. Some of the original items that were hand selected were shown to be problematic (e.g., highly skewed, highly kurtotic or did not converge well with the other items selected which was indicated by low internal consistency). The final list of items for each informant type, however, fit the theoretical basis of this construct and passed initial data checking tests. This list can be found in Table 1. To create warmth scores, these items were summed for each reporting agent which resulted in a total of 6 warmth sum scores [3 for older siblings (child reported warmth, parent reported warmth, and observer reported warmth) and 3 for younger siblings (child reported warmth, parent reported warmth, and observer reported warmth)].

Reliability analyses were conducted for these items for each reporting agent. Cronbach's alphas for baseline were as follows: for older sibs, youth reported warmth $\alpha=.69$, parent reported warmth $\alpha=.69$, and observer reported warmth $\alpha=.77$. For younger siblings, youth reported warmth $\alpha=.70$, parent reported warmth $\alpha=.66$, and observer 
reported warmth $\alpha=.74$. These newly created constructs also passed initial validity tests that support this assertion. For older siblings, parent-child attachment was significantly correlated with youth reported warmth $(\mathrm{r}=.195, p<.05)$ and parent reported warmth $(\mathrm{r}=.238, p<.05)$ and observer reported warmth was also positively correlated $(\mathrm{r}=.153$, $p=.125)$. For younger siblings, parent reported warmth $(\mathrm{r}=.208, p<.05)$ and observer reported warmth $(\mathrm{r}=.224, p<.05)$ were both significantly positively associated with parent-child attachment, and youth reported warmth was positively correlated with attachment $(\mathrm{r}=.08, p=.38)$. These direct parenting sum scores were $\mathrm{z}$-scored to use in the regression analyses. Interestingly, although reliability and validity tests did demonstrate that these constructs measured warmth, the intercorrelations between reporters were not significant. This finding highlights that there are different and distinct perceptions among reporting agents regarding each mother-child dyad. For this reason, a higher order construct for warmth was not created and analyses for each reporting agent were conducted separately.

Additionally, warmth constructs (i.e., direct parenting scores for warmth) from each reporting agent were examined in relation to both older siblings' and younger siblings' overt antisocial behavior as well as some other related factors to examine concurrent validity. Contrary to what was expected, warmth scores were not significantly correlated with TRF outcomes [for older siblings: youth reported direct warmth and TRF $(\mathrm{r}=.047, p=.629, \mathrm{n}=110)$, parent reported direct warmth and TRF $(\mathrm{r}=-.-020, p=.847$, $\mathrm{n}=92)$ and observer reported direct warmth and TRF $(\mathrm{r}=-.047, p=.649, \mathrm{n}=95)$; for younger siblings: youth reported direct warmth and $\operatorname{TRF}(\mathrm{r}=.163, p=.185, \mathrm{n}=68)$, parent reported 
direct warmth and TRF $(\mathrm{r}=-.058, p=.663, \mathrm{n}=59)$ and observer reported direct warmth and TRF $(\mathrm{r}=-.116, p=.370, \mathrm{n}=62)]$. As can be seen, these correlations were very close to zero (uncorrelated) for both older and younger siblings (see Table 2). However, warmth scores did show modest correlations with other factors such as parent-child attachment.

Table 1. Warmth Items by Reporting Agent.

PARENT REPORT

PIANTA 1 - I have a warm, caring relationship with this child

PIANTA 16 - It's easy to be in tune with what this child is feeling

PIANTA 30 - Dealing with this child makes me feel good about how I handle things PCRT 6 - How much do you enjoy...talking with your child

PCRT 9 - How much do you enjoy...comforting child

OBSERVER REPORT

HVIMP 27 - Did the mother speak to the older/younger child in a positive tone?

HVIMP 28 - Did the mother express a positive attitude when speaking about the older/younger child?

HVIMP 29- Did the mother initiate positive physical contact with the older/younger child?

CHILD REPORT

CACI 15 - My mom and I do things together

CACI 44 - I like my mom to hug me

CACI 89 - I talk to my mom about important things

CACI 90 - My mom plays with me

CACI 93 --- I like my mom to help me[like to help my mom]

CACI 101 - When I am sad, I like to be with my mom

Hostility. In a similar fashion, six hostility constructs were also created for the mother-child dyads. In other words, three informant types (youth, parent, and observer) reported on items that represent mother-child hostility for both dyads, mother-older sibling and mother-younger sibling. The final list of items, by reporter type, can be found on Table 2. The original list of face valid items were selected across measures to fit this domain. From that original list, some items were not utilized if they were highly skewed or kurtoitic or did not converge with other items of interest for a particular reporting 
agent (i.e., if they had low internal consistency with other items). Unfortunately, a few behavioral items that were dropped were parent reported items because they were problematic or had low base rates. Once the final list was determined for each reporting agent, these hostility items were then summed to create hostility scores for each reporting agent resulting in a total of 6 hostility sum scores [ 3 for older siblings (child reported hostility, parent reported hostility, and observer reported hostility) and 3 for younger siblings (child reported hostility, parent reported hostility, and observer reported hostility)]. Inter-item correlations and reliability analyses were also examined for hostility items for each reporter type. Cronbach's alphas for wave 1 were as follows: for older sibs, youth reported hostility $\alpha=.71$, parent reported hostility $\alpha=.69$ (r $=.53$ for the two items), and observer reported hostility $\alpha=.83$ ( $\mathrm{r}=.71$ for the two items); for younger sibs, youth reported hostility $\alpha=.68$, parent reported hostility $\alpha=.64(\mathrm{r}=.47)$, and observer reported hostility $\alpha=.80(\mathrm{r}=.69)$. Hostility constructs from each reporting agent (i.e., direct parenting scores) were examined in relation to both older siblings' and younger siblings' overt antisocial behavior as well as other related factors to examine concurrent validity. As expected, overt antisocial behavior as reported by the teacher was significantly positively correlated with youth reported hostility $(\mathrm{r}=.24, p<.05, \mathrm{n}=112)$ and parent reported hostility $(\mathrm{r}=.22, p<.05, \mathrm{n}=84)$, and approached significance with observer reported hostility $(\mathrm{r}=.20, p<.10, \mathrm{n}=86)$ for older siblings.

For younger siblings, parent reported hostility $(\mathrm{r}=.59, p<.001)$ and observer reported hostility $(\mathrm{r}=.23, \mathrm{p}<.05)$ were significantly positively associated with TRF scores as expected; however, the correlation with youth reported hostility was near zero. These 
hostility sum scores were standardized prior to use in the regression analyses. Similar to what was found for warmth constructs, the intercorrelations between reporters were not significant. This indicates that there are distinct perceptions among reporting agents regarding each mother-child dyad. Therefore, a higher-order construct containing reports from all informants was not created for hostility.

Table 2 Hostility Items by Reporting Agent.

\section{PARENT REPORT}

PIANTA 2 - This child and I always seem to be struggling with each other

PIANTA 21 - Dealing with this child drains all my energy

OBSERVER REPORT

HVIMP 26 - Did the mother express overt hostility or annoyance toward the older/younger child?

HVIMP 30 - Did the mother scold or hit older/younger child?

\section{CHILD REPORT}

CACI 3 - My mom yells at me

CACI 34 - My mom makes me really mad

CACI 39 - My mom stops talking to me when she's mad at me

CACI 48 - My mom spanks me

CACI 53 - My mom scolds me

CACI 55 - Mom gets angry with me

\section{Difference Scores - Parental Differential Treatment}

After warmth and hostility direct parenting constructs were created for each parent-child dyad as well as for each reporting agent, PDT scores for each domain were calculated through the use of relative difference scores. These difference scores (i.e., PDT scores) were obtained by subtracting the value of the younger sibling's direct parenting sum score for a particular domain (e.g., parent reported hostility of the mother-younger sibling dyad) from that of the older sibling's direct parenting sum score for that domain (e.g., parent reported hostility of the mother-older sibling dyad). The result of this calculation then represents the parental differential treatment for a given domain as 
reported from that particular perspective (e.g., parent reported PDT-Hostility). This was done for each reporting agent resulting in three PDT scores for each domain: youth reported PDT, parent reported PDT and observer reported PDT for a total of 6 PDT scores (i.e., youth reported PDT-Hostility, parent reported PDT-Hostility, observer reported PDT-Hostility, youth reported PDT-Warmth, parent reported PDT-Warmth, observer reported PDT-Warmth).

Each new PDT score indicates the direction and the value represents the degree of the difference. Positive scores indicate that the older sibling scored higher compared to his or her younger sibling, whereas negative scores indicate a younger sibling scored higher than the older sibling. Additionally, higher values indicate a larger magnitude of difference in regards to the differential treatment between siblings. It should also be noted that a score of zero indicates no difference between siblings. Descriptive statistics for these raw variables indicate the level and degree of PDT and can be found in Table 3. See Table 4 for interpreting PDT values.

Table 3 Descriptive Statistics of Raw Difference Scores between older sibling and younger sibling for each reporter's perspective of PDT-Warmth and PDT-Hostility.

\begin{tabular}{|c|c|c|c|c|c|}
\hline \multirow{2}{*}{$\begin{array}{l}\text { Difference Scores } \\
\text { PDT-Warmth }\end{array}$} & $\mathrm{M}$ & SD & Range & Min & $\operatorname{Max}$ \\
\hline & & & & & \\
\hline Child Report ( $\mathrm{n}=118)$ & .25 & 3.64 & 19 & -8 & 11 \\
\hline Parent Report ( $\mathrm{n}=101)$ & -1.12 & 2.88 & 19 & -12 & 7 \\
\hline $\begin{array}{l}\text { Observer Report }(\mathrm{n}=103) \\
\text { PDT-Hostility }\end{array}$ & -.64 & 2.18 & 16 & -8 & 8 \\
\hline Child Report $(\mathrm{n}=120)$ & .04 & 3.73 & 20 & -9 & 11 \\
\hline Parent Report (n=92) & .65 & 2.81 & 13 & -6 & 7 \\
\hline Observer Report ( $\mathrm{n}=92)$ & -.18 & 1.00 & 9 & -6 & 3 \\
\hline
\end{tabular}


Table 4 Parental Differential Treatment (PDT) Interpretation Table.

\begin{tabular}{c|l}
\hline PDT Score & \multicolumn{1}{c}{ Meaning } \\
\hline+ & $\begin{array}{l}\text { Older Sibling Treated with More of Specified Domain } \\
\text { Younger Sibling Treated with Less of Specified Domain }\end{array}$ \\
\hline 0 & Both Older Sibling and Younger Sibling Treated Equally \\
\hline- & $\begin{array}{l}\text { Younger Sibling Treated with More of Specified Domain } \\
\text { Older Sibling Treated with Less of Specified Domain }\end{array}$ \\
\hline
\end{tabular}

On average, youth reported that older siblings were treated with more warmth whereas both parents and observers reported that the younger siblings were treated with more warmth. Notice that parent reported PDT-Warmth revealed that younger siblings were treated with much more warmth than the other two reporting agents. Youth reported PDT-Hostility was fairly close to zero indicating equal treatment on average for that domain; however, parent reported PDT-Hostility illustrates that the older siblings were treated with more hostility, and observer reported PDT-Hostility indicates that the younger siblings were treated with slightly more hostility on average. It is important to examine the range of these values by reporting agent as well because the means are not always as meaningful. Additionally, it should be noted that the raw PDT scores were also standardized prior to use in the regression analyses.

Correlations were also conducted between the standardized direct warmth scores and the standardized PDT-Warmth scores as well as between the standardized direct hostility scores and the standardized PDT-Hostility scores. See Table 5. The bottom left of the table displays hostility and PDT-Hostility associations and the top right of the table displays warmth and PDT-Warmth associations. Interestingly, some of the strongest correlations for each domain are between parent reported direct parenting for older 
sibling and direct parenting for younger sibling as well as observer reported direct parenting for older sibling and direct parenting for younger sibling. 
Table 5 Correlations between direct parenting and PDT

\begin{tabular}{|c|c|c|c|c|c|c|c|c|c|c|}
\hline & & \multicolumn{3}{|c|}{$\begin{array}{l}\text { Direct Parenting - Older } \\
\text { Sibling }\end{array}$} & \multicolumn{3}{|c|}{$\begin{array}{c}\text { Direct Parenting - Younger } \\
\text { Sibling }\end{array}$} & \multicolumn{3}{|c|}{$\begin{array}{l}\text { Parental Differential } \\
\text { Treatment (PDT) }\end{array}$} \\
\hline & & 1. & 2. & 3. & 4. & 5. & 6. & 7. & 8. & 9. \\
\hline 1. & $\begin{array}{l}\text { Direct - } \\
\text { youth } \\
\text { (OS) }\end{array}$ & 1 & .01 & .06 & .06 & .00 & .01 & $.62 * *$ & .02 & .04 \\
\hline 2. & $\begin{array}{l}\text { Direct- } \\
\text { parent } \\
\text { (OS) }\end{array}$ & .16 & 1 & -.02 & -.06 & $.81^{* *}$ & -.07 & .06 & $.33^{* *}$ & .10 \\
\hline 3. & $\begin{array}{l}\text { Direct- } \\
\text { observer } \\
\text { (OS) }\end{array}$ & .10 & .13 & 1 & .11 & .12 & $.81^{* *}$ & -.04 & $-.22 *$ & $.33^{* *}$ \\
\hline $\begin{array}{l}4 . \\
5 .\end{array}$ & $\begin{array}{l}\text { Direct- } \\
\text { youth } \\
\text { (YS) }\end{array}$ & $.16+$ & -.07 & $.19+$ & 1 & .07 & .06 & $-.74^{* *}$ & $-.21^{*}$ & .09 \\
\hline $\begin{array}{l}6 . \\
7 .\end{array}$ & $\begin{array}{l}\text { Direct- } \\
\text { parent } \\
\text { (YS) }\end{array}$ & -.07 & .17 & $.24^{*}$ & -.02 & 1 & .09 & -.05 & $-.29 * *$ & .05 \\
\hline 6. & $\begin{array}{l}\text { Direct- } \\
\text { observer } \\
\text { (YS) }\end{array}$ & .14 & .11 & $.83^{* *}$ & .13 & $.36 * *$ & 1 & -.02 & $-.26 *$ & $-.28^{* *}$ \\
\hline 7. & $\begin{array}{l}\text { PDT- } \\
\text { youth }\end{array}$ & .58 & .15 & -.11 & $-.72^{* *}$ & -.06 & -.02 & 1 & $.18+$ & -.04 \\
\hline 8. & $\begin{array}{l}\text { PDT- } \\
\text { parent }\end{array}$ & .17 & $.62^{* *}$ & -.09 & -.04 & $-.67 * *$ & $-.20+$ & .15 & 1 & .06 \\
\hline 9. & $\begin{array}{l}\text { PDT- } \\
\text { observer }\end{array}$ & .03 & .03 & $.38 * *$ & .04 & $-.20+$ & $-.20+$ & -.06 & .18 & 1 \\
\hline
\end{tabular}

Correlations were conducted between standardized PDT scores and each sibling's antisocial behavior as reported by the teacher at baseline. For older siblings, all PDTHostility scores were positively correlated with their antisocial behavior, and youth reported PDT-Hostility was significantly positively correlated with antisocial behavior $(\mathrm{r}=.20, p<.05, \mathrm{n}=111)$. These correlations illustrate that when older siblings are treated with more hostility in comparison to younger siblings (no matter who reports that 
finding), older siblings' antisocial behavior as reported by the teacher is higher. The associations between PDT-Warmth and TRF scores were nonsignificant for all reporting agents. For younger siblings, PDT-Hostility and younger siblings' antisocial behavior were nonsignificant for all reporting agents. However, youth reported PDT-Warmth and TRF scores were significantly negatively associated $(\mathrm{r}=-.307, p<.05, \mathrm{n}=68)$. This negative finding may seem counterintuitive at first glance, but may also suggest that, when PDT is present in a home, more antisocial behavior occurs no matter which child is less favored. Such a result would be consistent with findings from other studies (see Boyle et al., 2004).

\section{PDT Re-examined}

Since there was little agreement among reporting agents about the occurrence of PDT and higher order constructs could not be created, an alternative model was examined in an attempt to better understand PDT across reporting agents. This analysis was based on the idea that growing up in high-PDT families, regardless of whether a child was preferred or disfavored, would ultimately lead to poorer outcomes for these children as compared to children growing up in egalitarian families. For this analysis, a categorical variable was created from the z-scored PDT variables of the three reporting agents. Treatment has been categorized in other studies (see McHale et al., 1995). For this study, categories were created by taking each interval level PDT score and categorizing it into three groups: older sibling treated with more hostility $(+1)$, older sibling and younger sibling treated equally (0), and younger sibling with more hostility (-1). The same process was used for the warmth domain. The division between categories was created based on 
whether the PDT score was one half standard deviation above or below the mean. More precisely, this decision rule was .55 standard deviations above the mean because of the distribution of standardized scores. This criterion was established because it was thought that treatment one half a standard deviation above or below the mean would be difficult to consider as egalitarian and therefore would be considered PDT. Thus, PDT scores within +/- .55 SDs were considered egalitarian-treatment families (i.e., egalitarian treatment or low PDT). Families that that exceeded .55 SDs above or below the mean were considered high-PDT as reported by that agent (youth, parent, or observer).

These categorized scores $(-1,0,1)$ were then examined across reporting agents. If two reporting agents agreed about the occurrence of high PDT (e.g., -1 or +1 ), then that agreed value was placed in the new cross-agent PDT variable (i.e, 1 for this particular family). Those cases for which all three reporting agents disagreed were considered missing for this new cross-agent PDT variable. While this strategy demonstrated good inter-rater agreement on PDT status between two agents for the majority of families, the most common match was for equal treatment of the two siblings ( $\mathrm{n}=65$ for PDT-Warmth; $\mathrm{n}=58$ for PDT-Hostility). For a small number of families, there was agreement of highPDT (Ns varied from 5 to 13), and these two groups (i.e., High PDT families and Egalitarian treatment families) were tested for differences on child adjustment outcomes at the baseline assessment even though the numbers in the High PDT group are small.

To examine whether there were statistically significant differences between these high-PDT families as compared to more egalitarian treatment families in sibling outcomes, a series of one-way ANOVAs were conducted. These analyses were 
conducted to examine whether high PDT as reported by at least two informants results in worse outcomes for children. Because the number of families in the high PDT crossagent group were so small, it was decided to examine mean differences between the high PDT group and the egalitarian treatment group on a variety of child adjustment outcomes. Thus, the outcomes examined for these ANOVA analyses included parent and teacher reported antisocial behavior, parent reported ineffective discipline, and parent reported parent-child attachment, and these were examined for both PDT-Hostility and PDTWarmth. See Table 6.The patterns for PDT-Hostility were clearly consistent with the hypothesis. Siblings in the high-PDT-Hostility group compared to siblings in egalitariantreatment households had significantly higher antisocial behavior scores as reported by parents: for older siblings, $F_{(\mathrm{df}=1,59)}=4.998, p=.029$; for younger siblings, $F_{(\mathrm{df}=1,58)}=$ 3.883, $p=.054$. A similar pattern emerged for teacher reported overt antisocial behavior

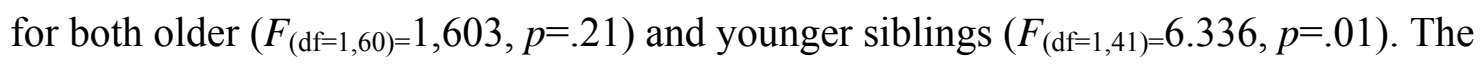
finding for younger siblings was significant; however, the test for homogeneity of variances was violated ( $p=.004$ on Levene's test) which could be at least partially explained by the unequal Ns between the two groups. Siblings in the high-PDT-Hostility group compared to siblings in the egalitarian treatment group also had significantly higher scores for parent reported Ineffective Discipline: for older siblings, $F_{(\mathrm{df}=1,67)}$ $=10.822, p=.002$; and for younger siblings, $\mathrm{F}_{(\mathrm{df}=1,66)}=5.620, p<.05$. Also, as predicted, there were significant differences between those in the high PDT-Hostility group and those in the egalitarian group for parent reported parent-child attachment (parent 
reported): for older siblings, $F_{(\mathrm{df}=1,65)}=10.219, p=.002$; there was a similar pattern found

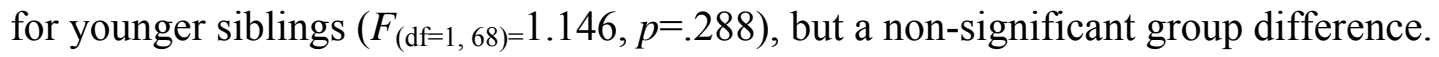

A series of one-way ANOVAs were also conducted with PDT-Warmth and the same outcomes of interest, namely parent and teacher reported antisocial behavior, parent reported ineffective discipline, and parent reported parent-child attachment. While the patterns of results displayed mean differences consistent with the hypothesis for the most part, no significant findings emerged for parent-child attachment, and ineffective discipline. Note, however, that Ns for high PDT-Warmth as reported by at least two reporting agents were particularly small.

Table 6 Egalitarian Group and High PDT Group Mean Differences on Child Adjustment Outcomes.

\begin{tabular}{|c|c|c|c|c|c|c|}
\hline & \multicolumn{3}{|c|}{ OLDER SIBLINGS- PDT-Hostility } & \multicolumn{3}{|c|}{ YOUNGER SIBLINGS - PDT-Hostility } \\
\hline \multirow[t]{2}{*}{ OUTCOMES } & & Egal & PDT & & Egal & PDT \\
\hline & & Means & Means & & Means & Means \\
\hline $\begin{array}{l}\text { AS Behavior } \\
\text { (teacher) }\end{array}$ & $\begin{array}{l}F_{(\mathrm{df}=1,60)}=1.603 \\
p=.210\end{array}$ & $\begin{array}{l}.36(.38) \\
n=51\end{array}$ & $\begin{array}{l}.55(.55) \\
n=9\end{array}$ & $\begin{array}{l}F_{(\mathrm{df}=1,41)}=6.336 \\
p=.016\end{array}$ & $\begin{array}{l}.27(.33) \\
n=34\end{array}$ & $\begin{array}{l}.67(.59) \\
n=7\end{array}$ \\
\hline $\begin{array}{l}\text { AS Behavior } \\
\text { (parent) }\end{array}$ & $\begin{array}{l}F_{(\mathrm{df}=1,59)}= \\
4.998, p=.029\end{array}$ & $\begin{array}{l}.78(.33) \\
n=50\end{array}$ & $\begin{array}{l}1.06(.47) \\
n=9\end{array}$ & $\begin{array}{l}F_{(\mathrm{df}=1,58)}= \\
3.883, p=.054\end{array}$ & $\begin{array}{l}.66(.35) \\
n=50\end{array}$ & $\begin{array}{l}.91(.29) \\
n=8\end{array}$ \\
\hline $\begin{array}{l}\text { Ineffective } \\
\text { Discipline }\end{array}$ & $\begin{array}{l}F_{(\mathrm{df}=1,67)} \\
=10.822, \\
p=.002\end{array}$ & $\begin{array}{l}2.60(.59) \\
n=57\end{array}$ & $\begin{array}{l}3.25(.47) \\
n=10\end{array}$ & $\begin{array}{l}F_{(\mathrm{df}=1,68)}=5.620, \\
p=.021\end{array}$ & $\begin{array}{l}2.57(.60) \\
n=57\end{array}$ & $\begin{array}{l}3.04 \\
(.63) \\
n=11\end{array}$ \\
\hline \multirow[t]{2}{*}{ Attachment } & $\begin{array}{l}F_{(\mathrm{df}=1,65)}= \\
10.219, p=.002\end{array}$ & $\begin{array}{l}3.76(.56) \\
n=57\end{array}$ & $\begin{array}{l}3.13(.67) \\
n=10\end{array}$ & $\begin{array}{l}F_{(\mathrm{df}=1,68)}=1.146 \\
p=.288\end{array}$ & $\begin{array}{l}3.90(.46) \\
n=57\end{array}$ & $\begin{array}{l}3.74 \\
(.51) \\
n=11\end{array}$ \\
\hline & \multicolumn{3}{|c|}{ OLDER SIBLINGS- PDT-Warmth } & \multicolumn{3}{|c|}{ YOUNGER SIBLINGS - PDT-Warmth } \\
\hline $\begin{array}{l}\text { AS Behavior } \\
\text { (teacher) }\end{array}$ & $\begin{array}{l}F_{(\mathrm{df}=1,64)}=.006 \\
p=.940\end{array}$ & $\begin{array}{l}.36(.42) \\
n=60\end{array}$ & $\begin{array}{l}.38(.53) \\
n=4\end{array}$ & $\begin{array}{l}F_{(\mathrm{df}=1,49)}=.005 \\
p=.945\end{array}$ & $\begin{array}{l}.32(.42) \\
n=43\end{array}$ & $\begin{array}{l}.33(.36) \\
n=6\end{array}$ \\
\hline $\begin{array}{l}\text { AS Behavior } \\
\text { (parent) }\end{array}$ & $\begin{array}{l}F_{(\mathrm{df}=1,58)}=1.069 \\
p=.306\end{array}$ & $\begin{array}{l}.74(.34) \\
n=55\end{array}$ & $\begin{array}{l}.96(.66) \\
n=3\end{array}$ & $\begin{array}{l}F_{(\mathrm{df}=1,67)}=1.218, \\
p=.274\end{array}$ & $\begin{array}{l}.67(.32) \\
n=55\end{array}$ & $\begin{array}{l}.56(.31) \\
n=12\end{array}$ \\
\hline $\begin{array}{l}\text { Ineffective } \\
\text { Discipline }\end{array}$ & $\begin{array}{l}F_{(\mathrm{df}=1,67)}=.027 \\
p=.871\end{array}$ & $\begin{array}{l}2.66(.60) \\
n=63\end{array}$ & $\begin{array}{l}2.61(.48) \\
n=4\end{array}$ & $\begin{array}{l}F_{(\mathrm{df}=1,76)}=.066 \\
p=.798\end{array}$ & $\begin{array}{l}2.55(.60) \\
n=63\end{array}$ & $\begin{array}{l}2.59(.68) \\
n=13\end{array}$ \\
\hline $\begin{array}{l}\text { Parent-Child } \\
\text { Attachment }\end{array}$ & $\begin{array}{l}F_{(\mathrm{df}=1,67)}=.090, \\
p=.766\end{array}$ & $\begin{array}{l}3.72(.52) \\
n=63\end{array}$ & $\begin{array}{l}3.64(.57) \\
n=4\end{array}$ & $\begin{array}{l}F_{(\mathrm{df}=1,76)}=.369 \\
p=.545\end{array}$ & $\begin{array}{l}3.90(.46) \\
n=63\end{array}$ & $\begin{array}{l}3.98(.35) \\
n=13\end{array}$ \\
\hline
\end{tabular}


Research Question 1 Regressions

This first research question takes a cross sectional examination of PDT and sought to examine how each reporter's perspective of PDT is linked to each sibling's overt antisocial behavior controlling for child effects (child age, and child gender) as well as direct parenting from another reporter. These regression analyses were all set up in a similar fashion following the cross-informant strategy implemented by Feinberg and Hetherington (2001). In these regressions, step or block one contained child's gender (e.g., older sib gender), child's age (e.g., older sib age), and one informant's report of direct parenting within a particular domain (e.g., parent reported direct parentinghostility), and the second block or step contained another informant's report of PDT (e.g., youth reported PDT-Hostility). The dependent variable in these analyses was the child's baseline TRF score (e.g., older sibling's baseline TRF score).

For each PDT reporting agent in this study (e.g., youth reporter), there were two direct parenting reporting agents [e.g., parent (section A) and observer (section B)] that could be controlled for in block one. Therefore, two separate regression models were tested for each PDT-reporting agent for each domain. These results are displayed in separate sections (i.e., A and B) in the tables. This procedure was conducted to control for direct parenting and at the same time examine the association between PDT and antisocial behavior in an attempt to avoid the effects of method variance. This meant that research question one and all its forms resulted in 6 separate regression analyses for older sibs for each domain and 6 separate regression analyses for younger sibs for each domain. See Tables 7-10. 
In spite of having a rigorous design that crossed contexts (i.e., from home to school), there were notable findings illustrating the association between PDT and child adjustment. The following paragraphs provide a summary of findings from the first research question. Gender significantly predicted antisocial behavior in most models with boys being more likely to exhibit antisocial behavior. For older siblings, youth reported PDT-Hostility significantly predicted antisocial behavior when controlling for the child effects (i.e., age and gender) and parent reported direct parenting ( $b=.144$, $\left.\mathrm{SE}_{\mathrm{b}}=.045, \beta=.332, p=.002\right)$ as well as when controlling for child effects and observer reported direct parenting $\left(\mathrm{b}=.118, \mathrm{SE}_{\mathrm{b}}=.041, \beta=.307, p=.005\right)$. The adjusted R-squared values revealed that the youth reported PDT-Hostility explained $8.2 \%$ additional variance in older siblings' antisocial behavior when controlling for observer reported direct parenting, and explained 9.9\% additional variance in older sibling's antisocial behavior when controlling for parent reported direct parenting. This was the most striking finding within this series of analyses because this was the only scenario in which this stringent cross-informant strategy (see Feinberg \& Hetherington, 2001) resulted in both versions (i.e., A \& B) significantly predicting older siblings' antisocial behavior.

Parent reported PDT-Hostility and observer reported PDT-Hostility significantly predicted older siblings' antisocial behavior, but only when controlling for one type of direct parenting. That is, parent reported PDT-Hostility significantly predicted $(b=.121$, $\left.\mathrm{SE}_{\mathrm{b}}=.051, \beta=.282, p=.021\right)$ and explained an additional $6.5 \%$ of the variance in older siblings' antisocial behavior at step 2 when controlling for observer reported direct hostility $(F$ Change $=5.653, p<.05)$. In addition, observer reported PDT-Hostility $(\mathrm{b}=.098$, 
$\mathrm{SE}_{\mathrm{b}}=.050, \beta=.203, p=.053$ ) explained an additional $3.1 \%$ of the variance in older siblings' antisocial behavior at step 2 when controlling for youth reported direct parenting (F Change $=3.856, p<.10$ ). See table 7 for all older sibling results with PDT-Hostility. PDT-Warmth did not show an additional unique influence on older siblings' antisocial behavior. For most regressions, step 1 which included older sibling age, older sibling gender, and direct parenting of warmth significantly (at least at $p<.10$ level) predicted older siblings' antisocial behavior primarily because gender was a variable included at that step; however, adding parental differential treatment of warmth (i.e., PDT-Warmth) at model 2 did not explain any additional variance in older siblings' antisocial behavior for any reporting agent. See all results of PDT-Warmth regression analyses in table 8.

For younger siblings, PDT-Hostility did not uniquely predict antisocial behavior in model 2 for any informant. See table 9 for PDT-Hostility regression results for younger siblings. However, there was evidence that youth reported PDT-Warmth explained additional variance in younger siblings' antisocial behavior after controlling for child factors (i.e., younger sibling age and gender) and direct parenting. See all PDTWarmth regression analyses in table 10. When controlling for younger sibling age, gender, and parent reported direct warmth at step 1, an additional $5.6 \%$ of the variance in younger siblings' antisocial behavior was explained by youth reported PDT-Warmth ( $b=$ $\left..128, \mathrm{SE}_{\mathrm{b}}=.055, \beta=-.314, p=.023\right)$. Moreover, when controlling for younger sibling age, gender and observer reported direct warmth at step 1, an additional $7.2 \%$ additional 
variance in younger siblings' antisocial behavior was explained in step $2(b=-.136$, $\left.\mathrm{SE}_{\mathrm{b}}=.055, \beta=-.313, p=.016\right)$. 
Table 7 RQ\#1 Older Siblings' Antisocial Behavior with PDT-Hostility as a predictor.

\begin{tabular}{|c|c|c|c|c|c|c|c|c|}
\hline \multirow{2}{*}{$\begin{array}{l}\text { Youth reported } \\
\text { PDT-Hostility }\end{array}$} & \multicolumn{4}{|c|}{$\mathbf{A}(\mathrm{n}=78)$} & \multicolumn{4}{|c|}{ B $(n=82)$} \\
\hline & $\mathrm{B}$ & SE B & $\beta$ & $\mathrm{t}$ & $\mathrm{B}$ & SE B & $\beta$ & $\mathrm{t}$ \\
\hline \multicolumn{9}{|l|}{ Step 1} \\
\hline OS Age & -.045 & .050 & -.099 & -.907 & -.020 & .043 & -.050 & -.451 \\
\hline OS Gender & .225 & .097 & .257 & $2.312^{*}$ & .180 & .088 & .223 & $2.056^{*}$ \\
\hline Direct Parenting & .090 & .050 & .197 & $1.784+$ & .074 & .048 & .171 & 1.559 \\
\hline $\mathrm{R}^{2}$ & .137 & & & & & .086 & & \\
\hline Adj $\mathrm{R}^{2}$ & .102 & & & & & .051 & & \\
\hline F Change & $3.93 *$ & & & & & $2.457+$ & & \\
\hline \multicolumn{9}{|l|}{ Step 2} \\
\hline OS Age & -.064 & .047 & -.141 & -1.362 & -.042 & .042 & -.107 & -.996 \\
\hline OS Gender & .231 & .092 & .263 & $2.512 *$ & .185 & .084 & .230 & $2.212^{*}$ \\
\hline Direct Parenting & .065 & .048 & .141 & 1.336 & .086 & .046 & .197 & $1.872+$ \\
\hline yPDT & .144 & .045 & .332 & $3.182 * *$ & .118 & .041 & .307 & $2.891 * *$ \\
\hline $\mathrm{R}^{2}$ & .243 & & & & .176 & & & \\
\hline Adj $R^{2}$ & .201 & & & & .133 & & & \\
\hline F Change & $10.127 * *$ & & & & $8.361 * *$ & & & \\
\hline \multirow{2}{*}{$\begin{array}{l}\text { Parent reported } \\
\text { PDT-Hostility }\end{array}$} & \multicolumn{4}{|c|}{$\mathbf{A}(\mathrm{n}=79)$} & \multicolumn{4}{|c|}{ B $(n=64)$} \\
\hline & $\mathrm{B}$ & SE B & $\beta$ & $\mathrm{t}$ & $\mathrm{B}$ & SE B & $\beta$ & $\mathrm{t}$ \\
\hline \multicolumn{9}{|l|}{ Step 1} \\
\hline OS Age & -.043 & .046 & -.095 & -.930 & -.042 & .051 & -.099 & -.818 \\
\hline OS Gender & .264 & .090 & .299 & $2.925 * *$ & .221 & .104 & .258 & $2.133^{*}$ \\
\hline Direct Parenting & .152 & .045 & .346 & $3.411 * * *$ & .098 & .053 & .224 & $1.850+$ \\
\hline $\mathrm{R}^{2}$ & .230 & & & & .132 & & & \\
\hline Adj $\mathrm{R}^{2}$ & .199 & & & & .089 & & & \\
\hline F Change & $7.457 * * *$ & & & & $3.041 *$ & & & \\
\hline \multicolumn{9}{|l|}{ Step 2} \\
\hline OS Age & -.046 & .046 & -.102 & -.993 & -.062 & .050 & -.147 & -1.238 \\
\hline OS Gender & .263 & .090 & .298 & $2.922 * *$ & .242 & .100 & .282 & $2.411^{*}$ \\
\hline Direct Parenting & .143 & .046 & .324 & $3.121 * *$ & .106 & .051 & .243 & $2.080^{*}$ \\
\hline pPDT & .044 & .045 & .101 & .975 & .121 & .051 & .282 & $2.378^{*}$ \\
\hline $\mathrm{R}^{2}$ & .240 & & & & .208 & & & \\
\hline Adj $R^{2}$ & .198 & & & & .154 & & & \\
\hline F Change & .951 & & & & $5.653 *$ & & & \\
\hline \multirow{2}{*}{$\begin{array}{l}\text { Observer } \\
\text { reported PDT- } \\
\text { Hostility }^{3}\end{array}$} & \multicolumn{4}{|c|}{$\mathbf{A}(\mathrm{n}=81)$} & \multicolumn{4}{|c|}{$\mathbf{B}(\mathrm{n}=64)$} \\
\hline & $\mathrm{B}$ & SE B & $\beta$ & $\mathrm{t}$ & $\mathrm{B}$ & SE B & $\beta$ & $\mathrm{t}$ \\
\hline \multicolumn{9}{|l|}{ Step 1} \\
\hline OS Age & -.039 & .041 & -.099 & -.952 & -.068 & .051 & -.161 & -1.342 \\
\hline OS Gender & .192 & .085 & .234 & $2.251 *$ & .172 & .104 & .201 & 1.663 \\
\hline Direct Parenting & .132 & .041 & .334 & $3.226 * *$ & .124 & .054 & .279 & $2.304 *$ \\
\hline $\mathrm{R}^{2}$ & .175 & & & & .157 & & & \\
\hline Adj $\mathrm{R}^{2}$ & .143 & & & & .115 & & & \\
\hline F Change & $5.450 * *$ & & & & $3.726^{*}$ & & & \\
\hline \multicolumn{9}{|l|}{ Step 2} \\
\hline OS Age & -.047 & .040 & -.119 & -1.159 & -.075 & .050 & -.179 & -1.496 \\
\hline OS Gender & .219 & .085 & .266 & $2.574 *$ & .197 & .104 & .230 & $1.901+$ \\
\hline Direct Parenting & .135 & .040 & .340 & $3.347 * * *$ & .119 & .053 & .267 & $2.223^{*}$ \\
\hline oPDT & .098 & .050 & .203 & $1.964+$ & .085 & .056 & .181 & 1.515 \\
\hline $\mathrm{R}^{2}$ & .215 & & & & .189 & & & \\
\hline Adj $R^{2}$ & .174 & & & & .134 & & & \\
\hline F Change & $3.856+$ & & & & 2.297 & & & \\
\hline \multicolumn{9}{|c|}{$\mathrm{p}<.05^{* *} \mathrm{p}<.01 * * * \mathrm{p}<.001^{+} \mathrm{p}<.10$. PDT $=$ Parental Differential Treatment. } \\
\hline
\end{tabular}


Table 8 RQ\#1 Older Siblings' Antisocial Behavior with PDT-Warmth as a predictor.

\begin{tabular}{|c|c|c|c|c|c|c|c|c|}
\hline \multirow{2}{*}{$\begin{array}{l}\text { Youth reported } \\
\text { PDT-Warmth }^{1}\end{array}$} & \multicolumn{4}{|c|}{$\mathbf{A}(\mathrm{n}=84)$} & \multicolumn{4}{|c|}{$\mathbf{B}(\mathrm{n}=89)$} \\
\hline & $\mathrm{B}$ & SE B & $\beta$ & $\mathrm{t}$ & $\mathrm{B}$ & SE B & $\beta$ & $\mathrm{t}$ \\
\hline \multicolumn{9}{|l|}{ Step 1} \\
\hline OS Age & -.028 & .048 & -.065 & -.584 & -.023 & .041 & -.059 & -.564 \\
\hline OS Gender & .230 & .095 & .267 & $2.428^{*}$ & .182 & .082 & .234 & $2.217^{*}$ \\
\hline Direct Parenting & -.012 & .047 & -.029 & -.255 & .008 & .041 & .020 & .190 \\
\hline $\mathrm{R}^{2}$ & .082 & & & & .060 & & & \\
\hline Adj $\mathrm{R}^{2}$ & .047 & & & & .027 & & & \\
\hline F Change & $2.371+$ & & & & 1.818 & & & \\
\hline \multicolumn{9}{|l|}{ Step 2} \\
\hline OS Age & -.028 & .049 & -.064 & -.571 & -.022 & .041 & -.056 & -.524 \\
\hline OS Gender & .231 & .096 & .268 & $2.400^{*}$ & .181 & .082 & .233 & $2.200^{*}$ \\
\hline Direct Parenting & -.012 & .047 & -.029 & -.256 & .008 & .041 & .020 & .188 \\
\hline yPDT & .003 & .046 & .008 & .076 & .008 & .041 & .021 & .198 \\
\hline $\mathrm{R}^{2}$ & .082 & & & & .061 & & & \\
\hline Adj $\mathrm{R}^{2}$ & .035 & & & & .016 & & & \\
\hline F Change & .006 & & & & .039 & & & \\
\hline \multirow{2}{*}{$\begin{array}{l}\text { Parent reported } \\
\text { PDT-Warmth }\end{array}$} & \multicolumn{4}{|c|}{$\mathbf{A}(\mathrm{n}=85)$} & \multicolumn{4}{|c|}{ B $(n=75)$} \\
\hline & $\mathrm{B}$ & SE B & $\beta$ & $\mathrm{t}$ & B & SE B & $\beta$ & $\mathrm{t}$ \\
\hline \multicolumn{9}{|l|}{ Step 1} \\
\hline OS Age & -.038 & .046 & -.090 & -.841 & -.066 & .048 & -.159 & -1.383 \\
\hline OS Gender & .249 & .092 & .288 & $2.698 * *$ & .202 & .097 & .237 & $2.082 *$ \\
\hline Direct Parenting & .042 & .047 & .095 & .887 & .007 & .049 & .015 & .135 \\
\hline $\mathrm{R}^{2}$ & .098 & & & & .086 & & & \\
\hline Adj $R^{2}$ & .065 & & & & .048 & & & \\
\hline F Change & $2.937 *$ & & & & $2.231+$ & & & \\
\hline \multicolumn{9}{|l|}{ Step 2} \\
\hline OS Age & -.041 & .048 & -.095 & -.856 & -.073 & .049 & -.175 & -1.479 \\
\hline OS Gender & .248 & .093 & .287 & $2.665 * *$ & .203 & .098 & .237 & $2.077 *$ \\
\hline Direct Parenting & .042 & .047 & .095 & .888 & .002 & .050 & .004 & .032 \\
\hline pPDT & -.009 & .048 & -.020 & -.187 & -.031 & .051 & -.072 & -.602 \\
\hline $\mathrm{R}^{2}$ & .099 & & & & .091 & & & \\
\hline Adj $R^{2}$ & .053 & & & & .039 & & & \\
\hline F Change & .035 & & & & .362 & & & \\
\hline \multirow{2}{*}{$\begin{array}{l}\text { Observer reported } \\
\text { PDT-Warmth }\end{array}$} & \multicolumn{4}{|c|}{$\mathbf{A}(\mathrm{n}=90)$} & \multicolumn{4}{|c|}{$\mathbf{B}(n=75)$} \\
\hline & $\mathrm{B}$ & SE B & $\beta$ & $\mathrm{t}$ & B & SE B & $\beta$ & $\mathrm{t}$ \\
\hline \multicolumn{9}{|l|}{ Step 1} \\
\hline OS Age & -.032 & .040 & -.082 & -.792 & -.070 & .051 & -.167 & -1.359 \\
\hline OS Gender & .188 & .082 & .239 & $2.296^{*}$ & .199 & .098 & .234 & $2.040^{*}$ \\
\hline Direct Parenting & .030 & .040 & .077 & .746 & -.012 & .051 & -.028 & -.225 \\
\hline $\mathrm{R}^{2}$ & .075 & & & & .087 & & & \\
\hline Adj $R^{2}$ & .043 & & & & .048 & & & \\
\hline F Change & $2.317+$ & & & & $2.243+$ & & & \\
\hline \multicolumn{9}{|l|}{ Step 2} \\
\hline OS Age & -.034 & .040 & -.087 & -.840 & -.073 & .053 & -.176 & -1.396 \\
\hline OS Gender & .200 & .082 & .255 & $2.422 *$ & .199 & .098 & .233 & $2.026^{*}$ \\
\hline Direct Parenting & .027 & .040 & .071 & .686 & -.015 & .053 & -.036 & -.285 \\
\hline oPDT & .044 & .042 & .112 & 1.065 & .019 & .053 & .042 & .362 \\
\hline $\mathrm{R}^{2}$ & .087 & & & & .088 & & & \\
\hline Adj $R^{2}$ & .044 & & & & .036 & & & \\
\hline F Change & 1.135 & & & & .131 & & & \\
\hline
\end{tabular}


Table 9 RQ\#1 Younger Siblings' Antisocial Behavior with PDT-Hostility as a predictor.

\begin{tabular}{|c|c|c|c|c|c|c|c|c|}
\hline \multirow{2}{*}{$\begin{array}{l}\text { Youth reported } \\
\text { PDT-H }^{1}\end{array}$} & \multicolumn{4}{|c|}{$\mathbf{A}(\mathrm{n}=48)$} & \multicolumn{4}{|c|}{ B $(n=53)$} \\
\hline & $\mathrm{B}$ & SE B & $\beta$ & $\mathrm{t}$ & $\mathrm{B}$ & SE B & $\beta$ & $\mathrm{t}$ \\
\hline \multicolumn{9}{|l|}{ Step 1} \\
\hline YS Age & .074 & .076 & .151 & .967 & .029 & .065 & .062 & .443 \\
\hline YS Gender & .095 & .114 & .126 & .832 & .198 & .100 & .273 & $1.977+$ \\
\hline Direct Parenting & .081 & .058 & .214 & 1.393 & .040 & .047 & .120 & .856 \\
\hline $\mathrm{R}^{2}$ & .055 & & & & .093 & & & \\
\hline Adj $\mathrm{R}^{2}$ & -.009 & & & & .038 & & & \\
\hline F Change & .853 & & & & 1.684 & & & \\
\hline \multicolumn{9}{|l|}{ Step 2} \\
\hline YS Age & .050 & .078 & .103 & .644 & .017 & .066 & .038 & .263 \\
\hline YS Gender & .096 & .114 & .127 & .843 & .216 & .103 & .298 & $2.110 *$ \\
\hline Direct Parenting & .072 & .059 & .190 & 1.232 & .034 & .048 & .102 & .719 \\
\hline yPDT & -.068 & .057 & -.182 & -1.204 & -.048 & .054 & -.127 & -.893 \\
\hline $\mathrm{R}^{2}$ & .086 & & & & .108 & & & \\
\hline Adj $\mathrm{R}^{2}$ & .001 & & & & .034 & & & \\
\hline F Change & 1.449 & & & & .798 & & & \\
\hline \multirow{2}{*}{$\begin{array}{l}\text { Parent reported } \\
\text { PDT-H }^{1}\end{array}$} & \multicolumn{4}{|c|}{$A(n=48)$} & \multicolumn{4}{|c|}{$\mathbf{B}(\mathrm{n}=40)$} \\
\hline & $\mathrm{B}$ & SE B & $\beta$ & $\mathrm{t}$ & B & SE B & $\beta$ & $\mathrm{t}$ \\
\hline \multicolumn{9}{|l|}{ Step 1} \\
\hline YS Age & .024 & .076 & .050 & .322 & .014 & .078 & .030 & .180 \\
\hline YS Gender & .045 & .117 & .059 & .383 & .120 & .126 & .157 & .956 \\
\hline Direct Parenting & .067 & .064 & .162 & 1.048 & .071 & .071 & .053 & 1.349 \\
\hline $\mathrm{R}^{2}$ & .037 & & & & .085 & & & \\
\hline Adj $\mathrm{R}^{2}$ & -.028 & & & & .009 & & & \\
\hline F Change & .569 & & & & 1.115 & & & \\
\hline \multicolumn{9}{|l|}{ Step 2} \\
\hline YS Age & .055 & .079 & .113 & 699 & .029 & .081 & .061 & .359 \\
\hline YS Gender & .093 & .122 & .123 & .766 & .148 & .131 & .193 & 1.126 \\
\hline Direct Parenting & .046 & .066 & .110 & .697 & .058 & .056 & .181 & 1.045 \\
\hline pPDT & -.082 & .064 & -.206 & -1.286 & -.057 & .072 & -.140 & -.792 \\
\hline $\mathrm{R}^{2}$ & .073 & & & & .101 & & & \\
\hline Adj $\mathrm{R}^{2}$ & -.013 & & & & -.002 & & & \\
\hline F Change & 1.653 & & & & .627 & & & \\
\hline \multirow{2}{*}{$\begin{array}{l}\text { Observer reported } \\
\text { PDT-H }^{1}\end{array}$} & \multicolumn{4}{|c|}{$A(n=53)$} & \multicolumn{4}{|c|}{$\mathbf{B}(\mathrm{n}=40)$} \\
\hline & B & SE B & $\beta$ & $\mathrm{t}$ & $\mathrm{B}$ & SE B & $\beta$ & $\mathrm{t}$ \\
\hline \multicolumn{9}{|l|}{ Step 1} \\
\hline YS Age & .004 & .063 & .009 & .066 & .015 & .082 & .031 & .179 \\
\hline YS Gender & .200 & .098 & .276 & $2.038^{*}$ & .152 & .126 & .199 & 1.205 \\
\hline Direct Parenting & .088 & .058 & .206 & 1.525 & .046 & .065 & .120 & .704 \\
\hline $\mathrm{R}^{2}$ & .122 & & & & .052 & & & \\
\hline Adj $\mathrm{R}^{2}$ & .068 & & & & -.027 & & & \\
\hline F Change & $2.261+$ & & & & .656 & & & \\
\hline \multicolumn{9}{|l|}{ Step 2} \\
\hline YS Age & .004 & .064 & .009 & .066 & .004 & .083 & .009 & .054 \\
\hline YS Gender & .200 & .101 & .276 & $1.979+$ & .171 & .128 & .224 & 1.340 \\
\hline Direct Parenting & .088 & .061 & .206 & 1.447 & .050 & .065 & .132 & .774 \\
\hline oPDT & .000 & .080 & -.001 & -.008 & .092 & .090 & .170 & 1.020 \\
\hline $\mathrm{R}^{2}$ & .122 & & & & .079 & & & \\
\hline Adj $\mathrm{R}^{2}$ & .048 & & & & -.026 & & & \\
\hline F Change & .000 & & & & 1.040 & & & \\
\hline \multicolumn{9}{|c|}{$\mathrm{p}<.05 * * \mathrm{p}<.01 * * * \mathrm{p}<.001^{+} \mathrm{p}<.10$. PDT $=$ Parental Differential Treatment. } \\
\hline
\end{tabular}


Table 10 RQ\#1 Younger Siblings' Overt Antisocial Behavior with PDT-Warmth as a predictor.

\begin{tabular}{|c|c|c|c|c|c|c|c|c|}
\hline \multirow{2}{*}{$\begin{array}{l}\text { Youth reported } \\
\text { PDT-W }^{1}\end{array}$} & \multicolumn{4}{|c|}{$\mathbf{A}(\mathrm{n}=55)$} & \multicolumn{4}{|c|}{$\mathbf{B}(\mathrm{n}=60)$} \\
\hline & $\mathrm{B}$ & SE B & $\beta$ & $\mathrm{t}$ & B & SE B & $\beta$ & $\mathrm{t}$ \\
\hline $\begin{array}{rr}\text { Step } 1 & \\
& \text { YS Age } \\
\text { YS Gender } \\
\text { Direct Parenting } \\
\mathrm{R}^{2} \\
\text { Adj } \mathrm{R}^{2} \\
\text { F Change } \\
\end{array}$ & $\begin{array}{l}.009 \\
.066 \\
-.046 \\
.030 \\
-.027 \\
.533 \\
\end{array}$ & $\begin{array}{l}.068 \\
.102 \\
.045\end{array}$ & $\begin{array}{l}.020 \\
.090 \\
-.146\end{array}$ & $\begin{array}{l}.140 \\
.647 \\
-1.026\end{array}$ & $\begin{array}{l}.017 \\
.123 \\
-.052 \\
.038 \\
-.014 \\
.730 \\
\end{array}$ & $\begin{array}{l}.068 \\
.104 \\
.051\end{array}$ & $\begin{array}{l}.034 \\
.159 \\
-.138\end{array}$ & $\begin{array}{l}.253 \\
1.189 \\
-1.026\end{array}$ \\
\hline $\begin{array}{r}\text { Step } 2 \\
\text { YS Age } \\
\text { YS Gender } \\
\text { Direct Parenting } \\
\text { yPDT } \\
\mathrm{R}^{2} \\
\text { Adj R }{ }^{2} \\
\text { F Change }\end{array}$ & $\begin{array}{l}.007 \\
.048 \\
-.061 \\
-.128 \\
.126 \\
.056 \\
5.491 \\
\end{array}$ & $\begin{array}{l}.065 \\
.098 \\
.044 \\
.055\end{array}$ & $\begin{array}{l}.014 \\
.066 \\
-.190 \\
-.314\end{array}$ & $\begin{array}{l}.102 \\
.494 \\
-1.385 \\
-2.343^{*}\end{array}$ & $\begin{array}{l}.024 \\
.114 \\
-.051 \\
-.136 \\
.135 \\
.072 \\
6.197 * \\
\end{array}$ & $\begin{array}{l}.065 \\
.099 \\
.049 \\
.055\end{array}$ & $\begin{array}{l}.046 \\
.147 \\
-.136 \\
-.313\end{array}$ & $\begin{array}{l}.363 \\
1.146 \\
-1.060 \\
-2.489 *\end{array}$ \\
\hline $\begin{array}{l}\text { Parent reported } \\
\text { PDT-W }^{2}\end{array}$ & $\mathrm{~B}$ & SE B & $\frac{(n=55)}{\beta}$ & $\mathrm{t}$ & $\mathrm{B}$ & SE B & $\begin{array}{l}=51) \\
\beta\end{array}$ & $\mathrm{t}$ \\
\hline $\begin{array}{rr}\text { Step } 1 & \text { YS Age } \\
\text { YS Gender } \\
\text { Direct Parenting } \\
\mathrm{R}^{2} \\
\text { Adj } \mathrm{R}^{2} \\
\text { F Change }\end{array}$ & $\begin{array}{l}.015 \\
.053 \\
.103 \\
.057 \\
.002 \\
1.02\end{array}$ & $\begin{array}{l}.065 \\
.101 \\
.065\end{array}$ & $\begin{array}{l}.032 \\
.072 \\
.218\end{array}$ & $\begin{array}{l}.229 \\
.521 \\
1.588\end{array}$ & $\begin{array}{l}-.007 \\
.094 \\
-.055 \\
.024 \\
-.038 \\
.389\end{array}$ & $\begin{array}{l}.075 \\
.119 \\
.061\end{array}$ & $\begin{array}{l}-.015 \\
.117 \\
-.136\end{array}$ & $\begin{array}{l}-.098 \\
.786 \\
-.898\end{array}$ \\
\hline $\begin{array}{r}\text { Step } 2 \\
\text { YS Age } \\
\text { YS Gender } \\
\text { Direct Parenting } \\
\text { pPDT } \\
\mathrm{R}^{2} \\
\text { Adj R }{ }^{2} \\
\text { F Change }\end{array}$ & $\begin{array}{l}.026 \\
.103 \\
.117 \\
.086 \\
.103 \\
.032 \\
2.55\end{array}$ & $\begin{array}{l}.065 \\
.104 \\
.064 \\
.053\end{array}$ & $\begin{array}{l}.055 \\
.141 \\
.248 \\
.229\end{array}$ & $\begin{array}{l}.406 \\
.987 \\
1.818+ \\
1.609\end{array}$ & $\begin{array}{l}.007 \\
.132 \\
-.031 \\
.080 \\
.057 \\
-.025 \\
1.617 \\
\end{array}$ & $\begin{array}{l}.076 \\
.122 \\
.063 \\
.063\end{array}$ & $\begin{array}{l}.013 \\
.164 \\
-.076 \\
.200\end{array}$ & $\begin{array}{l}.091 \\
1.077 \\
-.485 \\
1.271\end{array}$ \\
\hline $\begin{array}{l}\text { Observer } \\
\text { reported PDT-W }\end{array}$ & $\mathrm{B}$ & SE B & $\frac{(\mathrm{n}=60)}{\beta}$ & $\mathrm{t}$ & $\mathrm{B}$ & SE B & $\begin{array}{l}=51) \\
\beta\end{array}$ & $\mathrm{t}$ \\
\hline $\begin{array}{rr}\text { Step } 1 & \\
& \text { YS Age } \\
\text { YS Gender } \\
\text { Direct Parenting } \\
\mathrm{R}^{2} \\
\text { Adj } \mathrm{R}^{2} \\
\text { F Change } \\
\end{array}$ & $\begin{array}{l}.016 \\
.099 \\
.071 \\
.041 \\
-.010 \\
.802 \\
\end{array}$ & $\begin{array}{l}.068 \\
.102 \\
.063\end{array}$ & $\begin{array}{l}.031 \\
.127 \\
.148\end{array}$ & $\begin{array}{l}.234 \\
.966 \\
1.124\end{array}$ & $\begin{array}{l}-.008 \\
.073 \\
-.037 \\
.019 \\
-.044 \\
.297 \\
\end{array}$ & $\begin{array}{l}.076 \\
.117 \\
.051\end{array}$ & $\begin{array}{l}-.016 \\
.091 \\
-.109\end{array}$ & $\begin{array}{l}-.105 \\
.622 \\
-.731\end{array}$ \\
\hline $\begin{array}{r}\text { Step } 2 \\
\text { YS Age } \\
\text { YS Gender } \\
\text { Direct Parenting } \\
\text { oPDT } \\
\mathrm{R}^{2} \\
\text { Adj R }{ }^{2} \\
\text { F Change }\end{array}$ & $\begin{array}{l}.037 \\
.077 \\
.074 \\
-.141 \\
.074 \\
.007 \\
1.964\end{array}$ & $\begin{array}{l}.069 \\
.103 \\
.063 \\
.100\end{array}$ & $\begin{array}{l}.071 \\
.099 \\
.155 \\
-.189\end{array}$ & $\begin{array}{l}.529 \\
.745 \\
1.182 \\
-1.402\end{array}$ & $\begin{array}{l}-.009 \\
.073 \\
-.037 \\
.006 \\
.019 \\
-.067 \\
.002\end{array}$ & $\begin{array}{l}.080 \\
.119 \\
.052 \\
.128\end{array}$ & $\begin{array}{l}-.017 \\
.091 \\
-.109 \\
.007\end{array}$ & $\begin{array}{l}-.112 \\
.616 \\
-.724 \\
.044\end{array}$ \\
\hline
\end{tabular}




\section{Research Question 2 Regressions - Exploring Moderation}

This second research question and all its forms take a longitudinal examination of PDT in the context of the intervention. This question examined potential moderation. That is, does the intervention moderate PDT? This exploratory question begins to investigate whether the effect of PDT is altered by participation in the intervention. An interaction effect represents a situation in which two variables' influence on the third, the dependent variable, is not additive; instead, the level of the moderator influences the effect of the predictor (Aiken \& West, 1991; Sulloway, 1996). For these analyses, gender, direct parenting, PDT, and Treatment group were entered in the first block, and the interaction term representing Parental Differential Treatment X Treatment Group was entered in the second block. Results for these regression analyses for older siblings can be found in tables 10 and 11, and the results for younger siblings can be found in Tables 12 and 13. Since these regressions are predicting change scores [i.e., change in TRF score (intervention term score minus baseline score) rather than the TRF score at a particular wave], the interpretation of findings is different than the series of regressions that were conducted for research question one. A negative change score indicates reduced antisocial behavior after intervention (i.e., improvement) whereas a positive change score would indicate that children's antisocial behavior increased from baseline to completion of the intervention.

All regression analyses were set up in a similar fashion. The first step or block contained child gender (e.g., older sibling gender), one informant's direct parenting score 
(e.g., youth reported direct hostility), another informant's interval level PDT score (e.g., parent reported PDT-Hostility), and Treatment Group (i.e., CPT, PMT, or SPMT). The second step or block contained the interaction term (e.g., PDT-H*Treatment Group) created between the interval level PDT score and the treatment group variable. In each regression, the dependent variable was the sibling's TRF change score (e.g., older siblings' intervention term TRF score minus older siblings' baseline TRF score).

As expected, the intervention treatment group was a consistent and significant predictor of change in older siblings' antisocial behavior (at least at the $p<.10$ level) across analyses indicating that participation in the intervention was associated with decreases in antisocial behavior. This is consistent with what was expected particularly because PMT was primarily directed toward the older sibling. In many analyses, direct parenting of hostility also was predictive of older siblings' antisocial behavior as expected.

The primary interest in these regression analyses, however, was the predictive ability of the interaction terms on children's antisocial behavior, and there was some modest evidence of interaction effects. Two of the twelve analyses conducted on older siblings produced significant results and these were both for youth reported PDT. In both situations gender and direct parenting were also included in block one. The first controlled for parent reported direct hostility, and demonstrated that youth reported PDThostility $\left(\mathrm{b}=.121, \mathrm{SE}_{\mathrm{b}}=.069, \beta=.403, p=.083\right)$ and treatment group $\left(\mathrm{b}=-.131, \mathrm{SE}_{\mathrm{b}}=.051\right.$, $\beta=.-.321, p=.014)$ were both associated with older siblings' antisocial behavior, and the interaction term between youth reported PDT-Hostility and treatment also approached 
significance $\left(\mathrm{b}=-.086, \mathrm{SE}_{\mathrm{b}}=.045, \beta=-.437, p=.065\right)$. The interaction term in this particular regression analysis explained an additional $4.3 \%$ of the variance in older siblings' antisocial behavior. However, there were no significant findings for the interaction term when using the same set up and controlling for the other informant's (i.e., observer) direct hostility. Feinberg and Hetherington (2001) would not have interpreted this finding for that reason; however, since there is reduced power because of the small sample sizes, it is important to examine significant findings carefully. See Table 11 to review interaction effects between PDT-Hostility and treatment group for all reporters predicting older siblings' antisocial behavior.

The second significant result was found when controlling for gender, observer reported direct parenting, youth reported PDT-Warmth, and Treatment in block 1, and adding the interaction term in block $2(F$ change $=4.321, p<.05)$. These results revealed that youth reported PDT-Warmth $\left(\mathrm{b}=-.133, \mathrm{SE}_{\mathrm{b}}=.068, \beta=-.437, p=.054\right)$, and treatment group $\left(\mathrm{b}=-.095, \mathrm{SE}_{\mathrm{b}}=.048, \beta=-.231, p=.050\right)$ were associated with older siblings' antisocial behavior. Moreover, the interaction term $\left(b=.098, \mathrm{SE}_{\mathrm{b}}=.047, \beta=.462, p=.042\right)$ was also significantly predictive of older siblings' antisocial behavior at step 2 . The interaction term in this particular regression analysis explained an additional $4.5 \%$ of the variance in older siblings' antisocial behavior. Again, the same regression set up using the other informants' (i.e., parent) report of direct parenting as a control in block 1 did not show to have a significant interaction term. See Table 12 to review interaction effects between PDT-Warmth and treatment group for all reporters predicting older siblings' antisocial behavior. 
For younger siblings, there were also a couple of significant findings. See tables 13 and 14 for the results. It should be noted upfront, however, that the Ns for younger siblings were quite low and results should be interpreted with caution. Sometimes direct parenting, PDT, and treatment group were associated with younger sibling outcomes in the expected direction, but this was not always the case and these findings were not as consistent as they were for older siblings. Regression results revealed that $9.6 \%$ additional variance was explained by the interaction between parent reported PDTHostility and intervention group (controlling for youth reported direct parenting). However, PDT and treatment group were not significant on their own (in block 1) in this particular model, and $16.9 \%$ additional variance was explained by the interaction between parent reported PDT-Hostility and intervention group (controlling for observer reported direct parenting). 
Table 11 RQ\#2 Change in Older Siblings’ Antisocial Behavior with PDT-Hostility + RxStat

\begin{tabular}{|c|c|c|c|c|c|c|c|c|}
\hline \multirow{2}{*}{$\begin{array}{l}\text { Youth reported } \\
\text { PDT }^{1}\end{array}$} & \multicolumn{4}{|c|}{$\mathbf{A}(\mathrm{n}=58)$} & \multicolumn{4}{|c|}{$\mathbf{B}(\mathrm{n}=64)$} \\
\hline & B & SE B & $\beta$ & $\mathrm{t}$ & $\mathrm{B}$ & SE B & $\beta$ & $\mathrm{t}$ \\
\hline $\begin{array}{r}\text { Step } 1 \\
\text { Gender } \\
\text { Direct Parenting } \\
\text { PDT } \\
\text { Group } \\
\mathrm{R}^{2} \\
\text { Adj } \mathrm{R}^{2} \\
\text { F Change } \\
\end{array}$ & $\begin{array}{l}.051 \\
-.069 \\
.014 \\
-.132 \\
.143 \\
.078 \\
2.212+ \\
\end{array}$ & $\begin{array}{l}.087 \\
.044 \\
.039 \\
.052\end{array}$ & $\begin{array}{l}.078 \\
-.210 \\
.047 \\
-.323\end{array}$ & $\begin{array}{l}.587 \\
-1.555 \\
.360 \\
-2.515^{*}\end{array}$ & $\begin{array}{l}.013 \\
-.040 \\
-.003 \\
-.090 \\
.066 \\
.003 \\
1.049 \\
\end{array}$ & $\begin{array}{l}.082 \\
.041 \\
.037 \\
.052\end{array}$ & $\begin{array}{l}.020 \\
-.121 \\
-.010 \\
-.221\end{array}$ & $\begin{array}{l}.155 \\
-.956 \\
-.081 \\
-1.746+\end{array}$ \\
\hline $\begin{array}{r}\text { Step } 2 \\
\text { Gender } \\
\text { Direct Parenting } \\
\text { PDT } \\
\text { Group } \\
{\text { PDT }{ }^{*} \text { Group }}^{2} \\
\mathrm{R}^{2} \\
\text { Adj R } \\
\text { F Change }\end{array}$ & $\begin{array}{l}.071 \\
-.058 \\
.121 \\
-.131 \\
-.086 \\
.198 \\
.121 \\
3.555+\end{array}$ & $\begin{array}{l}.085 \\
.044 \\
.069 \\
.051 \\
.045\end{array}$ & $\begin{array}{l}.110 \\
-.176 \\
.403 \\
-.321 \\
-.437\end{array}$ & $\begin{array}{l}.835 \\
-1.322 \\
1.768+ \\
-2.552^{*} \\
-1.885+\end{array}$ & $\begin{array}{l}.015 \\
-.040 \\
.064 \\
-.097 \\
-.057 \\
.096 \\
.018 \\
1.916\end{array}$ & $\begin{array}{l}.081 \\
.041 \\
.061 \\
.051 \\
.041\end{array}$ & $\begin{array}{l}.023 \\
-.122 \\
.218 \\
-.237 \\
-.286\end{array}$ & $\begin{array}{l}.184 \\
-.966 \\
1.048 \\
-1.876+ \\
-1.384\end{array}$ \\
\hline Parent & & & $\mathrm{l}=59)$ & & & & 51) & \\
\hline reported PDT ${ }^{2}$ & $\mathrm{~B}$ & SE B & $\beta$ & $\mathrm{t}$ & $\mathrm{B}$ & SE B & $\beta$ & $\mathrm{t}$ \\
\hline $\begin{array}{r}\text { Step } 1 \\
\text { Gender } \\
\text { Direct Parenting } \\
\text { PDT } \\
\text { Group } \\
\\
\mathrm{R}^{2} \\
\text { Adj } \mathrm{R}^{2} \\
\text { F Change } \\
\end{array}$ & $\begin{array}{l}.012 \\
-.078 \\
.002 \\
-.132 \\
.158 \\
.095 \\
2.530+ \\
\end{array}$ & $\begin{array}{l}.082 \\
.042 \\
.042 \\
.052\end{array}$ & $\begin{array}{l}.019 \\
-.245 \\
.008 \\
-.322\end{array}$ & $\begin{array}{l}.149 \\
-1.870+ \\
.059 \\
-2.549 *\end{array}$ & $\begin{array}{l}-.043 \\
-.068 \\
-.033 \\
-.143 \\
.156 \\
.082 \\
2.122 \\
\end{array}$ & $\begin{array}{l}.092 \\
.044 \\
.047 \\
.061\end{array}$ & $\begin{array}{l}-.063 \\
-.208 \\
-.095 \\
-.322\end{array}$ & $\begin{array}{l}-.463 \\
-1.530 \\
-.695 \\
-2.357 *\end{array}$ \\
\hline $\begin{array}{r}\text { Step } 2 \\
\text { Gender } \\
\text { Direct Parenting } \\
\text { PDT } \\
\text { Group } \\
\text { PDT }^{*} \text { Group } \\
\mathrm{R}^{2} \\
\text { Adj R } \\
\text { F Change }\end{array}$ & $\begin{array}{l}.029 \\
-.083 \\
-.062 \\
-.129 \\
.055 \\
.175 \\
.097 \\
1.106 \\
\end{array}$ & $\begin{array}{l}.084 \\
.042 \\
.074 \\
.052 \\
.052\end{array}$ & $\begin{array}{l}.045 \\
-.262 \\
-.193 \\
-.313 \\
.244\end{array}$ & $\begin{array}{l}.351 \\
-1.985+ \\
-.834 \\
-2.482 * \\
1.052\end{array}$ & $\begin{array}{l}-.037 \\
-.067 \\
-.062 \\
-.144 \\
.023 \\
.158 \\
.064 \\
.118 \\
\end{array}$ & $\begin{array}{l}.094 \\
.045 \\
.096 \\
.061 \\
.067\end{array}$ & $\begin{array}{l}-.055 \\
-.208 \\
-.179 \\
-.324 \\
.097\end{array}$ & $\begin{array}{l}-.395 \\
-1.512 \\
-.639 \\
-2.346^{*} \\
.343\end{array}$ \\
\hline Observer & & & $\mathrm{l}=63)$ & & & & 51) & \\
\hline reported $\mathrm{PDT}^{3}$ & $\mathrm{~B}$ & SE B & $\beta$ & $\mathrm{t}$ & $\mathrm{B}$ & SE B & $\beta$ & $\mathrm{t}$ \\
\hline $\begin{array}{r}\text { Step } 1 \\
\text { Gender } \\
\text { Direct Parenting } \\
\text { PDT } \\
\text { Group } \\
\mathrm{R}^{2} \\
\text { Adj } \mathrm{R}^{2} \\
\text { F Change } \\
\end{array}$ & $\begin{array}{l}-.030 \\
-.074 \\
-.059 \\
-.095 \\
.128 \\
.068 \\
2.123+ \\
\end{array}$ & $\begin{array}{l}.083 \\
.038 \\
.045 \\
.051\end{array}$ & $\begin{array}{l}-.046 \\
-.242 \\
-.166 \\
-.227\end{array}$ & $\begin{array}{l}-.361 \\
-1.969+ \\
-1.318 \\
-1.847+\end{array}$ & $\begin{array}{l}-.023 \\
-.073 \\
-.041 \\
-.139 \\
.169 \\
.097 \\
2.337+ \\
\end{array}$ & $\begin{array}{l}.096 \\
.048 \\
.049 \\
.060\end{array}$ & $\begin{array}{l}-.034 \\
-.211 \\
-.117 \\
-.314\end{array}$ & $\begin{array}{l}-.239 \\
-1.520 \\
-.837 \\
-2.320 *\end{array}$ \\
\hline $\begin{array}{r}\text { Step } 2 \\
\text { Gender } \\
\text { Direct Parenting } \\
\text { PDT } \\
\text { Group } \\
\text { PDT }^{*} \text { Group } \\
\mathrm{R}^{2} \\
\text { Adj R } \\
\text { F Change } \\
\end{array}$ & $\begin{array}{l}-.032 \\
-.074 \\
-.047 \\
-.095 \\
-.015 \\
.129 \\
.053 \\
.086 \\
\end{array}$ & $\begin{array}{l}.084 \\
.038 \\
.062 \\
.052 \\
.052\end{array}$ & $\begin{array}{l}-.048 \\
-.242 \\
-.131 \\
-.228 \\
-.051\end{array}$ & $\begin{array}{l}-.379 \\
-1.953+ \\
-.752 \\
-1.842+ \\
-.293\end{array}$ & $\begin{array}{l}-.026 \\
-.074 \\
-.011 \\
-.143 \\
-.040 \\
.178 \\
.086 \\
.476 \\
\end{array}$ & $\begin{array}{l}.097 \\
.048 \\
.065 \\
.061 \\
.057\end{array}$ & $\begin{array}{l}-.039 \\
-.215 \\
-.033 \\
-.322 \\
-.126\end{array}$ & $\begin{array}{l}-.271 \\
-1.539 \\
-.178 \\
-2.360 * \\
-.690\end{array}$ \\
\hline
\end{tabular}


Table 12 RQ\#2 Change in Older Siblings’ Antisocial Behavior with PDT-Warmth + RxStat

\begin{tabular}{|c|c|c|c|c|c|c|c|c|}
\hline \multirow{2}{*}{$\begin{array}{l}\text { Youth reported } \\
\text { PDT }^{1}\end{array}$} & \multicolumn{4}{|c|}{$\mathbf{A}(\mathrm{n}=62)$} & \multicolumn{4}{|c|}{$\mathbf{B}(\mathrm{n}=69)$} \\
\hline & $\mathrm{B}$ & SE B & $\beta$ & $\mathrm{t}$ & $\mathrm{B}$ & SE B & $\beta$ & $\mathrm{t}$ \\
\hline \multicolumn{9}{|l|}{ Step 1} \\
\hline Gender & .076 & .087 & .114 & .874 & .005 & .078 & .008 & .066 \\
\hline Direct Parenting & .075 & .046 & .212 & 1.650 & -.074 & .039 & -.225 & $-1.895+$ \\
\hline PDT & -.023 & .040 & -.072 & -.566 & -.012 & .036 & -.040 & -.343 \\
\hline Group & -.112 & .053 & -.266 & $-2.098^{*}$ & -.095 & .049 & -.232 & $-1.955+$ \\
\hline $\mathrm{R}^{2}$ & .113 & & & & .116 & & & \\
\hline Adj $\mathrm{R}^{2}$ & .050 & & & & .061 & & & \\
\hline F Change & 1.808 & & & & 2.103 & & & \\
\hline \multicolumn{9}{|l|}{ Step 2} \\
\hline Gender & .083 & .087 & .124 & .954 & .012 & .076 & .019 & .165 \\
\hline Direct Parenting & .057 & .047 & .162 & 1.209 & -.068 & .038 & -.207 & $-1.781+$ \\
\hline PDT & -.117 & .083 & -.373 & -1.421 & -.133 & .068 & -.437 & $-1.962+$ \\
\hline Group & -.107 & .053 & -.255 & $-2.020 *$ & -.095 & .048 & -.231 & $-1.999^{*}$ \\
\hline PDT*Group & .075 & .057 & .351 & 1.309 & .098 & .047 & .462 & $2.079 *$ \\
\hline $\mathrm{R}^{2}$ & .139 & & & & .173 & & & \\
\hline Adj $\mathrm{R}^{2}$ & .062 & & & & .107 & & & \\
\hline F Change & 1.714 & & & & $4.321 *$ & & & \\
\hline \multirow{2}{*}{$\begin{array}{l}\text { Parent } \\
\text { reported } \mathrm{PDT}^{2}\end{array}$} & \multicolumn{4}{|c|}{$A(n=63)$} & \multicolumn{4}{|c|}{$\mathbf{B}(\mathrm{n}=57)$} \\
\hline & B & SE B & $\beta$ & $\mathrm{t}$ & $\mathrm{B}$ & SE B & $\beta$ & $\mathrm{t}$ \\
\hline \multicolumn{9}{|l|}{ Step 1} \\
\hline Gender & .043 & .084 & .064 & .510 & .006 & .092 & .008 & .060 \\
\hline Direct Parenting & -.071 & .045 & -.203 & -1.569 & -.057 & .051 & -.154 & -1.103 \\
\hline PDT & .080 & .051 & .202 & 1.563 & .043 & .056 & .105 & .764 \\
\hline Group & -.098 & .052 & -.232 & $-1.874+$ & -.092 & .059 & -.205 & -1.546 \\
\hline & .120 & & & & .096 & & & \\
\hline Adj $\mathrm{R}^{2}$ & .059 & & & & .026 & & & \\
\hline F Change & 1.969 & & & & 1.381 & & & \\
\hline \multicolumn{9}{|l|}{ Step 2} \\
\hline Gender & .052 & .084 & .078 & .618 & .012 & .093 & .017 & .125 \\
\hline Direct Parenting & -.063 & .045 & -.180 & -1.385 & -.049 & .053 & -.134 & -.934 \\
\hline PDT & .160 & .083 & .404 & $1.927+$ & .106 & .105 & .261 & 1.009 \\
\hline Group & -.089 & .053 & -.210 & $-1.683+$ & -.083 & .061 & -.187 & -1.373 \\
\hline PDT*Group & -.077 & .063 & -.257 & -1.220 & -.052 & .074 & -.179 & -.713 \\
\hline & .142 & & & & .105 & & & \\
\hline $\operatorname{Adj} \mathrm{R}^{2}$ & .067 & & & & .017 & & & \\
\hline F Change & 1.489 & & & & .509 & & & \\
\hline \multirow{2}{*}{$\begin{array}{l}\text { Observer } \\
\text { reported } \mathrm{PDT}^{3}\end{array}$} & \multicolumn{4}{|c|}{$\mathbf{A}(\mathrm{n}=70)$} & \multicolumn{4}{|c|}{ B $(n=57)$} \\
\hline & B & SE B & $\beta$ & $\mathrm{t}$ & B & SE B & $\beta$ & $\mathrm{t}$ \\
\hline \multicolumn{9}{|l|}{ Step 1} \\
\hline Gender & .009 & .079 & .014 & .120 & .045 & .094 & .066 & .485 \\
\hline Direct Parenting & -.061 & .037 & -.199 & $-1.682+$ & .055 & .048 & .157 & 1.158 \\
\hline PDT & .005 & .041 & .014 & .117 & .032 & .059 & .074 & .548 \\
\hline Group & -.096 & .049 & -.232 & $-1.966+$ & -.108 & .060 & -.242 & $-1.809+$ \\
\hline $\mathrm{R}^{2}$ & .099 & & & & .082 & & & \\
\hline Adj $\mathrm{R}^{2}$ & .044 & & & & .012 & & & \\
\hline F Change & 1.788 & & & & 1.164 & & & \\
\hline \multicolumn{9}{|l|}{ Step 2} \\
\hline Gender & .014 & .079 & .022 & .181 & .054 & .095 & .078 & .565 \\
\hline Direct Parenting & -.063 & .037 & -.205 & $-1.726+$ & .054 & .048 & .154 & 1.135 \\
\hline PDT & .098 & .122 & .287 & .801 & .114 & .145 & .259 & .783 \\
\hline Group & -.089 & .050 & -.216 & $-1.795+$ & -.104 & .060 & -.233 & -1.723 \\
\hline PDT*Groun & -.057 & .070 & -.288 & -.809 & -.056 & .091 & -.202 & -.614 \\
\hline $\mathrm{R}^{2}$ & .108 & & & & .089 & & & \\
\hline Adi $\mathrm{R}^{2}$ & .039 & & & & .000 & & & \\
\hline F Change & .654 & & & & .377 & & & \\
\hline
\end{tabular}


Table 13 RQ\#2 Change in Younger Siblings' Antisocial Behavior with PDT-Hostility + RxStat

\begin{tabular}{|c|c|c|c|c|c|c|c|c|}
\hline \multirow{2}{*}{$\begin{array}{l}\text { Youth reported } \\
\text { PDT }^{1}\end{array}$} & \multicolumn{4}{|c|}{$\mathbf{A}(\mathrm{n}=40)$} & \multicolumn{4}{|c|}{$\mathbf{B}(\mathrm{n}=41)$} \\
\hline & B & SE B & $\beta$ & $\mathrm{t}$ & $\mathrm{B}$ & SE B & $\beta$ & $\mathrm{t}$ \\
\hline $\begin{array}{r}\text { Step } 1 \\
\text { Gender } \\
\text { Direct Parenting } \\
\text { PDT } \\
\text { Group } \\
\mathrm{R}^{2} \\
\text { Adj } \mathrm{R}^{2} \\
\text { F Change }\end{array}$ & $\begin{array}{l}.034 \\
.034 \\
.181 \\
.119 \\
.245 \\
.159 \\
2.843^{*}\end{array}$ & $\begin{array}{l}.134 \\
.069 \\
.064 \\
.088\end{array}$ & $\begin{array}{l}.038 \\
.074 \\
.420 \\
.206\end{array}$ & $\begin{array}{l}.251 \\
.074 \\
.420 * * \\
1.365\end{array}$ & $\begin{array}{l}.010 \\
.023 \\
.129 \\
.062 \\
.151 \\
.057 \\
1.605 \\
\end{array}$ & $\begin{array}{l}.120 \\
.055 \\
.062 \\
.080\end{array}$ & $\begin{array}{l}.013 \\
.067 \\
.337 \\
.128\end{array}$ & $\begin{array}{l}.083 \\
.415 \\
2.080 * \\
.739\end{array}$ \\
\hline $\begin{array}{r}\text { Step } 2 \\
\text { Gender } \\
\text { Direct Parenting } \\
\text { PDT } \\
\text { Group } \\
\text { PDT }^{*} \text { Group } \\
\mathrm{R}^{2} \\
\text { Adj } \mathrm{R}^{2} \\
\text { F Change }\end{array}$ & $\begin{array}{l}.037 \\
.037 \\
.222 \\
.126 \\
-.033 \\
.249 \\
.139 \\
.169 \\
\end{array}$ & $\begin{array}{l}.136 \\
.070 \\
.119 \\
.090 \\
.080\end{array}$ & $\begin{array}{l}.043 \\
.081 \\
.515 \\
.218 \\
-.115\end{array}$ & $\begin{array}{l}.275 \\
.532 \\
1.871+ \\
1.401 \\
-.411\end{array}$ & $\begin{array}{l}.010 \\
.024 \\
.135 \\
.063 \\
-.005 \\
.151 \\
.030 \\
.005 \\
\end{array}$ & $\begin{array}{l}.122 \\
.059 \\
.108 \\
.081 \\
.073\end{array}$ & $\begin{array}{l}.014 \\
.071 \\
.353 \\
.128 \\
-.019\end{array}$ & $\begin{array}{l}.083 \\
.410 \\
1.249 \\
.773 \\
-.068\end{array}$ \\
\hline Parent & & & $\mathrm{l}=40)$ & & & & $=34)$ & \\
\hline reported $\mathrm{PDT}^{2}$ & B & SE B & $\beta$ & $\mathrm{t}$ & B & SE B & $\beta$ & $\mathrm{t}$ \\
\hline $\begin{array}{r}\text { Step } 1 \\
\text { Gender } \\
\text { Direct Parenting } \\
\text { PDT } \\
\text { Group } \\
\mathrm{R}^{2} \\
\text { Adj } \mathrm{R}^{2} \\
\text { F Change }\end{array}$ & $\begin{array}{l}.130 \\
-.210 \\
-.077 \\
.120 \\
.246 \\
.159 \\
2.848^{*}\end{array}$ & $\begin{array}{l}.138 \\
.073 \\
.069 \\
.088\end{array}$ & $\begin{array}{l}.148 \\
-.433 \\
-.174 \\
.208\end{array}$ & $\begin{array}{l}.942 \\
-2.856^{* *} \\
-1.121 \\
1.369\end{array}$ & $\begin{array}{l}.158 \\
-.085 \\
-.101 \\
.180 \\
.141 \\
.022 \\
1.189 \\
\end{array}$ & $\begin{array}{l}.151 \\
.070 \\
.081 \\
.105\end{array}$ & $\begin{array}{l}.190 \\
-.237 \\
-.235 \\
.325\end{array}$ & $\begin{array}{l}1.050 \\
-1.220 \\
-1.248 \\
1.717+\end{array}$ \\
\hline $\begin{array}{r}\text { Step } 2 \\
\text { Gender } \\
\text { Direct Parenting } \\
\text { PDT } \\
\text { Group } \\
\text { PDT }^{*} \text { Group } \\
\mathrm{R}^{2} \\
\text { Adj R } \\
\text { F Change }\end{array}$ & $\begin{array}{l}.167 \\
-.194 \\
.171 \\
.088 \\
-.191 \\
.351 \\
.255 \\
5.494^{*}\end{array}$ & $\begin{array}{l}.131 \\
.069 \\
.124 \\
.084 \\
.081\end{array}$ & $\begin{array}{l}.190 \\
-.401 \\
.388 \\
.153 \\
-.651\end{array}$ & $\begin{array}{l}1.275 \\
-2.796^{* *} \\
1.380 \\
1.056 \\
-2.344^{*}\end{array}$ & $\begin{array}{l}.238 \\
-.090 \\
.225 \\
.202 \\
-.265 \\
.330 \\
.211 \\
7.916^{* *} \\
\end{array}$ & $\begin{array}{l}.138 \\
.063 \\
.137 \\
.094 \\
.094\end{array}$ & $\begin{array}{l}.285 \\
-.251 \\
.524 \\
.365 \\
-.906\end{array}$ & $\begin{array}{l}1.719+ \\
-1.437 \\
1.645 \\
2.142 * \\
-2.814 * *\end{array}$ \\
\hline Observer & & & $\mathrm{i}=41)$ & & & & $=34)$ & \\
\hline reported $\mathrm{PDT}^{3}$ & B & SE B & $\beta$ & $\mathrm{t}$ & $\mathrm{B}$ & SE B & $\beta$ & $\mathrm{t}$ \\
\hline $\begin{array}{r}\text { Step } 1 \\
\text { Gender } \\
\text { Direct Parenting } \\
\text { PDT } \\
\text { Group } \\
\mathrm{R}^{2} \\
\text { Adj } \mathrm{R}^{2} \\
\text { F Change } \\
\end{array}$ & $\begin{array}{l}.040 \\
-.077 \\
-.080 \\
.074 \\
.111 \\
.012 \\
1.120 \\
\end{array}$ & $\begin{array}{l}.124 \\
.070 \\
.090 \\
.079\end{array}$ & $\begin{array}{l}.054 \\
-.178 \\
-.149 \\
.151\end{array}$ & $\begin{array}{l}.323 \\
-1.100 \\
-.888 \\
.937\end{array}$ & $\begin{array}{l}.077 \\
.004 \\
-.079 \\
.113 \\
.091 \\
-.034 \\
.725 \\
\end{array}$ & $\begin{array}{l}.156 \\
.079 \\
.113 \\
.100\end{array}$ & $\begin{array}{l}.092 \\
.010 \\
-.135 \\
.203\end{array}$ & $\begin{array}{l}.495 \\
.052 \\
-.701 \\
1.121\end{array}$ \\
\hline $\begin{array}{r}\text { Step } 2 \\
\text { Gender } \\
\text { Direct Parenting } \\
\text { PDT } \\
\text { Group } \\
\text { PDT }^{*} \text { Group } \\
\mathrm{R}^{2} \\
\text { Adj R }{ }^{2} \\
\text { F Change }\end{array}$ & $\begin{array}{l}.030 \\
-.084 \\
-.280 \\
.051 \\
.119 \\
.121 \\
-.004 \\
.420 \\
\end{array}$ & $\begin{array}{l}.126 \\
.071 \\
.322 \\
.087 \\
.184\end{array}$ & $\begin{array}{l}.040 \\
-.193 \\
-.523 \\
.104 \\
.386\end{array}$ & $\begin{array}{l}.236 \\
-1.169 \\
-.870 \\
.580 \\
.648\end{array}$ & $\begin{array}{l}.067 \\
.005 \\
-.233 \\
.097 \\
.088 \\
.095 \\
-.067 \\
.128\end{array}$ & $\begin{array}{l}.161 \\
.080 \\
.446 \\
.111 \\
.245\end{array}$ & $\begin{array}{l}.080 \\
.013 \\
-.397 \\
.176 \\
.265\end{array}$ & $\begin{array}{l}.416 \\
.067 \\
-.524 \\
.877 \\
.358\end{array}$ \\
\hline
\end{tabular}


Table 14 RQ\#2 Change in Younger Siblings' Antisocial Behavior with PDT-Warmth + RxStat

\begin{tabular}{|c|c|c|c|c|c|c|c|c|}
\hline \multirow{2}{*}{$\begin{array}{l}\text { Youth reported } \\
\text { PDT }^{1}\end{array}$} & \multicolumn{4}{|c|}{$\mathbf{A}(\mathrm{n}=45)$} & \multicolumn{4}{|c|}{ B $(n=46)$} \\
\hline & $\mathrm{B}$ & SE B & $\beta$ & $\mathrm{t}$ & B & SE B & $\beta$ & $\mathrm{t}$ \\
\hline $\begin{array}{r}\text { Step } 1 \\
\text { Gender } \\
\text { Direct Parenting } \\
\text { PDT } \\
\text { Group } \\
\mathrm{R}^{2} \\
\text { Adj } \mathrm{R}^{2} \\
\text { F Change }\end{array}$ & $\begin{array}{l}.094 \\
.019 \\
.054 \\
.135 \\
.115 \\
.027 \\
1.303 \\
\end{array}$ & $\begin{array}{l}.114 \\
.052 \\
.063 \\
.075\end{array}$ & $\begin{array}{l}.127 \\
.057 \\
.133 \\
.280\end{array}$ & $\begin{array}{l}.829 \\
.369 \\
.861 \\
1.792+\end{array}$ & $\begin{array}{l}.099 \\
-.029 \\
.068 \\
.133 \\
.105 \\
.017 \\
1.196 \\
\end{array}$ & $\begin{array}{l}.117 \\
.060 \\
.063 \\
.083\end{array}$ & $\begin{array}{l}.130 \\
-.079 \\
.167 \\
.266\end{array}$ & $\begin{array}{l}.852 \\
-.495 \\
1.096 \\
1.596\end{array}$ \\
\hline $\begin{array}{r}\text { Step } 2 \\
\text { Gender } \\
\text { Direct Parenting } \\
\text { PDT } \\
\text { Group } \\
\text { PDT }^{*} \text { Group } \\
\mathrm{R}^{2} \\
\text { Adj } \mathrm{R}^{2} \\
\text { F Change } \\
\end{array}$ & $\begin{array}{l}.028 \\
.053 \\
.199 \\
.111 \\
-.148 \\
.176 \\
.071 \\
2.883+\end{array}$ & $\begin{array}{l}.118 \\
.054 \\
.105 \\
.075 \\
.087\end{array}$ & $\begin{array}{l}.038 \\
.158 \\
.488 \\
.231 \\
-.449\end{array}$ & $\begin{array}{l}.242 \\
.974 \\
1.892+ \\
1.485 \\
-1.698+\end{array}$ & $\begin{array}{l}.080 \\
-.020 \\
.121 \\
.111 \\
-.059 \\
.114 \\
.004 \\
.446 \\
\end{array}$ & $\begin{array}{l}.121 \\
.061 \\
.101 \\
.090 \\
.089\end{array}$ & $\begin{array}{l}.105 \\
-.055 \\
.295 \\
.222 \\
-.178\end{array}$ & $\begin{array}{l}.664 \\
-.331 \\
1.202 \\
1.227 \\
1.227\end{array}$ \\
\hline Parent & & & $\mathrm{n}=45)$ & & & & $=40)$ & \\
\hline reported $\mathrm{PDT}^{2}$ & B & SE B & $\beta$ & $\mathrm{t}$ & B & SE B & $\beta$ & $\mathrm{t}$ \\
\hline $\begin{array}{rr}\text { Step } 1 & \\
\text { Gender } \\
\text { Direct Parenting } \\
\text { PDT } \\
\text { Group } \\
\mathrm{R}^{2} \\
\text { Adj } \mathrm{R}^{2} \\
\text { F Change }\end{array}$ & $\begin{array}{l}.131 \\
.045 \\
.056 \\
.115 \\
.125 \\
.038 \\
1.434 \\
\end{array}$ & $\begin{array}{l}.117 \\
.074 \\
.054 \\
.075\end{array}$ & $\begin{array}{l}.176 \\
.094 \\
.161 \\
.240\end{array}$ & $\begin{array}{l}1.114 \\
.610 \\
1.026 \\
1.548\end{array}$ & $\begin{array}{l}.141 \\
-.061 \\
.029 \\
.179 \\
.138 \\
.039 \\
1.396 \\
\end{array}$ & $\begin{array}{l}.139 \\
.082 \\
.065 \\
.095\end{array}$ & $\begin{array}{l}.171 \\
-.136 \\
.078 \\
.330\end{array}$ & $\begin{array}{l}1.014 \\
-.747 \\
.450 \\
1.879+\end{array}$ \\
\hline $\begin{array}{r}\text { Step } 2 \\
\text { Gender } \\
\text { Direct Parenting } \\
\text { PDT } \\
\text { Group } \\
\text { PDT }^{*} \text { Group } \\
\mathrm{R}^{2} \\
\text { Adj } \mathrm{R}^{2} \\
\text { F Change }\end{array}$ & $\begin{array}{l}.138 \\
.027 \\
-.047 \\
.117 \\
.088 \\
.166 \\
.060 \\
1.918 \\
\end{array}$ & $\begin{array}{l}.116 \\
.075 \\
.092 \\
.074 \\
.064\end{array}$ & $\begin{array}{l}.186 \\
.055 \\
-.135 \\
.243 \\
.358\end{array}$ & $\begin{array}{l}1.191 \\
.354 \\
-.511 \\
1.584 \\
1.385\end{array}$ & $\begin{array}{l}.149 \\
-.078 \\
-.104 \\
.193 \\
.113 \\
.198 \\
.080 \\
2.553 \\
\end{array}$ & $\begin{array}{l}.136 \\
.081 \\
.105 \\
.094 \\
.070\end{array}$ & $\begin{array}{l}.181 \\
-.173 \\
-.279 \\
.357 \\
.429\end{array}$ & $\begin{array}{l}1.094 \\
-.962 \\
-.992 \\
2.067 * \\
1.598\end{array}$ \\
\hline Observer & & & $n=46)$ & & & & $=40)$ & \\
\hline reported $\mathrm{PDT}^{3}$ & $\mathrm{~B}$ & SE B & $\beta$ & $\mathrm{t}$ & B & SE B & $\beta$ & $\mathrm{t}$ \\
\hline $\begin{array}{rr}\text { Step } 1 & \\
& \text { Gender } \\
\text { Direct Parenting } & \text { PDT } \\
\text { Group } \\
\mathrm{R}^{2} \\
\text { Adj } \mathrm{R}^{2} \\
\text { F Change }\end{array}$ & $\begin{array}{l}.123 \\
.019 \\
.084 \\
.100 \\
.094 \\
.006 \\
1.068 \\
\end{array}$ & $\begin{array}{l}.119 \\
.069 \\
.099 \\
.078\end{array}$ & $\begin{array}{l}.161 \\
.042 \\
.128 \\
.201\end{array}$ & $\begin{array}{l}1.038 \\
.280 \\
.850 \\
1.281\end{array}$ & $\begin{array}{l}.122 \\
-.002 \\
.098 \\
.155 \\
.126 \\
.026 \\
1.263 \\
\end{array}$ & $\begin{array}{l}.136 \\
.059 \\
.125 \\
.088\end{array}$ & $\begin{array}{l}.148 \\
-.005 \\
.125 \\
.287\end{array}$ & $\begin{array}{l}.891 \\
-.032 \\
.779 \\
1.758+\end{array}$ \\
\hline $\begin{array}{r}\text { Step } 2 \\
\text { Gender } \\
\text { Direct Parenting } \\
\text { PDT } \\
\text { Group } \\
\text { PDT }^{*} \text { Group } \\
\mathrm{R}^{2} \\
\text { Adj } \mathrm{R}^{2} \\
\text { F Change }\end{array}$ & $\begin{array}{l}.125 \\
.022 \\
.413 \\
.140 \\
-.204 \\
.122 \\
.012 \\
1.242 \\
\end{array}$ & $\begin{array}{l}.118 \\
.069 \\
.312 \\
.086 \\
.183\end{array}$ & $\begin{array}{l}.163 \\
.047 \\
.630 \\
.281 \\
-.529\end{array}$ & $\begin{array}{l}1.053 \\
.313 \\
1.327 \\
1.634 \\
-1.114\end{array}$ & $\begin{array}{l}.111 \\
-4.732 \mathrm{E}- \\
1.009 \\
.255 \\
-.486 \\
.189 \\
.070 \\
2.651\end{array}$ & $\begin{array}{l}.133 \\
.057 \\
.573 \\
.106 \\
.299\end{array}$ & $\begin{array}{l}.135 \\
.000 \\
1.287 \\
.471 \\
-1.187\end{array}$ & $\begin{array}{l}.830 \\
.000 \\
1.761+ \\
2.409 * \\
-1.628\end{array}$ \\
\hline
\end{tabular}


To more easily interpret the significant findings, it was decided to plot the five interactions that were significant $(\mathrm{p}<.05)$ or approached significance $(\mathrm{p}<.10)$. For clarity purposes, it was also decided to re-run the five significant interactions using the binary moderator whereby $0=$ control and $1=$ treatment $(\mathrm{PMT}$ and SPMT) as opposed to the ordinal treatment group variable $(0,1,2)$ used in the previous analyses. This was done so that the interaction plots would be more straightforward to understand. Using the binary moderator, treatment and control lines were plotted and examined for negative (-) PDT and positive $(+)$ PDT. It should be noted that relative differences scores were still used in these analyses, so the PDT interpretation table should continue to be utilized when interpreting the plots.

For older siblings, $(+)$ PDT meant the older sibling was treated with more of the specified domain and (-) PDT meant that older sibling was treated with less of the specified domain. The results for these regressions for older siblings can be found in table 15. Moreover, figures 1 and 2 display the interaction plots for older siblings using the binary moderator. Examining these plots carefully, it looks like the intervention may have had an influence on PDT in situations where the older sibling was experiencing more negative PDT (i.e., more hostility as compared to younger sibling - or- less warmth as compared to younger sibling). These two plots illustrate that older siblings in the treatment group improved (experienced a decrease in antisocial behavior as reported by the teacher) as compared to those in the control group. This is most evident when examining the right side of figure 1 (i.e., + PDT: older sibling treated with more hostility 
than younger sibling) and the left side of figure 2 (- PDT: older sibling treated with less warmth than younger sibling).

Table 15 Older Siblings' Significant Interactions using Binary Moderator for Treatment Group.

\begin{tabular}{|c|c|c|c|c|c|c|c|c|}
\hline \multirow{2}{*}{$\begin{array}{l}\text { Youth } \\
\text { reported PDT }\end{array}$} & \multicolumn{4}{|c|}{ Youth reported PDT-Hostility $(n=58)$} & \multicolumn{4}{|c|}{ Youth reported PDT-Warmth $(n=69)$} \\
\hline & $\mathrm{B}$ & SE B & $\beta$ & $\mathrm{t}$ & $\mathrm{B}$ & SE B & $\beta$ & $\mathrm{t}$ \\
\hline \multicolumn{9}{|l|}{ Step 1} \\
\hline Gender & .070 & .087 & .108 & .803 & .009 & .079 & .013 & .111 \\
\hline Direct Parenting & -.067 & .045 & -.204 & -1.488 & -.075 & .040 & -.229 & $-1.890+$ \\
\hline PDT & .013 & .040 & .044 & .329 & -.010 & .036 & -.034 & -.284 \\
\hline Group & -.208 & .096 & -.280 & $-2.166^{*}$ & -.126 & .092 & -.165 & -1.364 \\
\hline $\mathrm{R}^{2}$ & .119 & & & & .090 & & & \\
\hline Adj $R^{2}$ & .052 & & & & .033 & & & \\
\hline F Change & 1.786 & & & & 1.580 & & & \\
\hline \multicolumn{9}{|l|}{ Step 2} \\
\hline Gender & .077 & .086 & .118 & .892 & .001 & .077 & .001 & .009 \\
\hline Direct Parenting & -.054 & .045 & -.164 & -1.202 & -.071 & .039 & -.216 & $-1.830+$ \\
\hline PDT & .124 & .076 & .412 & 1.626 & -.170 & .082 & -.559 & $-2.077^{*}$ \\
\hline Group & -.213 & .094 & -.287 & $-2.259 *$ & -.133 & .090 & -.175 & -1.483 \\
\hline $\mathrm{PDT}^{*}$ Group & -.152 & .090 & -.436 & $-1.695+$ & .196 & .090 & .581 & $2.164 *$ \\
\hline $\mathrm{R}^{2}$ & .165 & & & & .153 & & & \\
\hline Adj $R^{2}$ & .085 & & & & .086 & & & \\
\hline F Change & $2.873+$ & & & & $4.682 *$ & & & \\
\hline
\end{tabular}

${ }^{*} \mathrm{p}<.05 * * \mathrm{p}<.01 * * * \mathrm{p}<.001{ }^{+} \mathrm{p}<.10$. PDT $=$ Parental Differential Treatment.

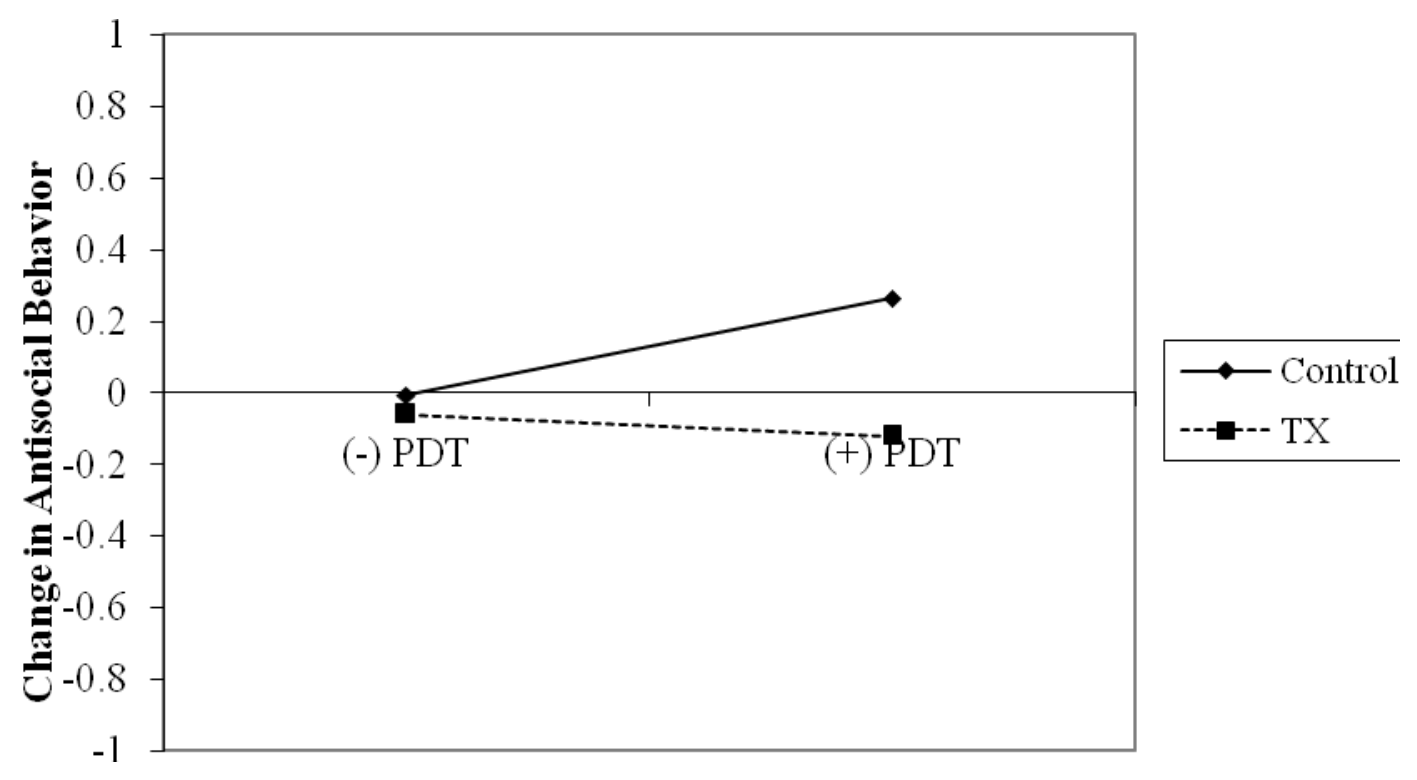

Figure 1. Older Sibling Interaction: Youth reported PDT-Hostility *Group n=58 


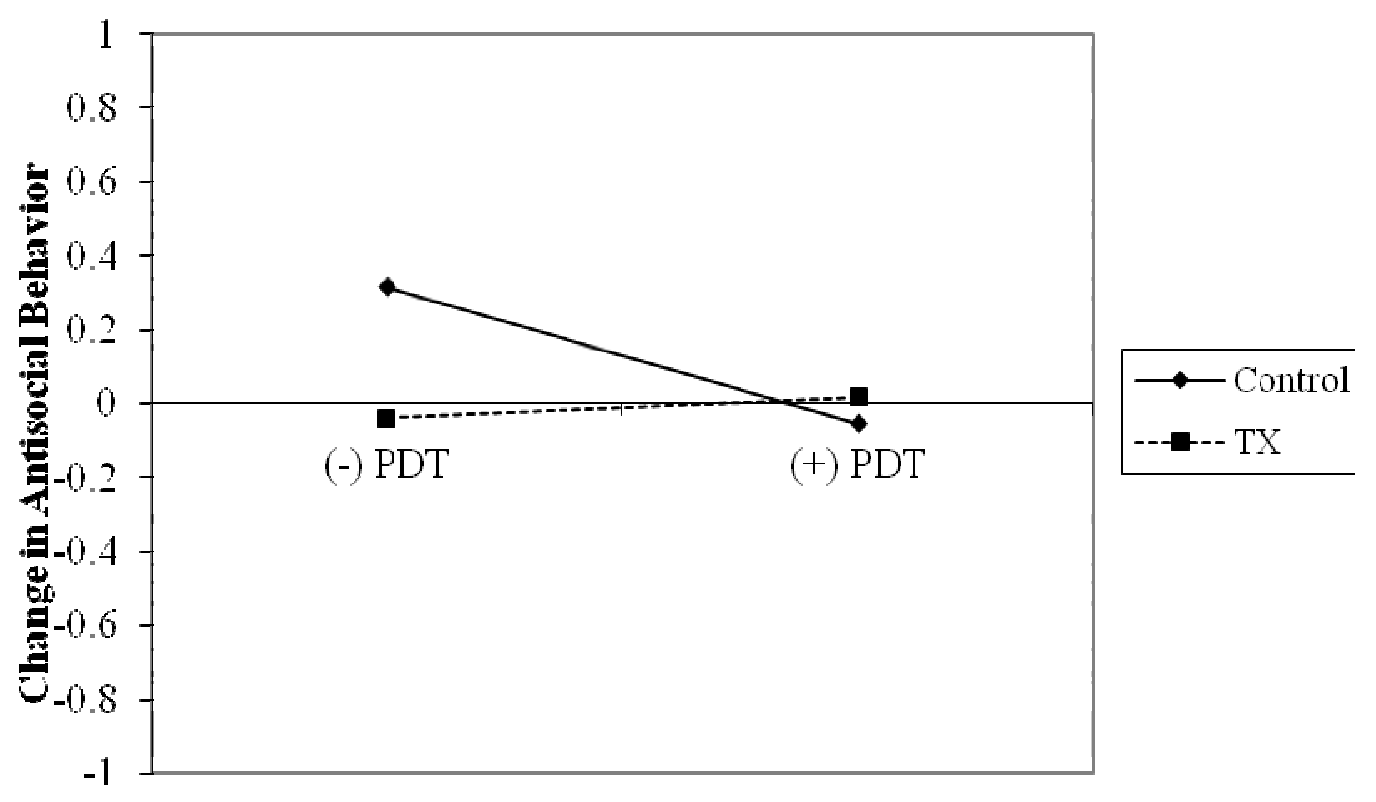

Figure 2. Older Sibling Interaction:Youth reported PDT-Warmth*Group n=69

For younger siblings, the results are less clear cut; however, this was somewhat expected. Of the three significant interactions found in the first series of regressions for younger siblings, two were for the same PDT reporting agent for PDT-Hostility. That is, parent reported PDT-Hostility was significant when controlling for youth reported direct hostility and observer reported direct hostility. Therefore, there were really two interactions of interest even though all three regressions were run using the binary moderator. The parent-reported PDT-Hostility regressions remained significant using the binary moderator; however, the third regression examining youth reported PDT-Warmth controlling for parent reported warmth, did not remain significant using the binary moderator. The table and figure below display the results for parent reported PDT- 
Hostility controlling for youth direct warmth. It was decided to include the plot of this regression as the numbers in this analysis $(n=40)$ were slightly higher than parent reported PDT-Warmth controlling for observer direct warmth $(n=34)$. The plots were similar for both.

Table 16 Parent reported PDT-Hostility predicting Change in Younger Sibling Antisocial Behavior

\begin{tabular}{|c|c|c|c|c|}
\hline \multirow{2}{*}{$\begin{array}{l}\text { Parent } \\
\text { reported PDT }\end{array}$} & \multicolumn{4}{|c|}{ Parent reported PDT-Hostility $(n=40)$} \\
\hline & $\mathrm{B}$ & SE B & $\beta$ & $\mathrm{t}$ \\
\hline \multicolumn{5}{|l|}{ Step 1} \\
\hline Gender & .138 & .131 & .158 & 1.052 \\
\hline \multirow[t]{2}{*}{ Direct Parenting } & -.221 & .071 & -.455 & - \\
\hline & & & & $3.114 * *$ \\
\hline PDT & -.082 & .066 & -.187 & -1.239 \\
\hline Group & .303 & .145 & .300 & $2.085^{*}$ \\
\hline $\mathrm{R}^{2}$ & .293 & & & \\
\hline Adj $R^{2}$ & .212 & & & \\
\hline F Change & $3.626^{*}$ & & & \\
\hline \multicolumn{5}{|l|}{ Step 2} \\
\hline Gender & .193 & .125 & .221 & 1.551 \\
\hline Direct Parenting & -.205 & .067 & -.422 & - \\
\hline & & & & $3.075 * *$ \\
\hline PDT & .229 & .141 & .518 & 1.622 \\
\hline Group & .207 & .141 & .205 & 1.463 \\
\hline PDT $^{*}$ Group & -.385 & .157 & -.785 & $-2.458 *$ \\
\hline $\mathrm{R}^{2}$ & .400 & & & \\
\hline $\operatorname{Adj} R^{2}$ & .311 & & & \\
\hline F Change & $6.044 *$ & & & \\
\hline
\end{tabular}




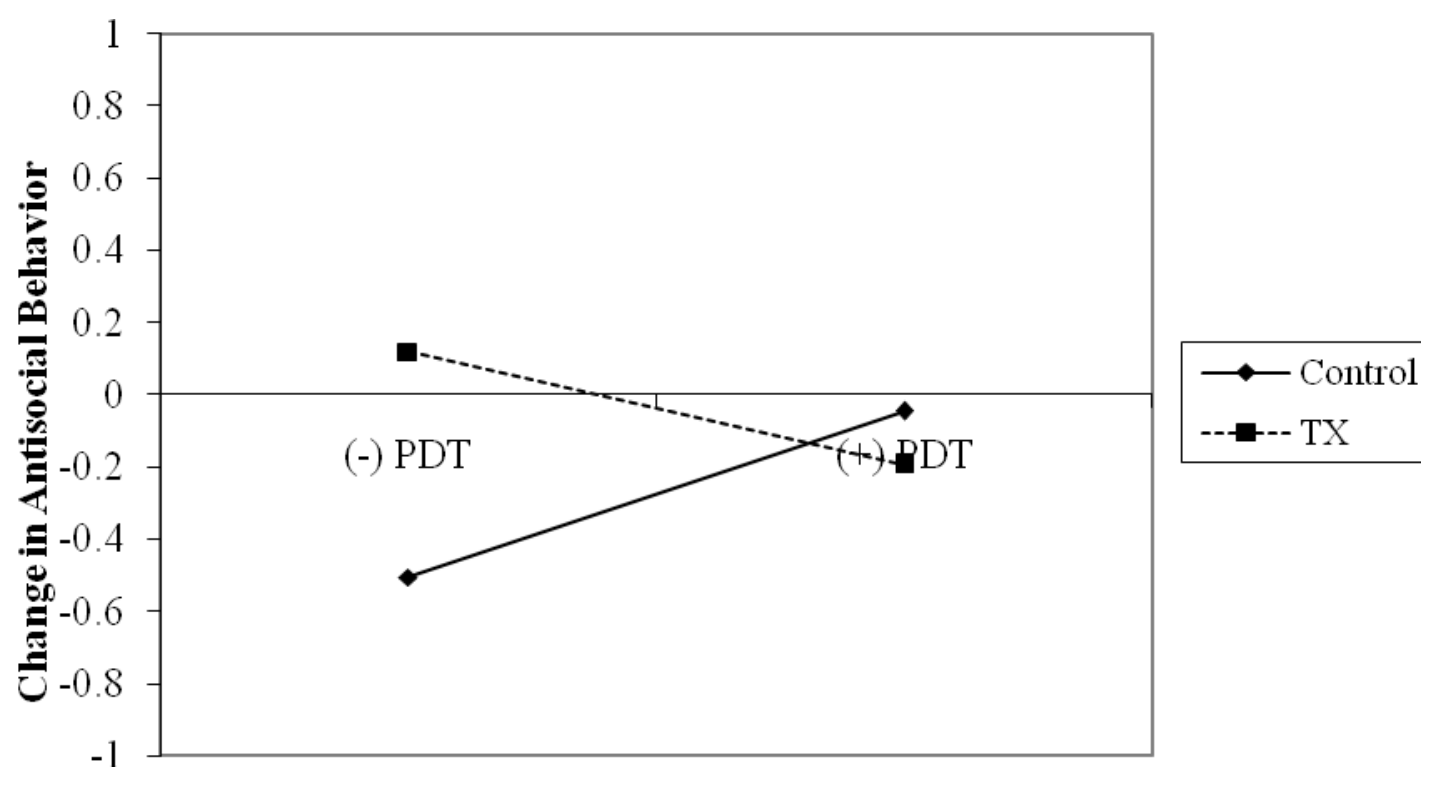

Figure 3: Younger Sibling Interaction: Parent Reported PDT-Hostility*Group n=40

\section{Research Question 3 ANOVAS - Exploring Malleability}

This question addressed the potential malleability of these two PDT domains. A series of ANCOVAs were conducted to explore whether there would be significant differences in PDT scores 6 months after enrollment at intervention term between intervention groups (i.e., SPMT and PMT) and control group (i.e., CPT), while controlling for baseline PDT scores. The expectation was that there would be PDT mean differences between the intervention groups (i.e., PMT and SPMT) and the control group (i.e, CPT). More specifically, it was expected that PDT levels in the intervention groups would closer to zero after participation in the parenting intervention indicating more egalitarian treatment. To test whether PDT was malleable after 6 months time and participation in an intervention, a total of six ANCOVAs were conducted: 3 for PDTHostility (youth reported, parent reported, and observer reported PDT change scores) and 
3 for PDT-Warmth (youth reported, parent reported, and observer reported PDT changes scores). The results of these malleability analyses did not turn out as expected. See Table 17. None of the 6 ANCOVA analyses were statistically significant. Examining the means of each group in each analysis as well as the estimated marginal means (i.e., "adjusted" means - removing the effect of PDT scores at baseline) more carefully, no clear patterns were witnessed between groups and across analyses. Sometimes the means for SPMT or PMT were closer to zero than the comparison PDT scores for the CPT group; however, sometimes the PDT scores of the CPT group were closer to zero than both the intervention groups.

In view of the fact that these data were collected as part of a RCT, however, it was thought that it may not be necessary to control for PDT levels and baseline. It was decided to run a series of ANOVA analyses for each reporting agent for each domain, examining mean differences in PDT at completion of intervention by treatment group. These six ANOVA analyses confirmed the results found in the ANCOVA analyses. No significant differences were found between groups for PDT at intervention term.

Therefore, these results indicate that PDT did not show to be malleable in this study.

These findings will be discussed in more detail in the discussion section.

Table 17 Examining Malleability of Parental Differential Treatment: Means of Each Group.

\begin{tabular}{clccc}
\hline & \multicolumn{4}{c}{ Means and SDs by Group } \\
\cline { 2 - 5 } PDT-HOSTILITY & $\mathrm{F}$ and $p$ Values & PMT & SPMT & CPT \\
\hline Youth Report & $\mathrm{F}=.367, p=.694$ & $-.09(.97)$ & $.00(1.10)$ & $.13(.83)$ \\
Parent Report & $\mathrm{F}=.265, p=.768$ & $-.03(1.20)$ & $.00(.73)$ & $-.01(1.16)$ \\
Observer Report & $\mathrm{F}=.581, p=.563$ & $-.10(.75)$ & $.21(1.56)$ & $-.18(.00)$ \\
\cline { 2 - 5 } PDT-WARMTH & & & & \\
\hline Youth Report & $\mathrm{F}=.258, p=.773$ & $.01(.88)$ & $-.04(1.15)$ & $-.14(.82)$ \\
Parent Report & $\mathrm{F}=2.26, p=.113$ & $-.26(.93)$ & $-.04(1.26)$ & $.27(.61)$ \\
Observer Report & $\mathrm{F}=.07, p=.931$ & $-.11(.84)$ & $-.07(.40)$ & $-.02(.52)$ \\
\hline
\end{tabular}




\section{CHAPTER V. DISCUSSION AND CONCLUSION \\ Primary Findings}

PDT has captured the interest of investigators for years, but it has not been examined in the context of an experimental design. Thus, the purpose of the current work was both to replicate cross-sectional and longitudinal work as well as to expand the literature to include an investigation of PDT within the context of an experimental study. The current PDT study examined two domains of PDT across three different PDT reporting agents in a sample of at-risk families enrolled in a randomized clinical trial with parenting and sibling intervention components. PDT-Warmth and PDT-Hostility were examined among children, mothers, and observers. In addition, parents and children's teachers reported on

older and younger sibling outcomes at baseline and 6-month assessments in the home and school settings. The results of this study do indicate that each agent's perspective of PDT is meaningful. These results highlight that cross-agent examination of PDT (i.e., when 2 reporters agree on the existence or occurrence of PDT) may help shed light on instances when PDT truly matters for kids. These findings help to illustrate, as other studies have done, that PDT may have a unique influence on children's outcomes, and that differential treatment by parents is at least one important factor in predicting children's behavior. These findings may also provide modest evidence that participation in an intervention moderates PDT in some cases; however, the results from this study provide no evidence that PDT is malleable after 6 months time. The subsequent paragraphs will review each research question and explore ways in which these results from this study can be interpreted. 
Two domains of parenting, warmth and hostility, were examined because it was thought that considerable differences between siblings in these domains would be more indicative of inappropriate or unjustified PDT, and therefore more strongly associated with children's adjustment. It could be argued that differential treatment is an expected aspect of parenting in the sense that children living in the same home often have different ages, are of different genders, and possess diverse abilities. For that reason, appropriate parenting practices recognize those child differences and accommodate each child. Nevertheless, if one child is treated with cold and harsh parenting compared to his or her sibling, or if one child is treated with an abundance of warmth compared to his or her sibling, it is thought that this leads to more antisocial behavior. Middle childhood is a developmental period when the occurrence of PDT has been observed and reported by different reporting agents, and the effects of differential treatment are well documented for both the disfavored child (Dunn, Stocker, \& Plomin, 1990; McHale \& Pawletko, 1992; McHale et al., 1995) as well as the other sibling (e.g., Boyle et al., 2004).

The findings first demonstrated that internally consistent indicators of warmth and hostility were created from existing items in the larger SIBS study for the three reporting agents. Some of the scales were based on a small number of items, so it could be argued that more items for each informant would have been helpful. The strongest constructs seemed to be the youth constructs likely because they were based on a larger number of items. From these warmth and hostility domains (also referred to as direct parenting scores), PDT scores were calculated by the use of relative difference scores. Reporting agents' scores of PDT were distinct, reflecting and highlighting, as other studies have 
done, the importance of individual perception (e.g., Kowal \& Kramer, 1997).

Correlations between direct parenting scores, as well as between direct parenting scores and PDT scores demonstrated that method variance is something that researchers should continue to consider. The strongest correlations were between parents reports of parentolder child direct parenting and parent-younger child direct parenting. Observers reports of the same were similarly strong.

Social cognitive factors such as attributions likely play a role when a reporting agent determines whether PDT is present. The children involved in this study were between the ages of 4 and 11, and results revealed that youth, parents, and observers witnessed differences in parental treatment. Similar to previous studies (e.g., Coldwell, Pike, \& Dunn, 1997), the descriptive statistics from this study demonstrated that children reported the most variation in their reports of PDT, and interestingly, youth-reported PDT-hostility was more strongly associated with older siblings' antisocial behavior compared to parent reported PDT and observer reported PDT. This correspondence between children's perceptions and children's outcomes has been demonstrated in other studies (Paulson, 1994). Furthermore, youth-reported PDT-warmth was more strongly associated with younger siblings' antisocial behavior compared to parents' and observers' reports of PDT-warmth. There may be developmental reasons for these findings. Additionally, these findings illustrate, as other studies have done (Coldwell, Pike, \& Dunn, 1997), that youth's perspectives matter. It should also be mentioned again, however, that the youth measures may have been the strongest since there were more 
items utilized for the warmth and hostility constructs as compared to parent and observer reported constructed.

Since higher order constructs could not be created, it was decided to conceptualize PDT into categories and examine PDT-Warmth and PDT-Hostility based on cross agent agreement in regards to three categories: older sibling treated with more of given domain (i.e., hostility or warmth), equal treatment to both siblings, and younger sibling treated with more of a given domain. The categories created for this analysis parallel the types of categories that have been examined in other studies (e.g., McHale et al., 1995); however, other studies have not examined cross-agent agreement by examining agreement across three informants. Agreement was established if at least two reporting agents agreed. This cross-agent analysis revealed that it is difficult to establish agreement between reporting agents. In some cases using this cross-agent method, no agreement was established between reporting agents which may again highlight the importance of individual perception. When cross-agent agreement ( 2 reporting agents indicating the same thing) was established, it was most often for egalitarian treatment (i.e., approximately equal parent-child treatment between siblings). This finding suggests that egalitarian treatment may be the most common occurrence in families (relative to the distribution).

The two PDT cross-agent agreement categories (where one or the other sibling was treated with more of a given domain) were then collapsed in order to examine siblings in high-PDT families (1) compared to those in more egalitarian-treatment families (0). Because there were only a small number of cases that met this cross-agent 
agreement criteria for high PDT, it was decided to examine TRF scores in addition to other outcomes to determine whether mean differences existed in outcomes between those who were part of the 'egalitarian-treatment' families and those that were a part of the 'high PDT' families to give more opportunities for findings.. In those instances when at least two reports agreed that higher levels of parental differential treatment existed, children's adjustment outcomes across contexts (i.e., school and home) and agents were different from those siblings in the egalitarian treatment group. In most instances the differences on outcomes between egalitarian families and high PDT families were statistically significant when examining PDT-Hostility. The pattern of results was similar for both domains for the most part; however, the findings were most notable across outcomes as a function of PDT-Hostility perhaps underscoring the potency of this domain. These results support the notion that siblings in high PDT households fare worse than those in egalitarian households when high PDT is visible by at least 2 reporting agents. These findings are consistent with other studies that have examined child outcomes in the context of high PDT (Dunn \& colleagues; McHale \& colleagues). This cross-agent agreement may be another way to move beyond individual perception of PDT.

The first series of regression analyses conducted for the first research question also demonstrated that PDT can have a unique contribution to child outcomes, as other studies have done (Boyle et al., 2004; Feinberg \& Hetherington, 2001). Research question one was pre-intervention and cross-sectional, so it did not differ much from previous work in this area. However, this study did allow for examining these 
associations in a high risk group. The results of research question one and all its forms/replications illustrated that, in some instances, PDT does account for additional variance in child adjustment outcomes. These regression analyses went beyond the simple bivariate associations, and explored the relationship between PDT and child antisocial behavior controlling for the child-level factors of age and gender, as well as the level of direct parenting of the given domain from a different reporting agent (see Feinberg \& Hetherington, 2001). Direct parenting was often predictive of child outcomes as expected, but gender seemed to be a particularly strong indicator of child's overt antisocial behavior as reported by the teacher.

Of the six regressions that were conducted for PDT-Hostility predicting older siblings' antisocial behavior, three regression analyses (two for youth reported PDTHostility and one for parent reported PDT-Hostility) were significant at $\mathrm{p}<.05$ and one observer reported PDT-Hostility approached significance $(p<.10)$ at step two. The adjusted $\mathrm{R}^{2} \mathrm{~s}$ revealed that PDT-Hostility, in these instances accounted for additional variance in older siblings' antisocial behavior after controlling for direct parenting. The additional variance accounted for by PDT is similar to what other studies have found (Feinberg \& Hetherington, 2001; McHale et al., 1995). A similar pattern was found for younger siblings and the PDT-Warmth domain, but the ANOVA analyses for these regression models were not significant at $\mathrm{p}<.05$ level revealing that there were not statistically significant differences between the two steps. These regressions, particularly those conducted for older siblings, reveal that additional variance in child adjustment can be explained by parental differential treatment. These findings were as expected and 
consistent with other research studies. The youth reported PDT finding for older siblings particularly stands out because both versions (i.e., A \& B of the Feinberg \& Hetherington approach) were significant.

The second and third research questions begin to unravel the extent to which an intervention moderates PDT as well as whether PDT is malleable. These questions were more exploratory in nature, took a longitudinal approach, and incorporated the RCT parenting intervention. As family systems theory implies, a change in the system can influence the parent-child subsystem as well as the entire family system (Broderick, 1993). Examining PDT in the context of a RCT parenting intervention allowed for examining this type of change in more detail. It was thought that participation in a parenting intervention would disrupt the typical ways of doing things in the family by potentially changing family members' roles and altering the status quo which in turn, would influence the parent-child relationship (Broderick, 1993). It was thought that the intervention may alter PDT level and that this change for families (i.e., learning and practicing new skills) would change PDT levels in the home. It was the hope that examining PDT within the context of a RCT would help in moving beyond correlations and begin to explore direction of effects.

The results for the second research question and all its forms provide some, albeit little, evidence that the intervention moderated PDT. A rigorous methodological approach was employed and child outcomes were examined across contexts (i.e., at school rather than at home), and there were some significant results. In the initial series of regressions/interactions run for this question using the ordinal group variable, five 
regressions were significant. It should be noted, however, that most of these were not significant for both versions controlling for different informants direct parenting scores using the Feinberg and Hetherington approach. However, it was decided to explore all of these significant findings especially because power was such an issue. That is to say, the numbers used in these regressions were much smaller than what would be ideal particularly for younger siblings. To more easily interpret these findings, these five regressions were re-run and plotted using a binary moderator.

The two significant interactions for older siblings were the most interesting and the plots were consistent with what was hypothesized. For youth PDT-Hostility, older siblings that were treated with more hostility and in the treatment group had teachers who reported improvement in their antisocial behavior as compared to older siblings in the control group. For youth reported PDT-Warmth, older siblings that were treated with less warmth than their sibling and in the treatment group had teachers who reported improvement in their antisocial behavior as compared to older siblings in the control group. These plots suggest that there may have been an interaction effect between treatment and level of different treatment. Specifically, the intervention seemed to yield more positive results in situations characterized by less favorable PDT directed at the older sibling. An alternative framing is that negative PDT directed at the older sibling was more likely to be associated with negative outcomes in the absence of the intervention. In this regard, it is noteworthy that the intervention was designed and delivered for the older siblings. Researchers may want to explore this further. 
Only parent reported PDT-Hostility for younger siblings showed to be significant controlling for youth reported direct parenting and observer reported direct parenting (two of the five initial significant regressions). Plots were also run and examined for significant findings for younger siblings. Using the binary moderator, two of the three regressions continued to be significant; however, they were both for parent reported PDT-Hostility. The interpretation of these plots was not clear-cut. This could be because the sample size for the younger sibling analyses may have contributed to this ambiguity as there was even less power. Furthermore, parent training was primarily focused on older siblings. This may have also contributed to the less straightforward interaction plots for younger siblings. Since the numbers of significant findings were small, future investigations should aim to keep numbers high for all siblings in the home and examine these patterns with larger samples to determine the direction of effects.

The results for the third research question do not provide any evidence that PDT is malleable after 6 months. Perhaps this finding is also because the parent training program focused primarily on older sibling and parents did not learn the skills to specifically target unfair parenting practices or focus on sibling related parenting challenges. It could be that a 6 month time period is not enough time to witness the impact of this change. Some changes in outcomes may not be visible until more time passes. Maybe the capacity of parents to generalize their skills to other children in the home will only develop with more time and more practice (i.e, more than 6 months). It could also be that more skilled parenting is not always equivalent to more equity based parenting. This intervention was not designed to specifically target reducing PDT. 
Interventions may need to be specifically designed to target PDT if reduction of PDT is a goal. The stability of PDT over time is also something to think about in light of this finding. Perhaps specific, well planned effort is needed to change PDT. There are potentially many explanations for the findings of this study, and readers should only begin to interpret findings with an understanding of the strengths and limitations of this study.

\section{Strengths and Limitations}

Strengths. The primary strength of this study is the innovative approach that was implemented by examining PDT within a RCT parenting intervention. This study attempted to expand the literature and the potential utility of PDT. Studying PDT in the context of an intervention allowed for examining the extent to which PDT can be changed, and the extent to which PDT interacts with an intervention in addition to the impact PDT has on children's adjustment. This multi-method, multi-informant dataset allowed for examining PDT from three distinct perspectives as well as examining PDT across reporting agents. This was particularly important in trying to avoid the effects of method variance which have been witnessed in this literature as well as other related literatures. In an additional attempt to avoid the effects of method variance, this study utilized a different reporting agent (i.e., teacher) for reporting the primary outcome for older and younger siblings (i.e., overt antisocial behavior). Moreover, the informant that reported on direct parenting (e.g., parent) was not the same as the informant who reported 
on PDT (e.g., youth) in any given analysis (see Feinberg \& Hetherington, 2001). This was a rigorous and conservative test for examining the effects of PDT.

This study also explored a new and important area of PDT, its malleability. Even though the intervention was not designed to target PDT, this study was able to examine whether PDT can be changed with participation in a parenting intervention. The fact that this study examined PDT in a high-risk sample is also strength. Much of the previous research has examined PDT in middle class or maritally intact families (Conger \& Conger, 1994; Shanahan et al., 2008; Tamrouti-Makkink et al., 2004). This study, however, examined this phenomenon among an economically vulnerable population which included diverse family forms. This study also examined PDT among both same sex and mixed sex sibling dyads. Researchers have indicated that PDT potentially occurs more often when families are stressed, and this study allowed for the exploration of that intensity among families and the differentials between siblings. Boyle and colleagues (2004) suggested that studies should examine within and between family differences in higher risk populations because differential effects may be more evident under those "structural, functional, and material circumstances".

There were other strengths that should also be mentioned. Child reports have been examined in the PDT literature, and the puppet interview (e.g., Coldwell, Pike, \& Dunn, 2007) has been a popular method to gather children's reports of PDT in recent studies. However, this was the first time that this author is aware that a computer assisted program was used to gather information from youth and then utilized to assess PDT. Youth seemed very comfortable with this format and youth as young as four years old 
were assessed using this method. This study also developed and employed a novel approach to examining PDT across reporting agents, and explored mean differences between high-PDT and egalitarian-treatment families.

Limitations. This study, however, is not without limitations. Although the data were from an experimental study, the initial analyses investigating associations between PDT and youth outcomes were based on cross-sectional baseline data. They were based on correlational methods and therefore could not establish the directionality or causality of effects.

This dissertation reported secondary data analysis rather than a prospective study. The relatively small sample size was not ideal especially considering the fact that there were small numbers in each of the three treatment groups. Another limitation had to do with the amount of missing data. Given that this was a high-risk group of families, there was quite a bit of attrition throughout the course of the intervention. While this was expected to some degree because this was an economically vulnerable sample living below the poverty line, missing data made data analysis challenging. The numbers were reduced substantially from baseline to intervention term (6 months after enrollment in the study). The desire to break these numbers down by sibling type (older vs. younger sibling) intervention group (CPT, PMT, and SPMT) and also by sibling gender (females and males), made the loss of cases even more unfortunate. The developed constructs could also have been stronger. Even though the construct scores met the minimal established criteria for internal consistency and validly, it would have been better to see stronger Cronbach's alphas and correlations particularly for certain reporting agents. 
Also, more items would have ideally been utilized for each reporting agent to ensure stronger construct validity. Because multiple methods and multiple agents were used to gather information, some participants did not have every type of information that was assessed. This resulted in different numbers for each particular analysis. Moreover, some of these analyses-particularly those for younger siblings-had fewer numbers than one would want as a rule of thumb. This was particularly noticeable when examining the results for the second research question for younger siblings.

It has been suggested that 10-15 participants are needed for each predictor variable, and Tabachnick and Fidell (2007) have recommend a formula for determining the number of individuals that that are necessary for a given analysis : $\mathrm{N} \geq 50+8 \mathrm{~m}$ (where $\mathrm{m}$ is the number of independent variables). Even though these rules were not always followed, a decision was made to complete the analyses that were proposed in an attempt to get a better sense of PDT in regards to moderation. Obviously, the small $\mathrm{N}$ means that results should be interpreted with caution as small sample size does influence the generalizability of findings. It should also be mentioned that only the minimal number of factors were used as covariates because of the small sample size. Consequently, this study was not able to control for other child factors (besides age and gender), parent or family factors, or environmental factors that likely also influence children's antisocial behavior.

Even though it was a strength of this study that data were collected from two siblings, this study did not include all children in the home. Moreover, even though this study examined economically vulnerable families, this sample was racially homogenous. 
Future research should make an effort to involve all children in the home as well as families with different ethnic and cultural backgrounds. Another limitation was the fact that the treatment interventions were not specifically designed to target PDT. There is good reason to believe that participation in the intervention will result in better, more equitable parenting; however, perhaps parents need to be taught specific skills about parenting multiple children in the home and dealing with sibling-specific situations. Perhaps general training is not precise enough to target sibling dilemmas that parents face, and the ways to avoid inequitable treatment of children. These limitations may also limit the generalizability of findings.

\section{Lessons Learned}

Numerous lessons were learned throughout the course of this study particularly in regards to methodological and analytic approaches in sibling research. For each analysis, there were many decisions that needed to be made about which approach was best to implement as well as which approach was feasible given the data available. This process demonstrated that there are always trade-offs in making these decisions because there are often both strengths and limitations involved with each and every decision. These methodological decisions became more complicated after deciding to use relative difference scores because difference scores are not always easily interpreted. There are various ways to calculate differences scores, and researchers should be cognizant about the ways differences scores can be calculated and which method would be most useful for any given analysis. Additionally, it was decided to use change scores as the dependent variable in some of these analyses to reduce the number of predictors variables used. 
However, more effort is needed when interpreting change scores as well. Careful attention to detail is required when utilizing these methods.

Lessons were also learned that may be helpful for the field. First, prospective studies should be encouraged in this area as well as obtaining large samples for quantitative analyses. In sibling research, there is a desire to break things down and compare same sex and mixed sex dyads, older and younger siblings, sibling constellations (e.g., older sisters with younger sisters, older sisters with younger brothers, etc) and so forth, and large samples are required in these research endeavors. Multiple methods have been used to examine PDT and siblings, and investigators and researchers should continue to be thoughtful of which methods would work best for particular questions and well as keep questioning and developing methodological approaches that may help advance our understanding and help move beyond correlational designs. The Hetherington and Feinberg (2001) approach was useful for this study since multiple perspectives were examined and there was an interest in avoiding the effects of method variance; however, other strategies could also have been utilized. Energy and effort should continue to utilize multiple methods and multiple agents in family research including each and every child and parent in the home to truly understand the nature of what is happening for siblings and families. Furthermore, studies should continue to examine diversity within children and families. 


\section{Importance and Implications}

\section{Importance to Social Work}

Wakefield (1988) indicated that social work is a justice oriented profession. Justice and fairness are also common goals within many families. Numerous folks have anecdotal evidence of the existence of parental differential treatment, and for decades, the PDT literature has shown associations between PDT and a number of negative outcomes for children. In many studies (Boyle et al., 2004; Singer \& Weinstein, 2000), as well as this one, PDT has also shown to explain additional variance in children's adjustment beyond the effects of direct parenting. Social workers, as well as professionals in other related fields should continue to promote justice within families. PDT provides an avenue through which researchers and practitioners can explore injustices within the family and work to reduce and/or eliminate those inequalities within the home. The following section discusses the ways this may be done by elaborating on the findings from this study as well as those in the broader literature.

\section{Implications \& Future Directions}

Implications for Practice, Policy and Future Research. This study is a first step in embedding PDT within an experimental design. Moreover, this study examined multiple reporting agents in an at-risk sample. Results suggest that participation in an intervention may only moderate PDT in particular instances; however, this study did illustrate that PDT may impact siblings' outcomes particularly within those families where differential treatment is noticeable by at least two reporting agents. This indicates that when PDT reaches a level that goes beyond one's individual perception, this 
visibility is also reflected in the child's outcomes. Researchers and practitioners should pay particular attention to this finding. Across the PDT literature, the results of studies are not always completely straightforward and sometimes the results reported in one study directly conflict with the results reported in another. Findings did reveal that different agents' reports of PDT are meaningful and unique which is consistent with the literature to date. Individual members of the family may have divergent perspectives about PDT perhaps partially because the reasons for differential treatment do not tend to be discussed within the family environment (Kowal, Krull, \& Kramer, 2006). McHale and colleagues (2000) suggest that researchers should examine the processes by which PDT has implications for siblings. This makes sense; however, it will also be important to focus on related factors that may also explain these children's outcomes such as parental and contextual factors including factors like maternal anger and household chaos (Aztaba-Poria \& Pike, 2008). It is essential to pay attention to what has been learned about PDT thus far and encourage people to develop and modify interventions that improve family communication regarding perceptions of PDT, and interventions that teach families strategies to change unfair parenting practices (Kramer, 2010).

Regardless, this study also makes one question whether examining PDT-child outcome links should continue to be a primary research agenda among sibling researchers. Even when PDT is significantly associated with child outcomes after controlling for other factors (e.g, child's age and gender, and direct parenting), PDT appears to explain only a small percentage of the variance in child's outcomes (usually less than 5\%). Furthermore, it has been shown that differential treatment seems to matter 
most when parenting is harsh. It can be easily argued that PDT matters significantly for some children with certain attributes and in specific contexts, yet perhaps it is noteworthy to pay attention to studies like this one. It may be time to make a shift in research and practice agendas and direct attention to factors such as parents' antisocial behavior and parents' aggression and other factors that might account for both PDT-Hostility and poor behavior outcomes for children. In families where parents exhibit high-rate antisocial behavior, PDT may not be a particularly helpful concept. That is, reducing PDT may not be as important as reducing parents' hostility more generally when all siblings in the home are experiencing high base rates of hostile treatment.

Future Directions. First, replication of sibling and family studies should continue among diverse family forms, different populations and within varied contexts, and investigators should push to advance the field by continuing to move beyond correlations. Studies should include all siblings and all parent figures. Rigorous designs and advanced statistical methods (i.e., HLM) should continue. Experimental designs such as randomized controlled trials (RCTs) should also be promoted and encouraged, and investigators should continue to find innovative ways to utilize experimental studies to advance research. Researchers also need to attend to many methodological issues, and efforts should focus on obtaining larger sample sizes so that there is sufficient statistical power to examine the various family and sibling constellations and so that cell sizes will not be too low for certain kinds of analyses like ANOVAs (i.e., sister-sister, sisterbrother, brother-sister, and brother-brother dyads). Future studies should begin to examine other contributing factors that may influence outcome differences including 
types and compositions of siblings (half-, step-, adoptive). Interactions between these various factors should also continue to be tested.

Second, investigators must continue to review and incorporate theoretical components in their research designs. From a systems perspective, research has demonstrated that one child's experience does not generalize to the experience of others within the home. Investigators need to analyze data from each and every child in the home instead of just one particular child to avoid making hasty generalizations about the individuals in the family and the family unit. Within this framework, each voice of each individual in the family is important, valued, and matters. Researchers should continue to evaluate the subjective evaluations of individuals' experiences in order to address the role of cognitive factors as well as how particular perceptions influence child outcomes. Researchers should also begin to take into account the influence of culture and family values (Shanahan et al., 2008) for these aspects also influence parenting and individuals' perceptions.

Since numerous child-, family- and contextual factors are present and may change over time, researchers ought to continue to examine PDT (as well as other related and influential factors) from a developmental perspective. Investigators should seek to evaluate the impact of PDT at various child ages, among numerous contexts, and across time. In addition to understanding the main effects efforts should also look to explore the developmental effects of parenting in context (see Feinberg \& Hetherington, 2001). This means that differential parenting may have unique impacts depending on the age of the child and the family context within which the child lives. As Shanahan, McHale, Crouter, 
\& Osgood (2008) pointed out, little is still known about the links between differential treatment and both adjustment and sibling relationships over time. Longitudinal studies should continue to examine the developmental impact of PDT (as well as other related and influential factors) and how and when PDT exerts its effect and for whom. It is reasonable to think that an eight year old girl with one younger sister may perceive inequitable parental treatment in a different fashion then a 17 year old boy with an older brother. Future studies should continue to explore the similarities and differences that may exist between same-gender and mixed-gender sibling dyads. Additionally, PDT studies should be prospective to truly understand its precursors and mechanisms.

In order to answer and address these concerns, researchers need to continue to design and implement rigorous studies, collect data from multiple family forms/constellations, and ensure that data are not only collected from the parent and child but also from each sibling and each parent figure (multiple informants and multiple perspectives). All of these concerns and suggestions, if addressed, have the potential to enhance what is already known about parental differential treatment (as well as other related factors) and its influence on children's adjustment.

\section{Conclusions}

These findings help to illustrate, as other studies have done, that PDT is associated with and may have a unique influence on children's outcomes, and that PDT is at least one important factor in predicting children's behavior. However, these findings do not provide overwhelming evidence that participation in an intervention moderates PDT. Moreover, these findings do not suggest that PDT is malleable after 6 months time. 
The results do suggest that PDT reports are based largely on an individual's perceptions, and social cognitive factors likely play a role when a reporting agent determines whether or not PDT is present. Since there was relatively good cross-agent agreement for egalitarian families, this finding suggests that when within-family behavior is largely equity based, it is likely to be consistently perceived across reporting agents. Moreover, when two reporting agents agree on the existence of high PDT, those children often fare worse on a variety of outcomes.

There could be many reasons as to why some of the results were not as hypothesized; however, this study did show that there are creative and innovative ways to examine phenomena within the context of an experimental design and move beyond simple associations. This is important for researchers to consider particularly in areas that are largely based on correlations.

This study also makes one wonder whether examining PDT-child outcome links should continue to be a principal research agenda among sibling researchers. In the August 2010 special section on siblings in Child Development Perspectives, PDT was shown to be a theme in sibling research which has been studied among some of the top sibling researchers in the field. However, even when PDT is significantly associated with child outcomes after controlling for other factors (e.g, child's age child gender, and direct parenting for a given domain), PDT appears to explain only a small percentage of outcome variance. That has been a common finding in the PDT literature. Additionally, it has been shown that differential treatment seems to matter most when parenting is harsh. Despite the fact that it can be easily argued that PDT matters for some children with 
certain attributes and in specific contexts, attention should be turned to studies like this one. Perhaps it is time to re-evaluate these efforts and shift attention to factors that more consistently influence children's adjustment outcomes or factors that explain a larger portion of the variance in children's outcomes. It may be more resourceful, especially in these economic times, to examine the ways to reduce or eliminate cold, harsh or extreme parenting as well as ways to teach parents and children ways to openly communicate as well as how to handle sibling specific issues. Perhaps sibling and family researchers should carefully assess what has been learned from the PDT literature including the factors that predict PDT and the ways in which PDT is associated with children's adjustment and the sibling relationship, and explore related areas that may explain more variance in children's outcomes. There are many valuable characteristics and factors to study among siblings, parents and families; therefore, it is important to continue to evaluate research efforts and adjust attention to the factors that may matter most for children and families. PDT does show to be linked to children's adjustment; nevertheless, it may not always be the most useful way to explore sibling and family outcomes. Empirical and anecdotal evidence contribute to the compelling nature of this topic; yet, it is my hope that other pertinent factors will also surface as key research agendas among sibling and family researchers. 


\section{REFERENCES}

Achenbach, T. M. (1991). Integrative guide for the 1991 CBCL/4-18, TRF profiles. Burlington, VT: University of Vermont, Department of Psychiatry.

Aiken, L. S., \& West, S. G. (1991). Multiple Regression: Testing and interpreting interactions. Newbury Park, CA: Sage.

Albow, J. C. \& Measelle, J. R. (1993). The Berkeley Puppet Interviw (BPI): Interviewing and coding systems manuals. Unpublished manual

Anderson, E. R., Hetherington, E. M., Reiss, D., \& Howe, G. (1994). Parents' nonshared treatment of siblings and the development of social competence during adolescence. Journal of Family Psychology, 8, 303-320.

Anderson, K. E., Lytton, H., \& Romney, D. M. (1986). Mothers' interactions with normal and conduct-disordered boys: Who affects whom. Developmental Psychology, 22, 604-609.

Ary, Tildesley, Hops, \& Andrews (1993). The influence of parent, sibling, and peer modeling and attitudes on adolescent use of alcohol. International Journal of the Addictions. 28(9), 853-880.

Atzaba-Poria, N. \& Pike, A. (2008). Correlates of parental differential treatment: Parental and contextual factors during middle childhood. Child Development, 79, 217-232.

Bank et al., (2000, November). Development of the Computer Assisted Child Interveiw (CACI). Paper presented at the annual meeting of the Association for the Advancement of Behavioral Therapy, New Orleans, LA. 
Bank, L. Patterson, G. R., \& Reid, J. B. (1987). Delinquency prevention through training parents in family management. Behavior Analyst, 10, 75-82.

Bank, L., Burraston, B. \& Synder, J. (2004). Sibling conflict and ineffective parenting as predictors of adolescent boys' antisocial behavior and peer difficulties: Additive and interactional effects. Journal of Research on Adolescence, 14, 99-125.

Bank, L., Patterson, G. R., \& Reid, J. B. (1996). Negative sibling interaction patterns as predictors of later adjustment problems in adolescent and young adult males. In G. H. Brody (Ed.), Sibling relationships: Their causes and consequences (pp. 197-229). Norwood, NJ: Ablex.

Bank, L., Synder, J., \& Prescott, A. (2002). Sibling relationship intervention in prevention and treatment of antisocial behavior: Rationale, description, and advantages. Upublished manuscript, Oregon Social Learning Center, Eugene, OR.

Bank, L., Synder, J., \& Wilson (2005). Sibling Intervention for Conduct-Problem Children: Benefits for Both Older and Younger Siblings. Unpublished manuscript, Oregon Social Learning Center, Eugene, OR

Baron, R. M., \& Kenny, D. A. (1986). The moderator-mediator variable distinction in social psychological research: Conceptual, strategic and statistical considerations. Journal of Personality and Social Psychology, 51, 1173-1182.

Baumrind, D. (1971). Current patterns of parental authority. Developmental Psychology, 4, 1-103. 
Bevelas, J. R., \& Segal, L. (1982). Family systems and communication theory. In B. B. Wolman \& G. Stricker (Eds.) Handbook of Family and Marital Therapy (pp. 94109). New York: Plenum.

Block, J. H. (1965). The Child-rearing practices report: A set of Q items for the description of parental socialization attitudes and values. Institute of Human Development, Berkeley, CA.

Bochner, A. P., \& Eisenberg, E. M. (1987). Family process: Systems perspectives. In C. R. Berger \& S. H. Chaffee (Eds.) Handbook of Communication Science (pp. 540563). Newbury Park, CA: Sage.

Boer, F., \& Dunn, J. (1992). Children's sibling relationship: Developmental and clinical issues. Hillsdale, NJ: Erlbaum.Boll, T., Ferring, D., \& Filipp, S. (2003). Perceived parental differential treatment in middle adulthood: Curvilinear relations with individuals' experienced relationship quality to sibling and parents. Journal of Family Psychology, 17, 472-487.

Bornstein, M. (1995). Handbook of parenting. Hillsdale, NJ: Erlbaum Boyle, M. H., Jenkins, J. M., Georgiades, J. C., Duku, E., \& Racine, Y. (2004).

Differential-maternal parenting behavior: Estimating within- and between-family effects on children. Child Development, 75, 1457-1476.

Brody, L. R., Copeland, A. P., Sutton, L. S., Richardson, D. R., \& Guyer, M. (1998). Mommy and daddy like you best: Perceived family favouritism in relation to affect, adjustment and family process. Journal of Family Therapy, 20, 269-291. 
Brody, G. H., \& Stoneman, Z. (1994). Sibling relationships and their association with parental differential treatment. Family Psychology, 8, 129-142.

Brody, G. H., Stoneman, Z., \& Burke, M. (1987). Child temperaments, maternal differential behavior and sibling relationships. Developmental Psychology, 23, 354-362.

Brody, G. H., Stoneman, Z., \& McCoy, J. K. (1992). Associations of maternal and paternal direct and differential behavior and sibling relationships:

Contemporaneous and longitudinal analysis. Child Development, 63, 82-92.

Brody, G. H., Stoneman, Z., \& McCoy, J. K. (1992). Parental differential treatment of siblings and sibling differences in negative emotionality. Jounral of Marriage and Family, 54, 643-651.

Brody, G. H., Stoneman, Z., \& McCoy, J. K. (1992). Associations of maternal and paternal direct and differential behavior with sibling relationships: contemporaneous and longitudinal analyses. Child Development, 63, 82-92.

Brody, G. H., Stoneman, Z., \& McCoy, J. K. (1994). Contributions of family relationships and child temperaments to longitudinal variations in sibling relationship quality and sibling relationship styles. Journal of Family Psychology, 8, 274-286.

Brody, G. H., Stoneman, Z., \& McCoy, J. K., \& Forehand, R. (1992). Contemporaneous and longitudinal associations of sibling conflict with family relationship assessments and family discussions about sibling problems. Child Development, 63, 391-400. 
Bronfenbrenner, U. (1979). The ecology of human development. Cambridge, MA: Harvard University Press.Bryant, B. \& Crockenberg, S. (1980). Correlates and dimensions of prosocial behavior: A study of female siblings with their mothers. Child Development, 51, 529-544.

Bugental, D. B., \& Johnston, C. (2000). Parent and child cognitions in the context of the family. Annual Reviews Psychology, 51, 315-344.

Buhrmester, D., \& Furman, W. (1990). Perceptions of sibling relationships during middle childhood and adolescence. Child Development, 61, 1387-1398.

Capaldi, D. M., \& Patterson, G. R. (1989). Psychometric properties of fourteen latent constructs from the Oregon Youth Study. New York: Springer-Verlag.

Caspi, A. C., Moffitt, T. E., Morgan, J., Rutter, M., Taylor, A., Arsenault, L. et al., (2004). Maternal expression emotion pre-behavioral development. Development Psychology, 40, 149-161.

Chamberlain, P., \& Reid, J. B. (1987). Parent observation and report of child symptoms. Behavioral Assessment, 9, 97-109.

Cicirelli, V. G. (1995). Sibling Relationships across the Life Span. New York: Plenum Press.

Cohen, J., Cohen, P., West, S. G., \& Aiken, L. S. (2003). Applied multiple regression/correlations analysis for the behavioral Sciences $\left(3^{\text {rd }}\right.$ Ed.). Mahwah, New Jersey: Lawrence Erlbaum Associates, Inc.

Coldwell, Pike, \& Dunn (2007). Maternal differential treatment and child adjustment: A multi-informant approach. Social Development, 17, 596-612. 
Collins, W. A., Maccoby, E. E., Steinberg, L., Hetherington, E. M., \& Bornstein, M. H. (2000). Contemporary research on parenting: The case for nature and nurture. American Psychologist, 55, 218-232.

Conger, K. J. \& Conger, R. D. (1994). Differential parenting and change in sibling differences in delinquency. Journal of Family Psychology, 8(3), 287-302.

Conger, R. D., \& Elder, G. H. (1994). Families in troubled times: Adapting to change in rural America. New York: Aldine.

Criss, M. M., \& Shaw, D. S. (2005). Sibling relationships as contexts for delinquency training in low income families. Journal of Family Psychology, 19, 592-600.

Crosnoe, R., \& Elder, G. H. (2002). Adolescents twins and emotional distress: The interrelated influence of nonshared environment and social structure. Child Development, 73, 1761-1774.

Crouter, A. C., McHale, S. M., \& Jenkins-Tucker, C. (1999). Does stress exacerbate parental differential treatment of siblings? A pattern-analytic approach. Journal of Family Psychology, 13, 286-299.

Daniels, D., Dunn, J., Furstenberg, F. F., \& Plomin, R. (1985). Differential experience of siblings in the same family. Developmental Psychology, 27, 747-760.

Daniels, D. \& Plomin, R. (1985). Differential experiences of siblings in the same family. Developmental Psychology, 21, 747-760.

Deater-Deckard, K., Pike, A., Petrill, S. A., Cutting, A. L., Hughes, C., \& O’Connor, T. G. (2001). Nonshared environmental processes in social-emotional development: 
An observational study of identical twin differences in the preschool period. Developmental Science, 4, F1-F6.

Dumas, J. E. (1989). Treating antisocial behavior in children: Child and family approaches. Clinical Psychology Review, 9, 197-222.

Dunn, J. D. (2005). Commentary: Siblings in their families. Journal of Family Psychology, 19, 654-657.

Dunn, J., \& McGuire, S. (1994). Young children's nonshared experiences: A summary of studies in Cambridge and Colorado. In E. M. Hetherington, D. Reiss, \& R. Plomin (Eds.), Separate social words of siblings: The impact of nonshared environment on development (pp. 111-128). Hillsdale, NJ: Erlbaum.

Dunn, J., \& Munn, P. (1985). Becoming a family member: Family conflict and the development of social understanding in the second year. Child Development, 56, 480-492.

Dunn, J., \& Munn, P. (1986a). Sibling quarrels and maternal intervention: Individual differences in understanding and aggression. Journal of Child Psychology \& Psychiatry, 27, 583-595.

Dunn, J., \& Munn, P. (1986b). Siblings and the development of prosocial behavior. International Journal of Behavior Development, 9, 265-284.

Dunn, J., \& Plomin, R. (1990). Separate lives: Why siblings are so different. New York: Basic Books.

Dunn, J., \& Plomin, R. (1991). Why are siblings so different? The significance of differences in sibling experiences within the family. Family Process, 30, 271-283. 
Dunn, J., Plomin, R., \& Daniels, D. (1986). Consistency and change in mothers' behavior towards young siblings. Child Development, 57, 348-356.

Dunn, J., \& Stocker, C. (1989). The significance of differences in siblings experiences within the family. In K. Kreppner \& R. M. Lerner (Eds.), Family systems and lifespan development (pp. 289-301). Hillsdale, NJ: Erlbaum.

Dunn, J. Stocker, C., \& Plomin, R. (1990). Nonshared experiences within the family: Correlates of behavioral problems in middle childhood. Development and Psychopathology, 2, 113-126.

East, P. L., \& Khoo, S. T., (2005). Longitudinal pathways linking factors and sibling relationship qualities to adolescent substance use and sexual risk behaviors. Journal of Family Psychology, 19, 571-580.

Farrington, D. P., \& Hawkins, J. D. (1991). Predicting participation, early onset and later persistence in officially recorded offending. Criminal Behavior and Mental Health, 1, 1-33.

Feinberg, M., E., Neiderhiser, J. M., Simmens, S., Reiss, D., Y Hetherington, E. M. (2000). Sibling comparison of differential parental treatment in adolescence. Child Development, 71, 1161-1628.

Feinberg, M. \& Hetherington, E. M. (2001). Differential parenting as a within-family variable. Journal of Family Psychology, 15(1), 22-37.

Feinberg, M. E., Reiss, J. D., Neiderhiser, M., and Hetherington, E. M. (2005). Differential association of family subsystem negativity on siblings' 
maladjustment: Using behavior genetics methods to test process theory. Journal of Family Psychology, 19, 601-610.

Festinger, L. (1954). A theory of social comparison processes. Human Relations, 7, 117140.

Forehand, R., Miller, K. S., Dutra, R., \& Chance, M. W. (1997). Role of parenting in adolescent deviant behavior: Replication across and within two ethnic groups. Journal of Consulting and Clinical Psychology, 65, 1036-1041.

Forgatch, M. S., \& Patterson, G. R. (1989). Parents and adolescents living together. Family problem solving. Eugene, OR: Castalia.

Forgatch, M. S., \& Rains, L. (1997). MAPS: Marriage and Parenting in Step Families (parent training manual).Eugene, OR: Oregon Social Learning Center.

Furman, W., \& Buhrmester, D. (1985). Children's perceptions of the qualities of sibling relationship. Child Development, 56, 448-461.

Harris, K. M., \& Morgan, S. P., (1991). Fathers, sons, and daughters: Differential parental involvement in parenting. Journal of Marriage and Family, 53, 531-544.

Hawkins, J. D., Catalano, R. F., \& Miller, J. Y. (1992). Risk and protective factors for alcohol and other drug problems in adolescence and early adulthood: Implications for substance abuse prevention. Psychological Bulletin, 112, 64-105.

Hetherington, E. M. (1988). Parents, children, and siblings six years after divorce. In R. A. Hinde \& J. Stevenson-Hinde (Eds.), Relationships within families: Mutual influences (pp. 311-331). New York: Oxford University Press. 
Hoffman, L. W. (1991). The influence of the family environment on personality: Accounting for sibling differences. Psychological Bulletin, 110, 187-203.

Jenkins, J. M., Rasbash, J., \& O'Connor, T. G. (2003). The role of the shared family context in differential parenting. Developmental Psychology, 39(1), 99-113.

Kowal, A., \& Kramer, L. (1997). Children's understanding of parental differential treatment. Child Development, 68, 113-126.

Kowal, A., Kramer, L., Krull, J. L., \& Crick, N. R. (2002). Children's perceptions of the fairness of parental preferential treatment and their socioemotional well-being. Journal of Family Psychology, 16, 297-306.

Kowal, A., K., Krull, J. L., \& Kramer, L. (2006). Shared understanding of parental differential treatment in families. Social Development, 15, 276-295.

Kramer, L. (2010). The essential ingredients of successful sibling relationships: An emerging framework for advancing theory and practice. Child Development Perspectives, 4, 87-94.

Kramer, L., \& Kowal, A. K. (2005). Sibling relationship quality from birth to adolescence: The enduring contributions of friends. Journal of Family Psychology, 19, 503-511.

Lamborn, S. D., Mounts, N.S., Steinberg, L., \& Dornbusch, S. M. (1991). Patterns of competence and adjustment among adolescents from authoritative, authoritarian, indulgent, and neglectful families. Child Development, 62, 1049-1065. 
Levine, M. P., Smolak, L., \& Hayden, H. (1994). The relations of sociocultural factors to eating attitudes and behaviors among middle school girls. Journal of Early Adolescence, 14, $471-490$.

Maccoby, E. E., (1992). The role of parents in the socialization of children: A historical review. Developmental Psychology, 28, 1006-1017.

McHale, S. M., \& Crouter, A. C. (1996). The family contexts of children's sibling relationships. In G. H. Brody (Ed.)., Sibling relationships: Their causes and consequences (pp. 173-195). Westport, CT: Ablex.

McHale, S. M., Crouter, A. C.,McGuire, S. A., \& Updegraff, K. A. (1995). Congruence between mothers' and fathers' differential treatment of siblings: Links with family relations and children's well-being. Child Development, 66, 116-128.

McHale \& Gamble, (1989). Sibling relationships and adjustment of children with disabled brothers and sisters. Journal of Children in Contemporary Society, 19, $131-158$.

McHale, S. M., \& Pawletko, T. M. (1992). Differential treatment of siblings in two family contexts. Child Development, 63, 68-81.

McHale, S. M., Updegraff, K. A., Jackson-Newsom, J., Tucker, C. J., \& Crouter, A. C. (2000). When does parents' differential treatment have negative implications for siblings? Social Development, 9, 149-172.

McGuire, S. Dunn, J. \& Plomin, R. (1995). Maternal differential treatment of siblings and children's behavioral problems: A longitudinal study. Development and Psychopathology, 7, 515-528. 
Miller, G. E., \& Prinz, R. J. (1990). The enhancement of social learning family interventions for childhood conduct disorder. Psychological Bulletin, 108, 291307.

Minuchin, S. (1974) Families and family therapy. Cambridge, MA: Harvard University Press.

Minuchin, S. (1981). Family therapy techniques. Cambridge, MA: Havard University Press. Minuchin, s. (1998). Where is the narrative in family therapy. Journal of Marriage and Family Therapy, 24, 397-403.

Nichols, M. P., \& Schwartz, R. C. (2001). Family therapy: concepts and methods. Boston: Allyn \& Bacon.

O’Connor, T. G. (2002). Annotation: The "effects" of parenting reconsidered: Findings, challenges, and applications. Jounral of Child Psychology and Psychiatry \& Allied Disciplines, 43, 555-572.

Pallant, J. (2005). SPSS Survival Guide. London, UK: Open University Books.

Parsons, J. P., Adler, T. F., \& Kaczala, C. M. (1982). Socialization of achievement attitudes and beliefs : parental influences. Child Development, 53, 310-321.

Patterson, G. R. (1982). A social learning approach: III. Coercive family process. Eugene, OR: Castalia.

Patterson, G. R. (1986). The contribution of siblings to training for fighting: A microsocial analysis. In D. Olweus, J. Block, \& M. Radke-Yarrow (Eds.), Development of antisocial and prosocial behavior: Research, theories, and issues (pp. 235-261). Orlando, FL: Academic Press. 
Patterson, G. R., \& Bank, L. (1989). Some amplifying mechanism for pathologic processes in families. In M. R. Gunnar \& E. Thelen (Eds.), Systems and development: The Minnesota Symposia on Child Psychology (Vol 22, pp. 167209). Hillsdale, NJ: Erlbaum.

Patterson, G. R., Dishion, T. J., \& Chamberlain, P. (1993). Outcomes and methodologies issues relating the treatment of children. In T. R. Giles (Ed.)., Effective psychotherapy: A handbook a comparative research (pp. 43-83). New York: Plenum.

Patterson, G. R., \& Forgatch, M. S. (1987). Parents and adolescents: I. Living together. Eugene, OR: Castalia Publishing Company.

Pianta, R. C. (1992). Child-parent relationship scale. Unpublished measure. University of Virginia.

Pike, A.,Reiss, D., Hetherington, E. M., \& Plomin, R. (1996). Using MZ differences in the search for nonshared environmental effects. Journal of child Psychology and Psychiatry, 37, 695-704.

Plomin, R., \& Daniels, D. (1987). Why are children in the same family so different from one another? Behavioral and Brain Sciences, 10, 1-16.

Plomin, R. (1994). Genetics and experience. Thousand Oaks, CA: Sage.

Pomeroy , E. A., Gibbons F. X., Gerrard, M., Cleveland, M. J., , Brody, G. H., Wills, T. (2005). Families and risk: prospective analyses of familial and social influences on adolescent substance use. Journal of Family Psychology 19, 560-570. 
Rauer, A. J., \& Volling, B. L. (2007). Differential parenting and sibling jealousy: Developmental correlates of young adults' romantic relationships. Personal Relationships, 14, 495-511.

Richmond, M. K., Stocker, C. M., \& Rienks, S. L. (2005). Longitudinal associations between sibling relationship quality, parental differential treatment, and children's adjustment. Journal of Family Psychology, 19(4), 550-559.

Rivers, J. W. \& Stoneman, Z. (2008). Child temperaments, differential parenting, and the sibling relationships of children with Autism Spectrum Disorder. Journal of Autism Development Discord, 38, 1740-1750.

Rosenthal, J. A. (1996). Qualitative descriptors of strength of association and effective size. Journal of Social Service Research, 21, 37-59.

Ross, H. G., \& Milgram, J. I., (1982). Important variables in adult sibling relationships: A qualitative study. In M. E. Lamb, \& B. Sutton-Smith (Eds.), Sibling relationships: Their nature and significance across the lifespan (pp. 235-249). Hillsdale, NJ: Lawrence Erlbaum.

Roth, J. K. (1990). A theory of justice. In F. N. Magill (Ed.), Masterpieces of world philosophy. New York: Harper Collins.

Rovine, M. (1994). Estimating nonshared environment using sibling discrepancy scores. In E. M. Hetherington, D. Reiss, \& R. Plomin (Eds.), Separate social worlds of siblings: The impact on nonshared environment on development (pp. 33-61). Hillsdale, NJ: Erlbaum. 
Rowe, D. C., \& Gulley, B.L. (1992). Sibling effects on substance use and delinquency. Criminology, 30, 217-233.

Ruble, D., \& Frey, K. (1987). Social comparison and self-evaluation in the classroom: Developmental changes in knowledge and function. In J. Masters \& W. Smith (Eds.), Social comparison, social justice, and relative deprivation: Theoretical, empirical, and policy perspectives. Hillsdale, NJ: Erlbaum.

Russell, A., Pettit, G. S., \& Mize, J. (1998). Horizontal qualities in parent-child relationships: Parallels with and possible consequences for children's peer relationships. Developmental Review, 18, 313-352.

Santrock, J. W., Readdick, C.A., \& Pollard, L. (1980). Social comparison processes in sibling and peer relations. The Journal of Genetic Psychology, 137, 91-107.

Santrock, J. W., Smith, P.C., \& Bourbeau, P. E. (1976). The effects of social comparison on the aggressive and regressive behavior of young children. Child Development, 47, 831-837.

Scaramella, L. V., Conger, R. D., \& Simons, R. L. (1999). Parental protective influences and gender-specific increases in adolescent internalizing and externalizing problems. Journal of Research on Adolescence, 9, 111-141.

Shanahan, L., McHale, S. M., Crouter, A. C., \& Osgood, D. W. (2008). Linkages between parents' differential treatment, youth depressive symptoms, and sibling relationships. Journal of Marriage and Family, 70, 480-494.

Singer, A. T., \& Weinstein, R. S. (2000). Differential parental treatment predicts 
achievement and self-perceptions in two cultural contexts. Journal of Family Pscyhology, 14, 491-509.

Slomkowski, C., Rende, R.,Conger, K,. Simons, R., \& Conger, R., (2001). Sisters, Brothers, and Delinquency: Evaluating social influence during early and middle adolescence. Child Development. 72(1) 271-783.

Steinberg, L. (1990). Autonomy, conflict, and harmony in the family relationship. In S. S. Feldman \& G. R. Elliott (Eds.), At the threshold: The developing adolescents (pp. 255-276). Cambridge, MA: Harvard University Press.

Stocker, C. M. (1995). Differences in mothers' and fathers' relationships with siblings: Links with children's behavior problems. Development and Psychopathology, 7 , 499-513.

Stocker, C., Dunn, J., \& Plomin, R. (1989). Sibling relationships: Links with child temperament, maternal behavior, and family structure. Child Development, 60, 715-727.

Synder \& Stoolmiller (2002). Reinforcement and coercion mechanisms in the development of antisocial behavior: The Family.

Tabachnick, B. G., \& Fidell, L. S. (2007). Using Multivariate Statistics (5 ${ }^{\text {th }}$ ed.). Boston, MA: Allyn and Bacon.

Tarullo, L. M., DeMulder, E. K., Ronsaville, D. S., Brown, E., \& Radke-Yarrow, M. (1995). Maternal depression and maternal treatment of siblings as predictors of child psychopathology. Developmental Psychology, 31, 395-405. 
Tamrouti-Makkink, I. D., Dubas, J. S., Gerris, J. R., \& van Aken, M. A. (2004). The relation between the absolute level of parenting and differential parental treatment with adolescent siblings' adjustment. Journal of Child Psychology and Psychiatry, 45, 1397-1406.

Volling, B. L., \& Belsky, J. (1992). The contribution of mother-child and father-child relationships to the quality of sibling interaction: A longitudinal study. Child Development, 63, 1209-1222.

Wakefield, J. C. (1988). Psychotherapy, distributive justice, and social work: Part 1 Distributive justice as a conceptual framework for social work. Social Service Review, 62, 187-210.

Wagner, B. M., \& Cohen, P. (1994). Adolescent sibling differences in suicidal symptoms: The role of parent-child relationhips. Journal of Abnormal Child Psychology, 22, 321-337.

White, D. M., \& Klein, J. M. (2008). Family Theories ( $3^{\text {rd }}$ Ed.). Thousand Oaks, CA: Sage Publications.

Wills, T. A. (1991). Similarity and self-esteem in downward comparison. In J. Suls \& T. A. Wills (Eds.), Social comparison: Contemporary theory and research. Hillsdale, NJ: Erlbaum.

Wonderlich, S., Ukestad, L., \& Perzacki, R. (1994). Perceptions of nonshared childhood environment in bulimia nervosa. Journal of the American Academy of Child and Adolescent Psychiatry, 33, 740-747. 